\title{
DUAL WAVELENGTH POLARIMETRY FOR MONITORING GLUCOSE IN THE PRESENCE OF VARYING BIREFRINGENCE
}

\author{
A Thesis \\ by \\ QIUJIE WAN \\ Submitted to the Office of Graduate Studies of \\ Texas A\&M University \\ in partial fulfillment of the requirements for the degree of \\ MASTER OF SCIENCE
}

December 2004

Major Subject: Biomedical Engineering 


\title{
DUAL WAVELENGTH POLARIMETRY FOR MONITORING GLUCOSE IN THE PRESENCE OF VARYING BIREFRINGENCE
}

\author{
A Thesis \\ by \\ QIUJIE WAN \\ Submitted to Texas A\&M University \\ in partial fulfillment of the requirements \\ for the degree of \\ MASTER OF SCIENCE
}

Approved as to style and content by:

Gerard Coté

(Chair of Committee)

Henry Taylor

(Member)

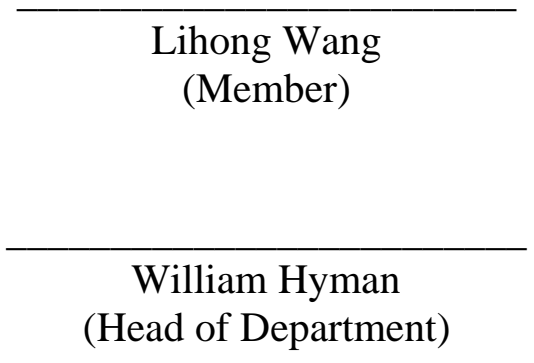

December 2004

Major Subject: Biomedical Engineering 


\author{
ABSTRACT \\ Dual Wavelength Polarimetry for Monitoring Glucose in the Presence of Varying \\ Birefringence. (December 2004) \\ Qiujie Wan , M.S., Anhui University of Technology \\ Chair of Advisory Committee: Dr. Gerard L. Coté
}

In a continuing effort to develop a noninvasive means of monitoring glucose levels using the aqueous humor of the eye, a dual wavelength system has been developed in order to show that varying birefringence, similar to what is seen with a moving cornea, can be compensated. In this paper a dual wavelength, closed-loop, system was designed and a model was developed to extract the glucose concentration information. The system and model were tested using various concentrations of glucose in a birefringent test cell subject to motion artifact. The results show that for a static, non-moving sample, glucose can be predicted to within $10 \mathrm{mg} / \mathrm{dl}$ for the entire physiologic range $(0-600 \mathrm{mg} / \mathrm{dl})$ for either laser wavelength (523nm or $635 \mathrm{~nm})$. In the presence of moving birefringence, each individual wavelength produced standard errors on the order of a few thousand $\mathrm{mg} / \mathrm{dL}$. However, when the two wavelengths are combined into the developed model, this error is less than $20 \mathrm{mg} / \mathrm{dL}$. The approach shows that multiple wavelengths can be used to drastically reduce the error in the presence of a moving birefringent sample. This research also shows promising preliminary results that the error is less than $25 \mathrm{mg} / \mathrm{dl}$ in presence of a motion induced cornea birefringence artifact in NZW rabbits' eyes. 


\section{DEDICATION}

This thesis is dedicated to my parents and to my husband, Hui Chen. 


\section{ACKNOWLEDGMENTS}

I would like to thank my committee chair Dr. Gerard Coté for his giving me an opportunity to work on this project and for his encouragement throughout this research. I would also like to thank the committee members, Dr. Lihong Wang and Dr. Henry Taylor for their direction that led to complete understanding of the nature of the project.

I would also like to thank Justin Baba, a former Ph.D student and Brandon Dixon, a current student in the Optical Bio-sensing Laboratory, for their help to understand the project. Many thanks to all the graduate students in Optical Bio-sensing Laboratory for their help and support. 


\section{TABLE OF CONTENTS}

\section{Page}

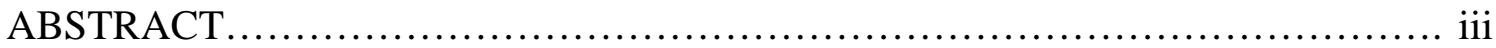

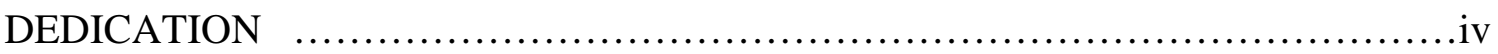

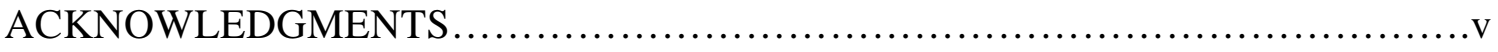

TABLE OF CONTENTS....................................................... vi

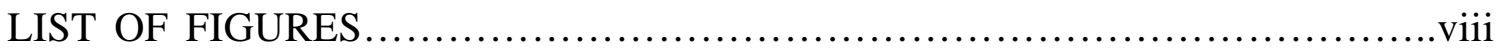

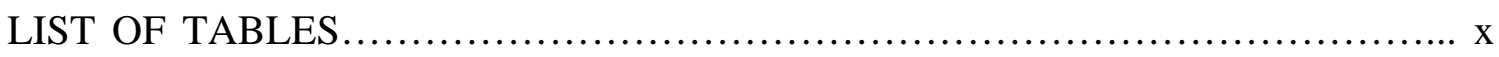

\section{CHAPTER}

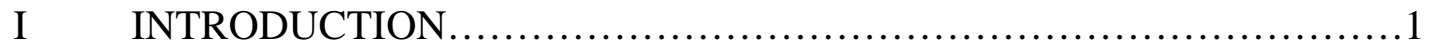

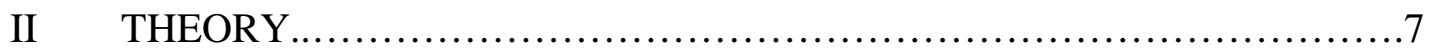

2.1 Polarized Light ...................................................

2.2 Optical Rotation..................................................

2.3 Optical Rotatory Dispersion and Drude's Equation.................. 14

2.4 Faraday Rotation in Polarimeter....................................18

2.5 Polarimeter ........................................................20

2.5.1 Basic Polarimeter ....................................20

2.5.2 A Single Wavelength Polarimeter..........................21

2.5.3 Modeling the Polarimeter................................22

2.5.4 Dual Wavelength Polarimeter.............................26

2.6 In Vivo Glucose Detection ......................................28

2.6.1 Relevant Anatomy of the Eye.............................28

2.6.2 The Composition of Aqueous Humor.......................30

2.6.3 Corneal Birefringence ...................................32

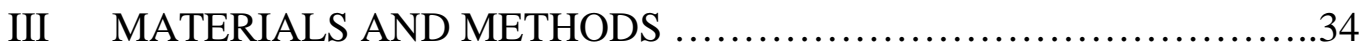

3.1 Characterization of the Test Cell Birefringence ......................34

3.2 Open-loop Experiments........................................... 36

3.3 Closed-loop Experiments ........................................40

3.3.1 Experiment Setup........................................40

3.3.2 Control System ......................................42

3.3.3 Experimental Procedure.................................44 
CHAPTER Page

IV RESULTS AND DISCUSSION ................................... 48

4.1 Characterization of the Test Cell Birefringence .....................48

4.2 Open-loop Experiments ......................................50

4.3 Closed-loop Experiments .....................................52

4.3.1 Closed-loop in the Motionless System ....................53

4.3.2 Closed-loop in the Motion System ......................57

4.3.3 Closed-loop with Motion Artifact in NZW Rabbit Eyes ...62

V CONCLUSIONS AND FUTURE WORK ..............................67

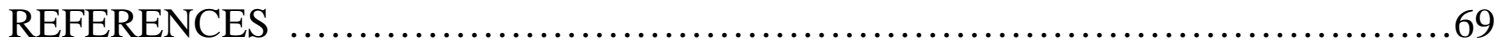

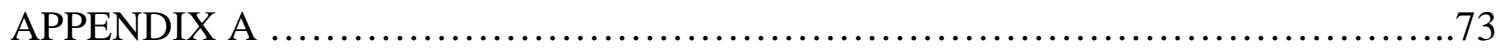

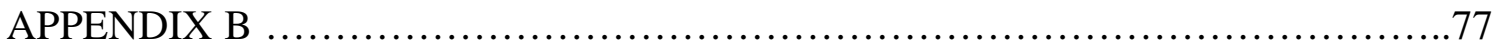

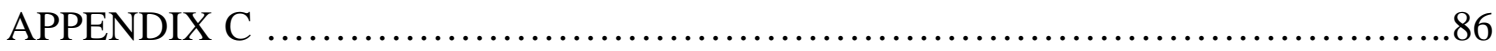

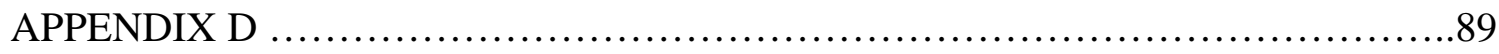

VITA................................................................... 


\section{LIST OF FIGURES}

FIGURE

Page

1. Linear Polarized Light. The Transverse Electric Field Wave Is Accompanied by a Magnetic Field Wave as Illustrated................... 8

2. Circularly Polarized Light Consists of Two Perpendicular Electromagnetic Plane Waves of Equal Amplitude and $90^{\circ}$ Difference in Phase. The Light Illustrated Is Right-circularly Polarized

3. Elliptically Polarized Light Consists of Two Perpendicular Waves of Unequal Amplitude which Differ in Phase by $90^{\circ}$. The illustration Shows Right-elliptically Polarized Light

4. An Example of Optically Active Enantiomers.......................... 13

5. Glucose ORD Curve in the Visible Spectrum........................ 16

6. Observed Optical Rotations for Physiological Concentrations of Aqueous Humor Analytes, Glucose, Albumin, and Ascorbic Acid for $1 \mathrm{~cm}$ Path Length

7. A Faraday Effect Modulator....................................... 19

8. Block Diagram of a Basic Polarimeter............................... 20

9. Block Diagram of a Common Polarimeter............................ 21

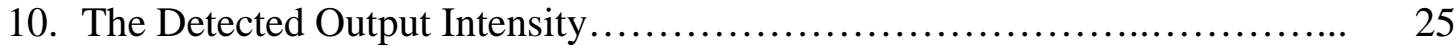

11. Anatomy of the Eye............................................ 29

12. Flow of the Aqueous Humor...................................... 31

13. Experimental Setup to Assess Sample Cell Birefringence.................. 35

14. Block Diagram of the System Open-loop System $\ldots \ldots \ldots \ldots \ldots \ldots \ldots \ldots \ldots \ldots \ldots$

15. Block Diagram of the System with the Closed-loop System................. 41 
16. Intensity Change of the Detected Signal as a Function of the Angle of Rotation of the Test Cell Recorded at Five Different Locations on the Test Cell.

17. Regression Relationships Between the Two Detected Signals from 0 to 600

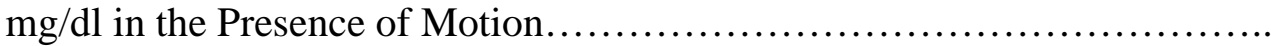

18. Actual versus Predicted Glucose Concentration for Glucose-doped Water for Sample Experiments without Motion................................

19. Actual versus Predicted Glucose Concentration for Glucose-doped Water Coupled with Varying Birefringence Signal Using the Single Wavelength Closed-loop System for Each Wavelength

20. Actual versus Predicted Glucose Concentration for Glucose-doped Water Coupled with Varying Birefringence Signal Using the Dual Wavelength Closed-loop System.

21. Mean Actual versus Predicted Glucose Concentration for Glucose-doped Water Coupled with Varying Birefringence Signal Using the Dual Wavelength Closed-loop System.......................................

22. Actual versus Predicted Glucose Concentration for Glucose-doped Water Coupled with Motion Artifact in Rabbit Eyes Using the Dual Wavelength Closed-loop System.

23. Mean Predicted Concentrations with Error Bars for Three Eyes Using the Dual Wavelength (635 Nm And $523 \mathrm{Nm}$ ) Closed-loop System in the Presence of Motion Artifact............................................ 


\section{LIST OF TABLES}

TABLE Page

1. Specific Rotation of Some Organic Molecules ........................ 14

2. Specific Rotation of Glucose at Various Wavelength of Light ............ 15

3. Jones Matrices for Common Optical Polarization Components ........... 23

4. Slope Values (From Fig 2) of the Fitted Lines for the Open-loop Glucose Measurements Coupled with Motion across the Range of 0-600 mg/dl .... 52

5. Summary of Correction Coefficients and Standard Deviation for the Closed-loop in the Motionless System ............................... 


\section{CHAPTER I}

\section{INTRODUCTION}

Diabetes mellitus afflicts about 180 million people worldwide and 18.2 million people in the United States. ${ }^{1}$ In the U.S., diabetes, along with its associated complications, is the sixth leading cause of death. ${ }^{2}$ Diabetes mellitus is characterized by the inability of the body to produce or properly utilize insulin, a hormone that regulates the transport of glucose from the blood stream into the tissue. ${ }^{2}$ When there is an insufficient level of insulin in the body, hyperglycemia occurs, an elevation of the blood glucose levels to much higher than normal. Alternatively, when blood glucose levels are below normal a condition known as hypoglycemia occurs. Without treatment, consistently low glucose levels can lead to diabetic coma and possibly death, while consistently high glucose levels can lead to long-term complications such as coronary artery disease, hypertension and retinopathy. ${ }^{3,4,5}$ Research has shown that intensive control of blood sugar is an effective means to prevent or slow the progression of long-term diabetic complications such as kidney failure, heart disease, and blindness. ${ }^{5}$ Since blood glucose levels frequently fluctuate due to daily activities such as eating and exercise, the intensive control of blood glucose requires frequent monitoring for those without the built in insulin control system. It is recommended that measuring blood glucose at least five 
times a day can help diabetics in avoiding the secondary complication associated with abnormal glucose levels. ${ }^{2}$

Currently, the most common methods for measuring blood glucose levels are invasive. These methods require patients to break skin to obtain a blood sample using a lancet or needle, causing pain as well as possible infection. Because of this, very few patients adhere to strict monitoring of blood glucose.

In the last few years, over 100 companies and universities have been involved in research to develop noninvasive technologies to measure blood glucose using various approaches. Very few of these technologies, however, are currently available commercially. One such device available commercially is the GlucoWatch (C), which uses fluid extraction from the skin. However it is not marketed as an independent glucose sensor since it is not intended to replace conventional blood glucose measurement methods, but rather supplement them and provide additional information on the patient's glucose fluctuations throughout the day. ${ }^{6}$ This technology draws fluid through the skin and is thus not truly noninvasive. It also requires the analyzer pack in the watch to be replaced quite regularly, proving to be quite expensive over time. Other promising technologies currently being researched are near-infrared light spectroscopy, far-infrared radiation spectroscopy, Raman spectroscopy, fluorescence spectroscopy, radio wave impedance, optical rotation of polarized light, and interstitial fluid 
harvesting. ${ }^{7-9}$

An optical polarimetric glucose sensor could be a very useful technique for noninvasive measurement of blood glucose. The primary advantage of such a device over current technologies is that it has the potential to obtain actual glucose concentration values noninvasively. It also could be more cost effective as the device would not have disposables that need to be continuously replaced. This method also avoids the complications of the temperature sensitivity of IR absorption due to the large water peaks and is less invasive than fluorescence techniques currently being researched, which require the implantation of fluorophore doped polymers. ${ }^{7,8}$

Polarization applied to glucose detection is based on the ability of optically active molecules, such as glucose, to rotate the polarization plane of a light beam. ${ }^{10,11}$ Fundamentally, the concentration of the optically active sample is proportional to the observed rotation value of the polarization plane for a given specific rotation and path length. Thus, the concentration of the sample can be calculated from the observed rotation for a given path length and specific rotation.

Research towards the use of polarimetry to measure blood glucose concentration in the aqueous humor has existed for over 20 years. In 1982, March et al. were first to report the use of the eye as a potential sensing site for optical polarimetry to detect glucose levels in the body. ${ }^{12,13}$ Using a rabbit model, they proposed that glucose 
concentration in the aqueous humor is related to that in the blood with a slight time delay (on the order of minutes ). Further, March et al reported that the acids (lactic, ascorbic, and amino) contribute to rotation in the aqueous humor composition of the rhesus monkey, however, these acids are on the order of ten times less than the rotation due to glucose. ${ }^{13}$ Previously, with direct extraction of aqueous humor, Pohjola's research showed that glucose concentration in the aqueous humor of the eye is correlated to that of blood. ${ }^{14}$ Many groups have set out to improve the stability, repeatability and accuracy of this approach. Cote et al. reported the potential for millidegree sensitivity through the development of a true phase technique in vitro and proposed a potential in vivo system. ${ }^{15}$ Following their work, Goetz reported a closed-loop feedback system with less than a millidegree standard deviation using a faraday rotator for signal modulation and feedback. ${ }^{16}$ In order to be able measure other optically active compounds, King et al. developed another multi-spectral polarimeter using a single pockels cell in vitro. ${ }^{17}$ In their study, they demonstrated in vitro a multispectral approach to compensate for the presence of multiple optically active compounds in a sample, such as ascorbic acid and albumin. To further improve repeatability and stability while preserving accuracy, Cameron et al. developed a faraday-based system that demonstrated the potential to compensate for rotation due to the presence of other optically active components using a digital closed-loop feedback technique with sub-millidegree sensitivity in vitro. ${ }^{18,19}$ 
This same group showed that the time lag between blood and aqueous humor glucose levels is on average less than 5 min in New Zealand rabbits, thus validating the ability of this sensing sight to correlate with blood glucose levels. ${ }^{20}$ An eye coupling device was developed to couple the input laser beam through the anterior chamber of the eye for an in vivo system. ${ }^{19}$ It was also determined that other optically active components in the aqueous humor as well as the effects of the temperature and $\mathrm{pH}$ are negligible in sensing glucose via polarimetry within physiological ranges. ${ }^{21}$

Other research groups have developed different polarimetric methods to measure glucose. Chou et al. reported on a polarimeter system utilizing an optical heterodyne approach and phase lock-in technology with sensitivity to detect glucose levels below 10 $\mathrm{mg} / \mathrm{dl}$ in vitro. ${ }^{22,23}$ More recently, Ansari et al. proposed a theoretical model utilizing Brewster's reflection angle off the lens of the eye for detecting glucose levels. ${ }^{24,25}$ While these techniques, along with those previously mentioned, have shown results in vitro, it has been difficult to use a polarimetric approach to accurately measure blood glucose in vivo primarily due to the difficulties associated with the birefringence of the cornea coupled with motion artifact. $^{26}$ The motion of the eye masks the detected glucose signal due to the birefringence of the cornea. Anumula et al. presented a theoretical model and proposed a system to compensate for this, but his method still did not overcome the time-varying problem due to the motion of the cornea. ${ }^{27}$ Baba et al. 
designed and implemented a dual orthogonal polarization detection system to compensate for motion artifact but the results showed low accuracy due to the open-loop nature of the system. ${ }^{28}$

This research describes a digital dual wavelength dual closed-loop polarimeter used in vitro with the presence of motion artifact induced birefringence. This polarimeter system and algorithm minimize the effect of the time-varying birefringence signal due to motion artifact, and allow for repeatable, accurate glucose measurements in the presence of such motion. 


\section{CHAPTER II}

\section{THEORY}

This chapter describes the theories involved in this research. The initial section discusses the principles to understand the plane of polarized light and three kinds of polarized light. This chapter also introduces a detailed overview of optical rotation, Drude's equation, Jones matrices and other theories used to describe a basic polarimeter. Next section discusses the dual wavelength polarimetry for monitoring glucose in the presence of varying birefringence. The final section presents the anatomy of human eyes, the physiology of aqueous humor and corneal birefringence.

\subsection{Polarized Light}

Light consists of oscillating electrical fields, denoted by E, and magnetic fields, denoted by $\mathrm{B}$, which are mutually perpendicular. The electric field strength is used to define the state of polarization of light waves.

Light emitted by an atom in a single event has a fixed plane of oscillation. However, light waves emitted by other atoms do not have the same plane. Thus, light emitted by the substance as a whole, consists of different light waves, each with its different plane of oscillation, i.e. a random change in the direction of the light keeps occurring. Such light is known as unpolarized, and includes, for example, light from the Sun, bulbs, 
candles etc.

Light whose electric field oscillates in a particular way is polarized. If the oscillation is in a plane, the light is plane-polarized (Figure 1). Plane polarized light can be polarized in different directions. Light can also be circularly polarized, with its electric field direction spiraling in a screw pattern. Circularly polarized light can be right- or left-handed (Figure 2). Light can consist of a combination of plane and circular polarization as well; its electric field spirals in a screw fashion with an elliptical cross-section. Such light is called elliptically polarized (Figure 3).

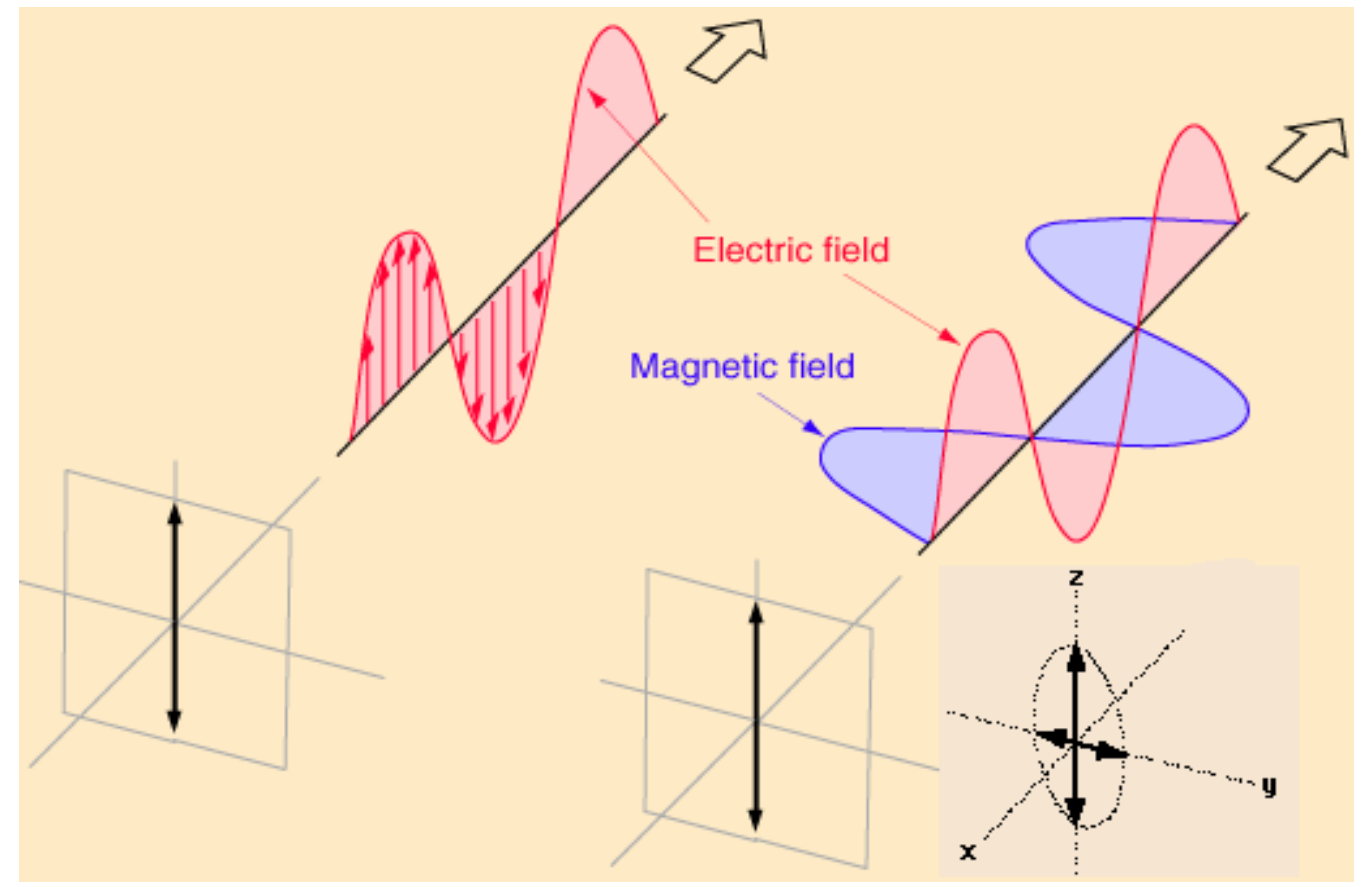

Figure 1 Linear polarized light. The transverse electric field wave is accompanied by a magnetic field wave as illustrated. ${ }^{29}$ 


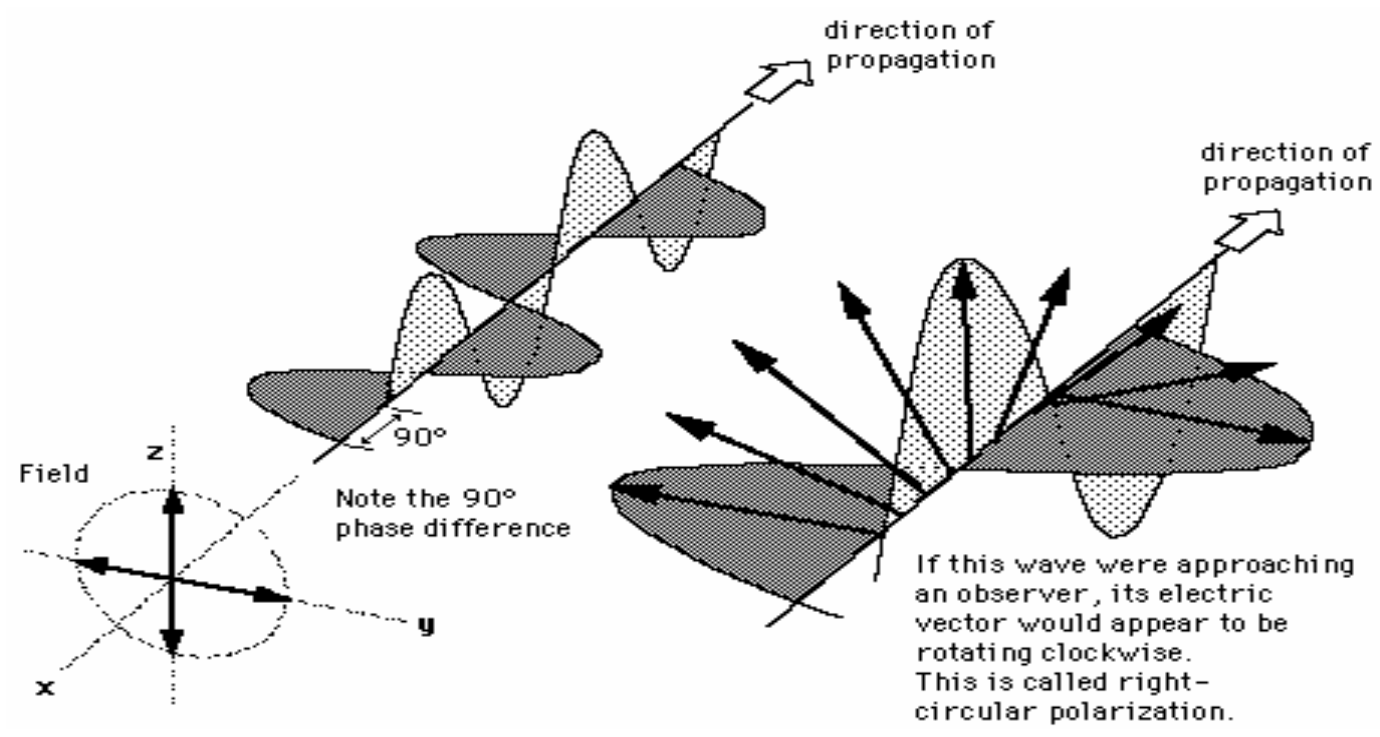

Figure 2 Circularly polarized light consists of two perpendicular electromagnetic plane waves of equal amplitude and $90^{\circ}$ difference in phase. The light illustrated is rightcircularly polarized. ${ }^{29}$

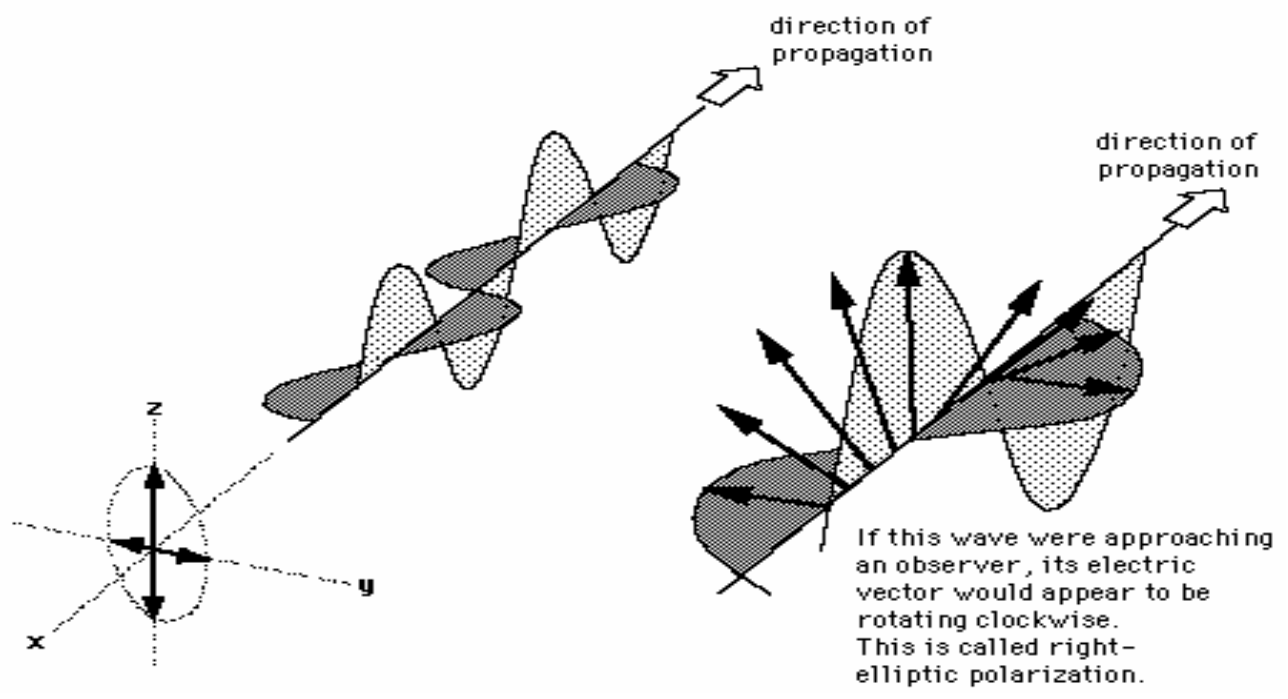

Figure 3 Elliptically polarized light consists of two perpendicular waves of unequal amplitude which differ in phase by $90^{\circ}$. The illustration shows right-elliptically polarized light. $^{29}$ 
The unpolarized light and the three kinds of polarized light can be expressed mathematically. Consider light traveling in a direction perpendicular to the plane of the screen. Two axes, $\mathrm{Y}$ and $\mathrm{Z}$ are two perpendicular directions in the plane, and all the electric fields can be projected into $\mathrm{Y}$ and $\mathrm{Z}$ direction. Let us consider one light wave whose components are Ey and Ez. The fact that the electric field changes its direction randomly with time, can be mathematically expressed as a phase difference, $\delta$, between Ey and Ez. Hence,

$$
\begin{aligned}
& \mathrm{Ey}=\mathrm{E}_{1} \sin (\omega \mathrm{t}-\mathrm{kx}+\delta) \\
& \mathrm{Ez}=\mathrm{E}_{2} \sin (\omega \mathrm{t}-\mathrm{kx})
\end{aligned}
$$

The angle between electric field and the $\mathrm{Y}$ axis can be expressed as,

$$
\tan \theta=\mathrm{Ez} / \mathrm{Ey}=\left(\mathrm{E}_{1} \sin (\omega \mathrm{t}-\mathrm{kx}+\delta)\right) /\left(\mathrm{E}_{2} \sin (\omega \mathrm{t}-\mathrm{kx})\right)
$$

Since there is a random chage in $\delta$ with respect to time, so there is also a random change in $\theta$. Hence, the light is unpolarized.

If $\delta=0$, $\tan \theta=\mathrm{E}_{2} / \mathrm{E}_{1}=$ constant.

Therefore, $\theta$ is a constant and the light is linearly polarized.

If $\delta=\pi$, $\tan \theta=-\mathrm{E}_{2} / \mathrm{E}_{1}=$ constant.

Therefore, $\theta$ is a constant and the light is again linearly polarized. 
If $\delta=\pi / 2$,

$\tan \theta=\left(\left(\mathrm{E}_{2} \sin (\omega \mathrm{t}-\mathrm{kx}) /\left(\mathrm{E}_{1} \sin (\omega \mathrm{t}-\mathrm{kx}+\pi / 2)\right)\right)\right.$

if $\mathrm{E}_{2}=\mathrm{E}_{1}$,

$\tan \theta=\tan (\omega \mathrm{t}-\mathrm{kx})$

Therefore,

$\theta=\omega \mathrm{t}-\mathrm{kx}$

This means that the angle $\theta$, increases uniformly with time. The resultant electric field therefore is

$\mathrm{E}^{2}=\mathrm{Ey}^{2}+\mathrm{Ez}^{2}=\mathrm{E}_{1}^{2} \cos ^{2}(\omega \mathrm{t}-\mathrm{kx})+\mathrm{E}_{2}^{2} \sin ^{2}(\omega \mathrm{t}-\mathrm{kx})=\mathrm{E}_{1}^{2}$

Therefore, the magnitude of the electric field remains constant, but as $\theta$ increases uniformly with time, the tip of the electric field goes in a circle with uniform angular speed, $\omega$. This light will then be called circularly polarized light.

If $\delta=\pi / 2$, and $E_{2}$ is not equal to $E_{1}$, the magnitude of the electric field will change periodically. Hence, its tip will trace out an ellipse, due to which the light will then be called elliptically polarized light.

Several methods can be employed to polarized light in the required direction. One instrument for this purpose is known as a polarizer. Polarizing sheets, commercially known as polaroids, consist of long-chained molecules, such as hydrocarbons, which are aligned in one direction, and embedded in plastic sheets. When light is sent through 
these sheets, only the electric components which are parallel to one particular direction are transmitted, whereas the rest are absorbed by the polarizer. That direction is known as the polarizing direction or the transmission axis of the polarizer. Thus the emergent light is linearly polarized, whose direction can be controlled by changing the orientation of the polarizer.

\subsection{Optical Rotation}

When polarized light passes through a substance containing chiral molecules (or nonchiral molecules arranged asymmetrically), the direction of polarization can be changed. This phenomenon is called optical rotation or optical activity. Biot was the first one to observe that chiral organic molecules can rotate the polarization plane of a light beam when it passes through such medium.

The plane of polarization could rotate clockwise or counter-clockwise due to the molecular conformation of an optically active compound. Molecules possessing the ability to rotate light to the left or counter-clockwise are denoted as levorotatory and those rotate light to the right or clockwise are referred to as dextrorotatory (Figure 4). In fact, one name for glucose, dextrose, refers to the fact that it causes linearly polarized light to rotate to the right. Similarly, levulose, more commonly known as sucrose, causes the plane of polarization to rotate to the left. 


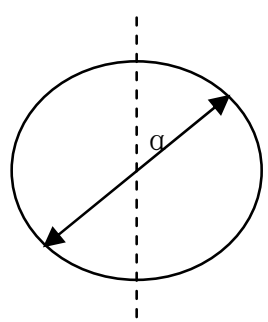

Dextrorotatory rotates light to the right (clockwise)

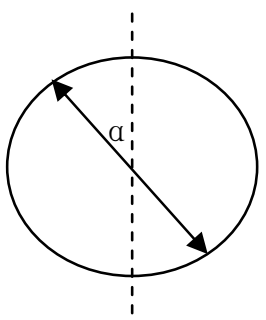

Levorotatory rotates light to the left (counter-clockwise)

Figure 4 An example of optically active enantiomers. ${ }^{30}$

The rotation in the plane of polarization is an intrinsic property of optically molecules. It follows that the amount of rotation is proportional to the number of molecules encountered by a polarized light beam as it passes through a sample of an optically active compound. ${ }^{11}$

The equation, which describes the optical rotation and specific rotation, is given by equation (1):

$$
[\alpha]_{\lambda, p H}^{T}=\frac{100 \alpha}{L C}
$$

Where $[\alpha]_{\lambda, p H}^{T}$ is the specific rotation of an optically active compound.

$\alpha$ is the observed rotation in degrees,

$\mathrm{L}$ is the path length in $\mathrm{dm}$.

$\mathrm{C}$ is the concentration of the sample in gram of mass per ml of solution.

Specific rotation is usually specified at a temperature of $600 \mathrm{C}$ for the yellow sodium D line that exists at $589.3 \mathrm{~nm}$. The specific rotation of some organic molecules 
is shown in Table 1.

Table 1 Specific rotation of some organic molecules ${ }^{11}$

\begin{tabular}{|l|l|l|l|}
\hline Compound & {$[\alpha]_{\mathrm{D}}\left[{ }^{\circ}(\mathrm{dm} \mathrm{g} / \mathrm{L})\right]$} & Compound & {$[\alpha]_{\mathrm{D}}[\%(\mathrm{dm} \mathrm{g} / \mathrm{L})]$} \\
\hline Benzene & 0.00 & Cholesterol & -31.50 \\
\hline$\alpha$-D-glucose & +112.00 & Morphine & -132.00 \\
\hline$\beta$-D-glucose & +18.70 & Penicillin V & +223.00 \\
\hline Camphor & +44.26 & Sucrose & +66.47 \\
\hline
\end{tabular}

Thus, if the specific rotation of the compound is known and the observed rotation can be measured for a given path length, the concentration of the optically active compound can be solved through equation (1). In fact, this is the fundamental theory of polarimetry.

\subsection{Optical Rotatory Dispersion and Drude’s Equation}

As a chiral molecule, glucose is an optically active substance since it does not possess any axis of symmetry. Glucose, when dissolved in water, cyclizes reversibly between a 36:64 mixture of two anomers, ie the $\alpha$-anomer and the $\beta$-anomer-glucose having specific rotation of 112.20 and 18.70 respectively. ${ }^{30}$ After a while, which is dependant 
on the temperature and the $\mathrm{pH}$ of the solution, the net optical rotation of pure D-glucose dissolved in water eventually reaches an equilibrium value of +52.6 . This phenomenon is known as mutarotation and results from the inter-conversion of the two anomers in the solution. ${ }^{30}$. In equation (1), it is assumed that the wavelength of monochromatic polarized light is constant. If the wavelength varies, the rotation also changes. The variation in rotation with the wavelength of the light is called optical rotatory dispersion ( ORD ). The ORD values for glucose through the visible spectrum is shown in Table 2. ${ }^{10}$ The plot of specific rotation as a function of wavelength is called ORD curve, shown in Figure $5 .^{26}$

Table 2 Specific rotation of glucose at various wavelength of light ${ }^{10}$

\begin{tabular}{|l|c|c|c|c|c|c|}
\hline Wavelength $(\mathrm{nm})$ & 656 & 589 & 535 & 508 & 479 & 447 \\
\hline $\begin{array}{l}\text { Specific Rotation } \\
\%(\mathrm{dm} \mathrm{g} / \mathrm{L})\end{array}$ & 41.9 & 52.8 & 65.4 & 73.6 & 83.9 & 96.6 \\
\hline
\end{tabular}

It is obvious that equation (1) can only be used for one optically active substance in a sample and the use of single wavelength polarimeter is sufficient to measure the concentration of the sample. If there is more than one optically significant active substance in a sample, the use of a single wavelength is not sufficient to measure the unknown concentrations because each optically active substance contributes an additional amount of rotation. In fact, blood and aqueous humor, another potential 
sensing site, do contain many optical confounders. Figure 6 shows the observed optical rotations for physiology concentrations of aqueous humor. ${ }^{21}$

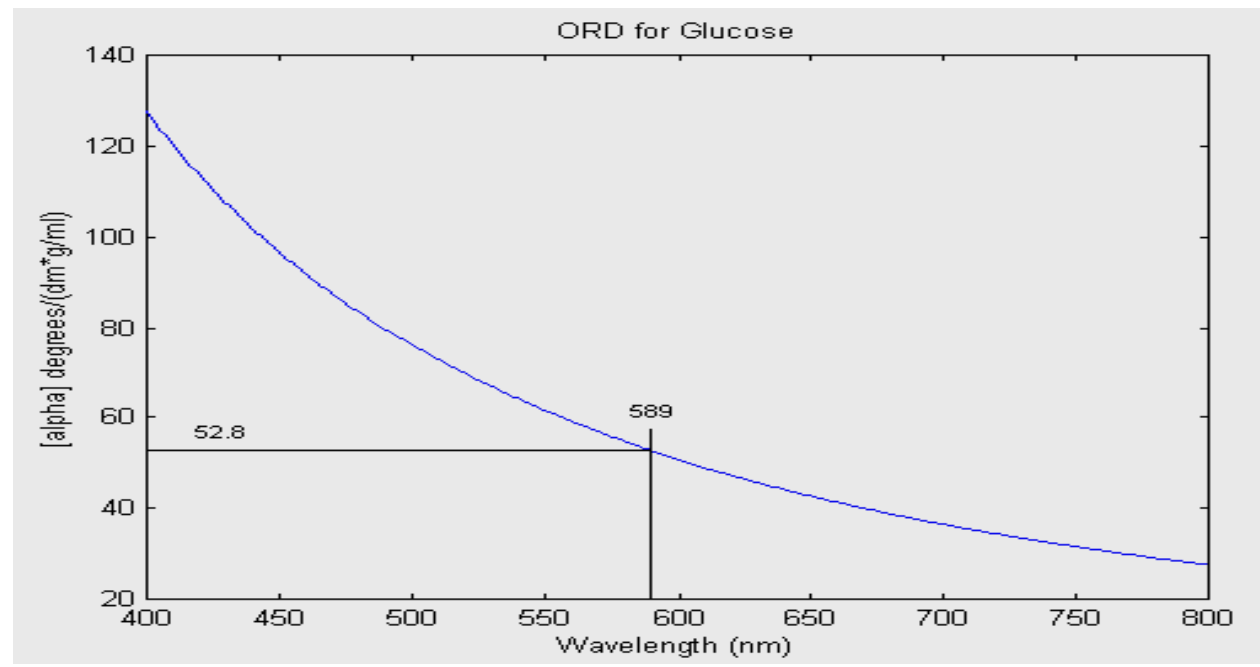

Figure 5 Glucose ORD curve in the visible spectrum ${ }^{26}$

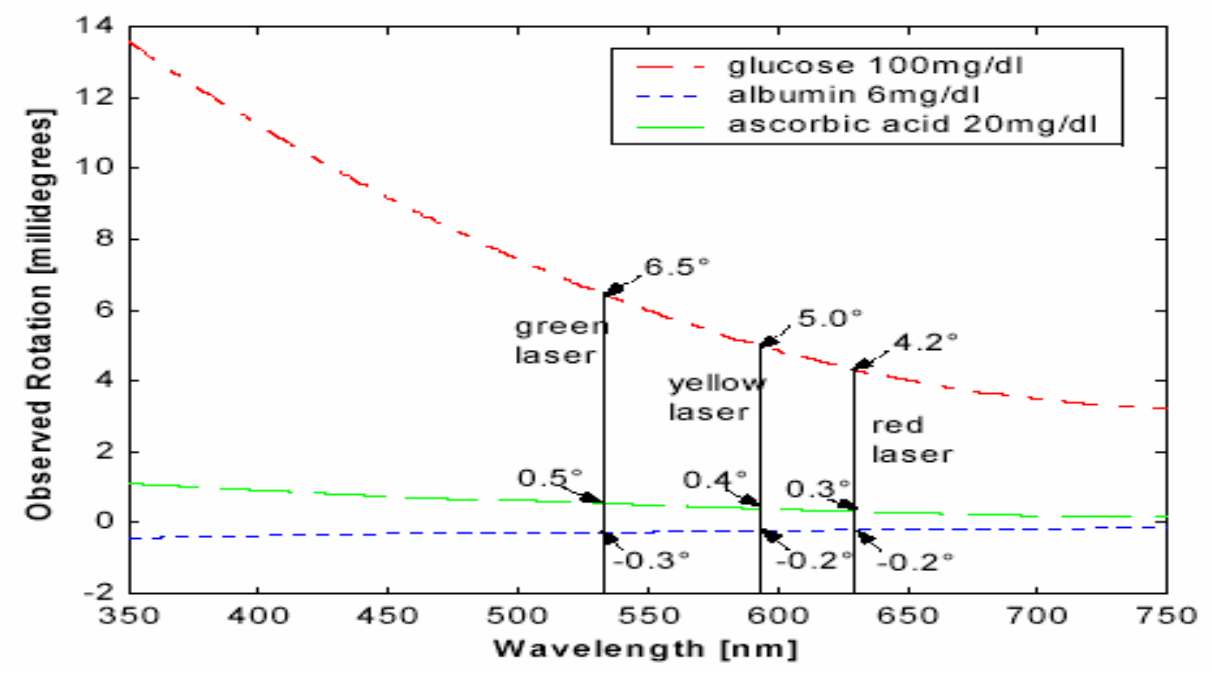

Figure 6 Observed optical rotations for physiological concentrations of aqueous humor analytes, glucose, albumin, and ascorbic acid for $1 \mathrm{~cm}$ path length. ${ }^{21}$ 
Using multi-specrtral polarimeter can help to solve this issue. For instance, if there are two optically active substance in a sample and if the two ORD curves are known for each substance, two equations for the two unknown concentrations can be derived from using the dual wavelength polarimeter. Thus, the two unknown concentrations can be acquired through this system. ${ }^{17,26}$

As stated above, the ORD curves must be known for each optically active substance. Drude's equation describes the relationship between wavelength and specific rotations, shown below.

$[\alpha]=\frac{k_{1}}{\lambda^{2}-\lambda_{1}^{2}}+\frac{k_{2}}{\lambda^{2}-\lambda_{2}^{2}}+\frac{k_{3}}{\lambda^{2}-\lambda_{3}^{2}}+\ldots$

where $\alpha$ is the specific rotation,

$\lambda$ is the wavelength of interest,

$\mathrm{k}_{1}, \mathrm{k}_{2}$ and $\mathrm{k}_{3}$ are the rotational constants corresponding to the wavelength of maximal absorption in the optically active region. ${ }^{16}$

If the wavelength is away from the absorption band, equation (2) can be simplified to:

$$
[\alpha]=\frac{k_{0}}{\lambda^{2}-\lambda_{0}^{2}}
$$

Equation (3) is only valid outside of the absorption region of the molecular of interest. Given a rotation of a molecule at two wavelengths, the $\mathrm{k}_{0}$ and $\lambda_{0}$ can be acquired from Drude's equation. The specific rotation can be calculated at the 
wavelength of interest within the region and the ORD curve can be acquired if these constants are known.

\subsection{Faraday Rotation in Polarimeter}

In this research, three Faraday rotators were used for modulation of the polarization vector and two for compensation of the polarization vector. The Faraday rotator functions based on the Faraday effect. The Faraday effect or Faraday rotation is an interaction between light and a magnetic field. The rotation of the plane of polarization is proportional to the intensity of the component of the magnetic field in the direction of the beam of light. Michael Faraday discovered this effect in $1845 .^{31}$ When current is passing through a coil wrapped around a magneto-optical crystal, it generates a magnetic field in the crystal, which is proportional to the current. If an alternating current is passes through the coil, it will generate an alternating magnetic field, which modulates the polarization light vector at a frequency equal to that of the magnetic field. The axial magnetic field is produced by a current, which flows through a coil that surrounds the propagation medium. The equation, which describes the rotation to magnetic flux density and path length, is given blow. ${ }^{31}$

$$
\beta=v B d
$$

where $\beta$ is the observed rotation in arc minutes 
$v$ is the factor of proportionality known as Verdet constant,

$\mathrm{B}$ is the static magnetic flux density,

$\mathrm{d}$ is the path length of the propagation.

The strength of magnetic field is proportional to the voltage applied to the coil. Thus, the amount of rotation in polarization is proportional to the applied voltage. Figure 7 shows a Faraday effect modulator.

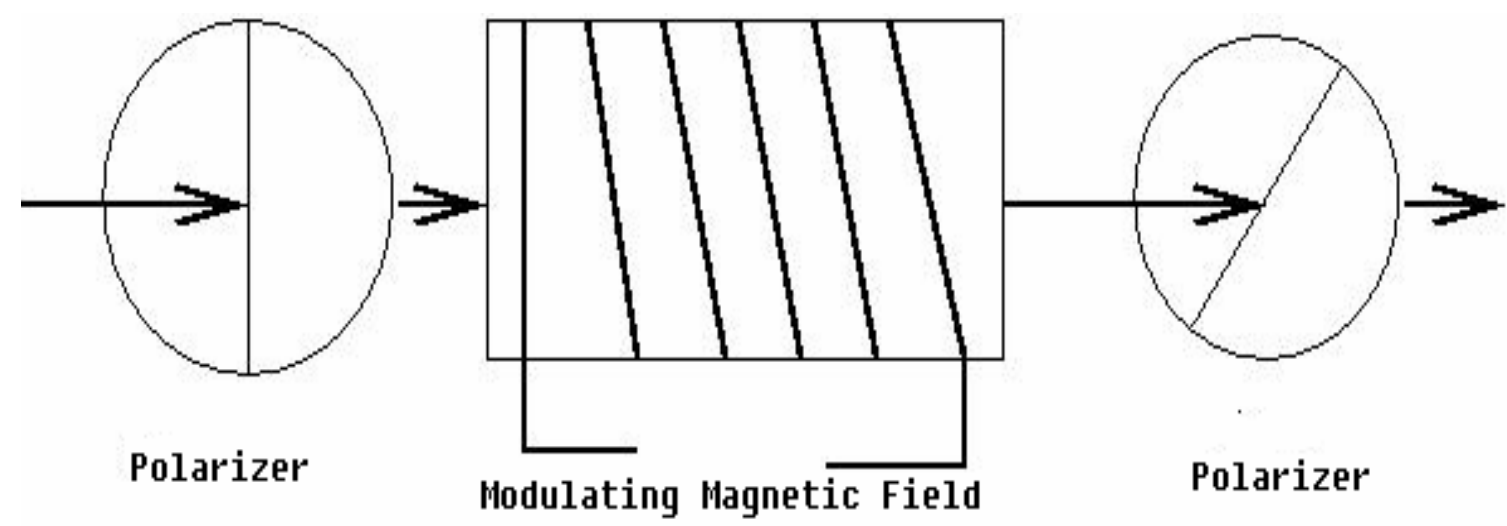

Figure 7 A Faraday effect modulator

In order to achieve a good signal-to noise ratio, the modulation frequency can be chosen between 0.5 and $3 \mathrm{kHz}{ }^{26}$ For this research, $1.09 \mathrm{kHz}$ was chosen as the modulation frequency.

In addition, Faraday rotators were also used as compensation component of the rotation due to glucose. This compensator utilizes a DC instead of an AC source to drive 
the coil. The rotation in polarization due to the optically active sample is thus compensated by this kind of Faraday rotator.

\subsection{Polarimeter}

\subsubsection{Basic Polarimeter}

A polarimeter is an optical instrument to measure rotation due to an optical active substance. Most polarimeters include some basic components such as laser, polarizer, sample of interest, analyzer(a second polarizer) and a detector. This basic polarimeter is illustrated in Figure 8.

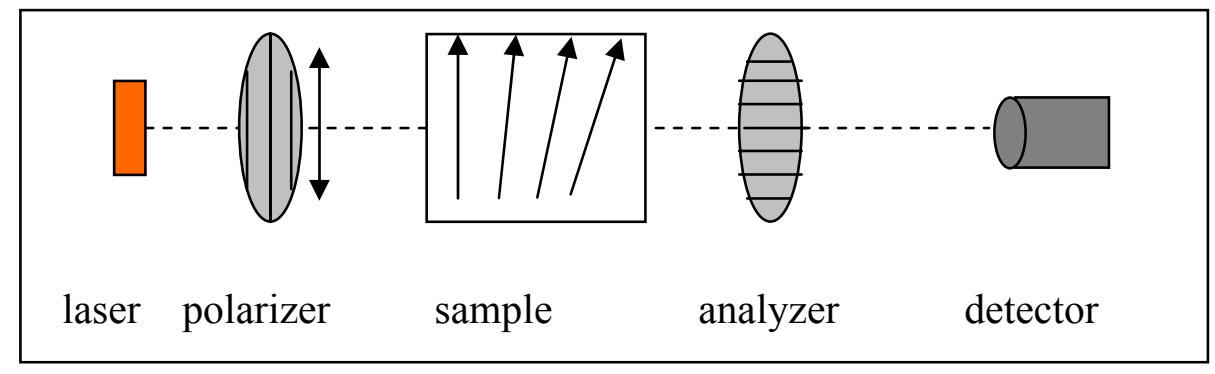

Figure 8 Block diagram of a basic polarimeter

A laser is used as the light source. After the beam passes through the polarizer, the light is linearly polarized. In the sample, the plane of the polarization is rotated due to the concentration of the glucose and path length through the sample. The analyzer is used to determine the rotation due to glucose concentration. Generally, the analyzer is oriented perpendicular to the first polarizer. If no optically active substance is present, 
theoretically no light would be transmitted from the analyzer. If an optically active sample is introduced into the system, perpendicular component of the polarized light is transmitted through the analyzer and the intensity of this part of light is proportional to the amount of rotation, which depends on the concentration of the optically active medium if the path length is kept constant. Thus, the concentration of the medium can be calculated through the polarimeter.

\subsubsection{A Single Wavelength Polarimeter}

A single wavelength polarimeter setup is shown in Figure 9. This polarimeter was first reported by Cameron et al. ${ }^{18}$

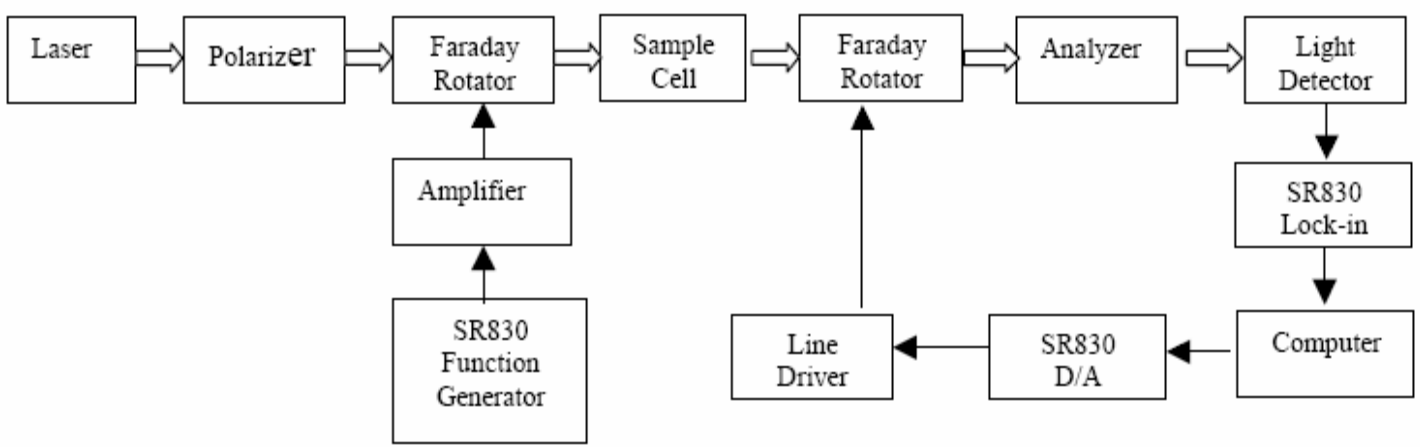

Figure 9 Block diagram of a common polarimeter. ${ }^{18}$

The initial polarizer linearly polarizes the laser beam. A Faraday rotator is employed in order to provide a modulated signal. Driving the modulation Faraday via SR830 function generator generates a small modulation depth of approximately $\pm 1^{\circ}$. The modulated signal passes through an optically active sample. The light passes through the 
analyzer, which is orientated perpendicular to the initial polarizer. The photo-diode detector measures the output intensity. The lock-in amplifier is used to measure the signal at modulation frequency. The output of the lock-in, which is sent to the computer, is proportional to the measured intensity. A program is used to record the lock-in output voltage because the output is proportional to the glucose concentration.

In the open-loop system, the measured signal lacks stability due to fluctuation of laser intensity as well as noise. Thus, a closed-loop system is employed to improve repeatability and stability while preserve accuracy. In the closed-loop system, another Faraday rotator is employed as feedback component. A control algorithm program decides the course of action to take in order to compensate the rotation due to sample. The controller provides the feedback voltage to the compensation Faraday rotator after a $\mathrm{D} / \mathrm{A}$ converter and the applied feedback voltage to null the system or rather compensate for the rotation due to glucose is recorded by the computer.

\subsubsection{Modeling the Polarimeter}

In section, a model of the detected signal is derived by the use of Jones matrices. The main optical components of the polarimeter are a laser, polarizer, Faraday modulator, optically active sample, Faraday compensation, analyzer and detector.

The Jones vector provides a convenient way to represent polarized light for these 
optical components. A Jones vector represents the electric field vector and can be written in the following form:

$$
E=\left[\begin{array}{l}
E_{x}(t) \\
E_{y}(t)
\end{array}\right]
$$

where $E_{x}(t)$ and $E_{y}(t)$ represent the instantaneous scalar components of E. An optical element performs an operation on the polarization vector as it passes through the element. It can be represented by a 2 X 2 Jones matrix. ${ }^{31}$ The Jones matrices are listed in the Table $3 .^{31}$

Table 3 Jones matrices for common optical polarization components ${ }^{31}$

\begin{tabular}{|c|c|}
\hline Optical Element & Jones Matrix \\
\hline Horizontal Linear Polarization & {$\left[\begin{array}{ll}1 & 0 \\
0 & 0\end{array}\right]$} \\
\hline Vertical Linear Polarization & {$\left[\begin{array}{ll}0 & 0 \\
0 & 1\end{array}\right]$} \\
\hline $\begin{array}{l}\text { Optically Active Sample (Clockwise } \\
\text { rotation) }\end{array}$ & {$\left[\begin{array}{cc}\cos \left(\phi_{g}\right) & -\sin \left(\phi_{g}\right) \\
\sin \left(\phi_{g}\right) & \cos \left(\phi_{g}\right)\end{array}\right]$} \\
\hline $\begin{array}{l}\text { Compensation } \\
\text { Faraday(counter-clockwise rotation) }\end{array}$ & {$\left[\begin{array}{cc}\cos \left(\phi_{f}\right) & \sin \left(\phi_{f}\right) \\
-\sin \left(\phi_{f}\right) & \cos \left(\phi_{f}\right)\end{array}\right]$} \\
\hline Polarization Modualtor & {$\left[\begin{array}{cc}\cos \left(\theta_{m} \sin \left(\omega_{m} t\right)\right) & -\sin \left(\theta_{m} \sin \left(\omega_{m} t\right)\right) \\
-\sin \left(\theta_{m} \sin \left(\omega_{m} t\right)\right) & \cos \left(\theta_{m} \sin \left(\omega_{m} t\right)\right)\end{array}\right.$} \\
\hline
\end{tabular}

Where $\theta_{\mathrm{m}}$ is the depth of the Faraday modulation, $\omega_{\mathrm{m}}$ is the modulation frequency, $\mathrm{t}$ is 
time and $\phi_{\mathrm{g}}$ and $\phi_{\mathrm{f}}$ represent the rotation angle induced by the optical activity of glucose and compensation faraday rotator, respectively.

The output Jones matrix can be derived by:

$$
\begin{aligned}
& \mathrm{E}=\left[\begin{array}{l}
E_{x}(t) \\
E_{y}(t)
\end{array}\right]=\left[\begin{array}{ll}
1 & 0 \\
0 & 0
\end{array}\right] *\left[\begin{array}{cc}
\cos \left(\phi_{f}\right) & \sin \left(\phi_{f}\right) \\
-\sin \left(\phi_{f}\right) & \cos \left(\phi_{f}\right)
\end{array}\right] *\left[\begin{array}{cc}
\cos \left(\phi_{g}\right) & -\sin \left(\phi_{g}\right) \\
\sin \left(\phi_{g}\right) & \cos \left(\phi_{g}\right)
\end{array}\right] * \\
& {\left[\begin{array}{cc}
\cos \left(\theta_{m} \sin \left(\omega_{m} t\right)\right) & -\sin \left(\theta_{m} \sin \left(\omega_{m} t\right)\right) \\
-\sin \left(\theta_{m} \sin \left(\omega_{m} t\right)\right) & \cos \left(\theta_{m} \sin \left(\omega_{m} t\right)\right)
\end{array}\right] *\left[\begin{array}{ll}
0 & 0 \\
0 & 1
\end{array}\right] *\left[\begin{array}{l}
0 \\
1
\end{array}\right]} \\
& =\left[\begin{array}{c}
-\sin \left(\theta_{m} \sin \left(\omega_{m} t\right)+\phi_{g}-\phi_{f}\right) \\
0
\end{array}\right]
\end{aligned}
$$

The output intensity I is proportional to the square of the electric filed:

$I \propto E^{2}=\sin ^{2}\left(\theta_{m} \sin \left(\omega_{m} t\right)+\phi\right) \quad$ where $\quad \phi=\phi_{g}-\phi_{f}$

Since the $\left(\theta_{m} \sin \left(\omega_{m} t\right)+\phi\right)$ is very small and the assumption is used:

$$
\begin{aligned}
I & \propto E^{2}=\sin ^{2}\left(\theta_{m} \sin \left(\omega_{m} t\right)+\phi\right) \approx\left(\theta_{m} \sin \left(\omega_{m} t\right)+\phi\right)^{2} \\
I & \propto\left[\theta_{m} \sin \left(\omega_{m} t\right)+\phi\right]^{2}=\theta_{m}^{2} \sin ^{2}\left(\omega_{m} t\right)+2 \phi \theta_{m} \sin \left(\omega_{m} t\right)+\phi^{2} \\
& =\frac{\theta_{m}^{2}}{2}-\frac{\theta_{m}^{2}}{2} \cos \left(2 \omega_{m} t\right)+2 \phi \theta_{m} \sin \left(\omega_{m} t\right)+\phi^{2} \\
& =\left(\frac{\theta_{m}^{2}}{2}+\phi^{2}\right)+2 \phi \theta_{m} \sin \left(\omega_{m} t\right)-\frac{\theta_{m}^{2}}{2} \cos \left(2 \omega_{m} t\right)
\end{aligned}
$$

\section{DC offset $\quad 1.09 \mathrm{kHz}, 1 \mathrm{f} \quad 2.18 \mathrm{kHz}, 2 \mathrm{f}$}

As seen from the equation (6) and shown in Figure 10, the detected output intensity consists of a DC term, a frequency-doubled term and a modulated frequency term. ${ }^{32}$ This modulation frequency term is used as the input of the compensation Faraday rotator. 
Locking the frequency at the modulated frequency in the null system (1f term forced to zero), one can calibrate the glucose concentrations according to the input voltages of compensation Faraday rotator.

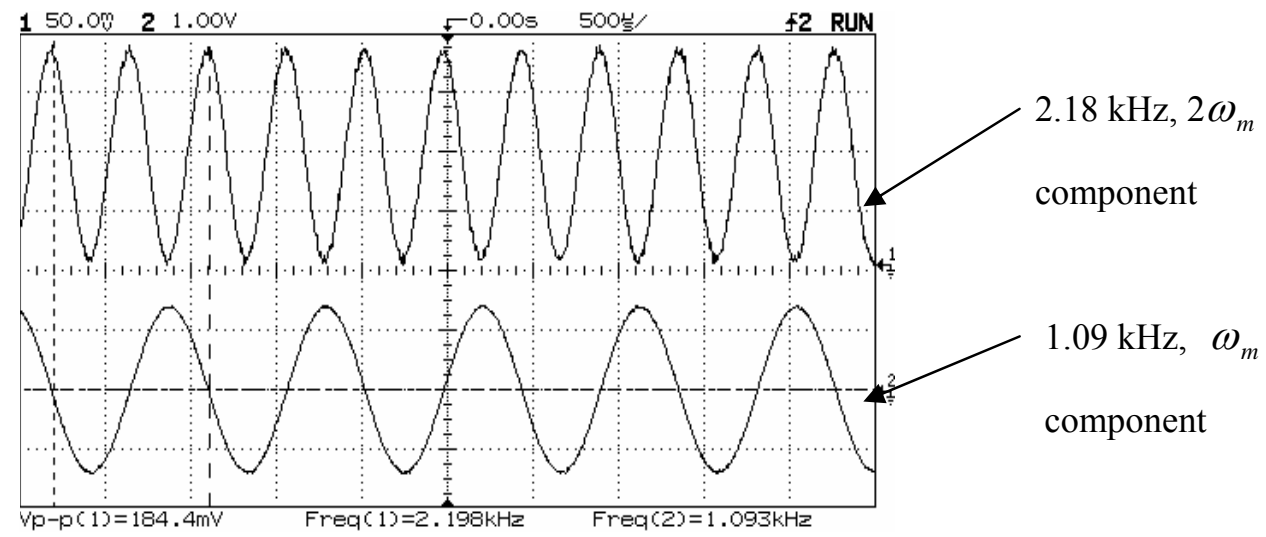

(a)

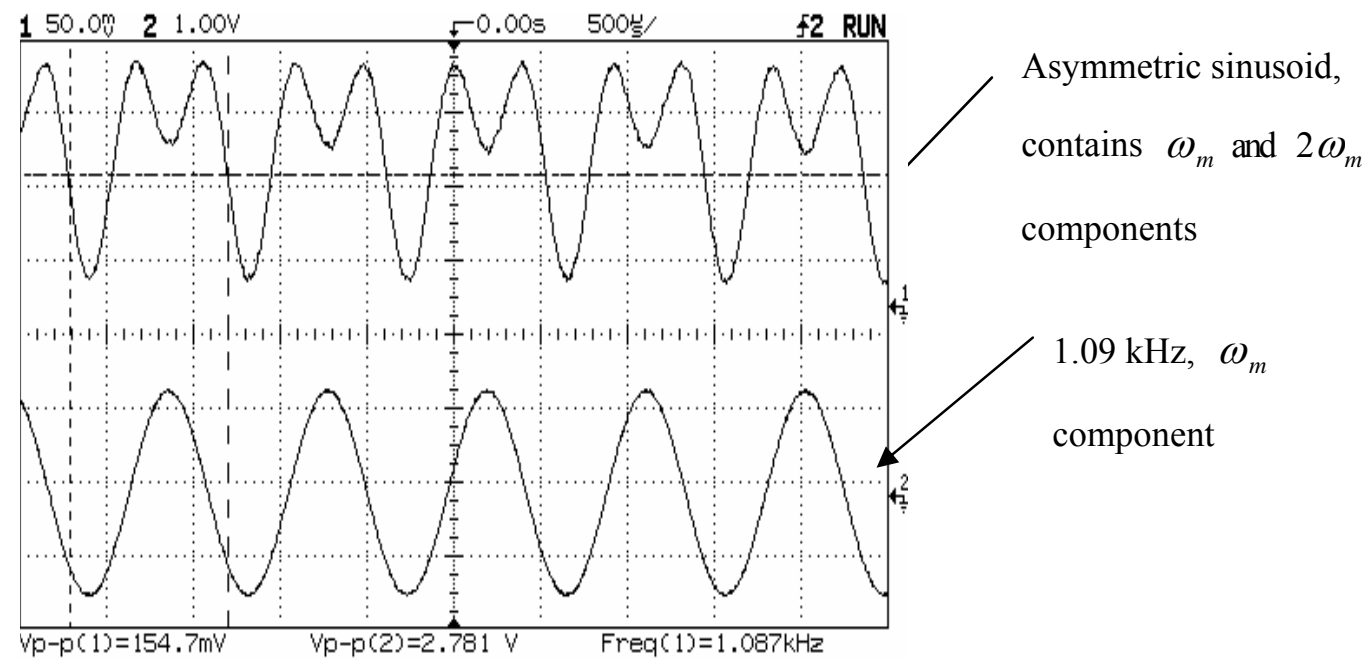

(b)

Figure 10 The detected output intensity. (a) The top sinusoid is modulation signal and bottom sinusoid is the double frequency. (b) This is the detected signal of optically active sample. 


\subsubsection{Dual Wavelength Polarimeter}

Currently, there is a problem hindering the development of a useful polarimter. The single wavelength described above is able to measure the concentration of glucose doped water and aqueous humor with high accuracy. ${ }^{18}$ However, the polarimeter can not measure glucose concentration in vivo because the cornea eye is birefringent and this birefringence changes with motion artifact Thus, a digital dual wavelength, closed-loop system was proposed to overcome the variable birefrigence in this research.

The output intensity for each wavelength in the original, non-birefringent open-loop system is governed by Eqs.(7-8) below, where $\theta_{m}$ is the depth of the Faraday modulation, $\omega_{m}$ is the modulation frequency, $\mathrm{t}$ is time, $\phi_{1}$ and $\phi_{2}$ represent the total rotation from each wavelength. The rotations at each wavelength can be further broken down into $\phi_{g 1}$ and $\phi_{g 2}$, which represent the rotation angle induced by the optical activity of glucose, as well as $\phi_{f 1}$ and $\phi_{f 2}$ which are the rotations caused by the Faraday rotators. For the closed-loop system the amplitude of the fundamental harmonic of the output $\left(\omega_{m}\right)$ for each wavelength is forced to zero using the two Faraday rotators after the initial polarizers and light sources. The voltage across the Faraday rotator necessary to do this is proportional to $2 \phi_{n} \theta_{m}$, in which $n$ is a subscript for either 1 or 2 depending on the wavelength. ${ }^{18}$ Given that the modulation depth is kept constant, one can determine the rotation due to glucose from this feedback voltage. 


$$
\begin{aligned}
& I_{1} \propto E_{1}^{2}=\left(\phi_{1}^{2}+\frac{\theta_{m}^{2}}{2}\right)+2 \phi_{1} \theta_{m} \sin \left(\omega_{m} t\right)-\frac{\theta_{m}^{2}}{2} \cos \left(2 \omega_{m} t\right) \\
& I_{2} \propto E_{2}^{2}=\left(\phi_{2}^{2}+\frac{\theta_{m}^{2}}{2}\right)+2 \phi_{2} \theta_{m} \sin \left(\omega_{m} t\right)-\frac{\theta_{m}^{2}}{2} \cos \left(2 \omega_{m} t\right)
\end{aligned}
$$

\section{DC offset $\quad 1.09 \mathrm{kHz}, 1 \mathrm{f} \quad 2.18 \mathrm{kHz}, 2 \mathrm{f}$}

$$
\phi_{1}=\phi_{g 1}-\phi_{f 1}=\phi_{g 2}-\phi_{f 2}
$$

If the birefringence of the sensing site did not change, then the glucose concentration could be easily extracted from $\phi$ by simply measuring the feedback voltage that it takes to null the first harmonic (i.e. setting $\phi_{f}$ equal to $\phi_{g}$ ). However, when birefringence is introduced into the system, $\phi$ becomes a function of birefringence, glucose, and the feedback of the faraday for a given wavelength: $\phi=\phi_{g}+\phi_{b}-\phi_{f}$, where $\phi_{b}$ is the change caused by the birefringence, making it impossible to distinguish rotation due to glucose from the rotation due to birefringence of the sample with just one wavelength as equation (8) now has two unknowns (glucose and birefringence). In order to correct for this effect, a second wavelength has been introduced to provide an additional equation (9). Note from chapter IV that the individual birefringence at each wavelength does not need to be constant but rather only that the relationship (i.e. slope) between the birefringence at the two wavelengths need to be related regardless of the glucose concentration. Secondly it should be noted that the only assumption that was made in the original derivation was 
the small angle assumption, namely that as long as $\theta_{m} \sin \left(\omega_{m} t\right)+\phi$ is small then the $\sin \left(\theta_{m} \sin \left(\omega_{m} t\right)+\phi\right)=\theta_{m} \sin \left(\omega_{m} t\right)+\phi .^{26}$ This is true since the birefringence and glucose rotation in the test cell and in the eye are less than the modulation depth and the modulation depth is less than 2 degrees. Further, for the closed loop system, the voltage applied to the feedback Faraday rotators is such that we ensure that $\phi=0$. A more detailed discussion of the signal and the control system can be found in chapter III.

\subsection{In Vivo Glucose Detection}

This research mainly focus on in vitro glucose detection, however, the polarimeter will eventually be used in vivo for glucose detection within the aqueous humor of the eye since eye has been chosen as the sensor site. This section reviews the anatomy of eye that is related to this research and the transport of the glucose from blood to aqueous humor.

\subsubsection{Relevant Anatomy of the Eye}

The anatomy of the human eye is shown in Figure 11. The entire eye is a spherical structure approximately $2.5 \mathrm{~cm}$ in diameter. The outer part of the eye is composed of three layers of tissue. The outside layer is the sclera, a protective coating. At the front of 
the eyeball, it is continuous with the transparent cornea. The middle layer of the coating of the eye is the choroid, a vascular layer lining the posterior three-fifths of the eyeball. The choroid is continuous with the ciliary body and with the iris, which lies at the front of the eye. The innermost layer is the light-sensitive retina. ${ }^{33}$

The cornea is a five-layered membrane through which light is transmitted to the interior of the eye. Behind the cornea is a chamber filled with clear, watery fluid, the aqueous humor, which separates the cornea from the crystalline lens.

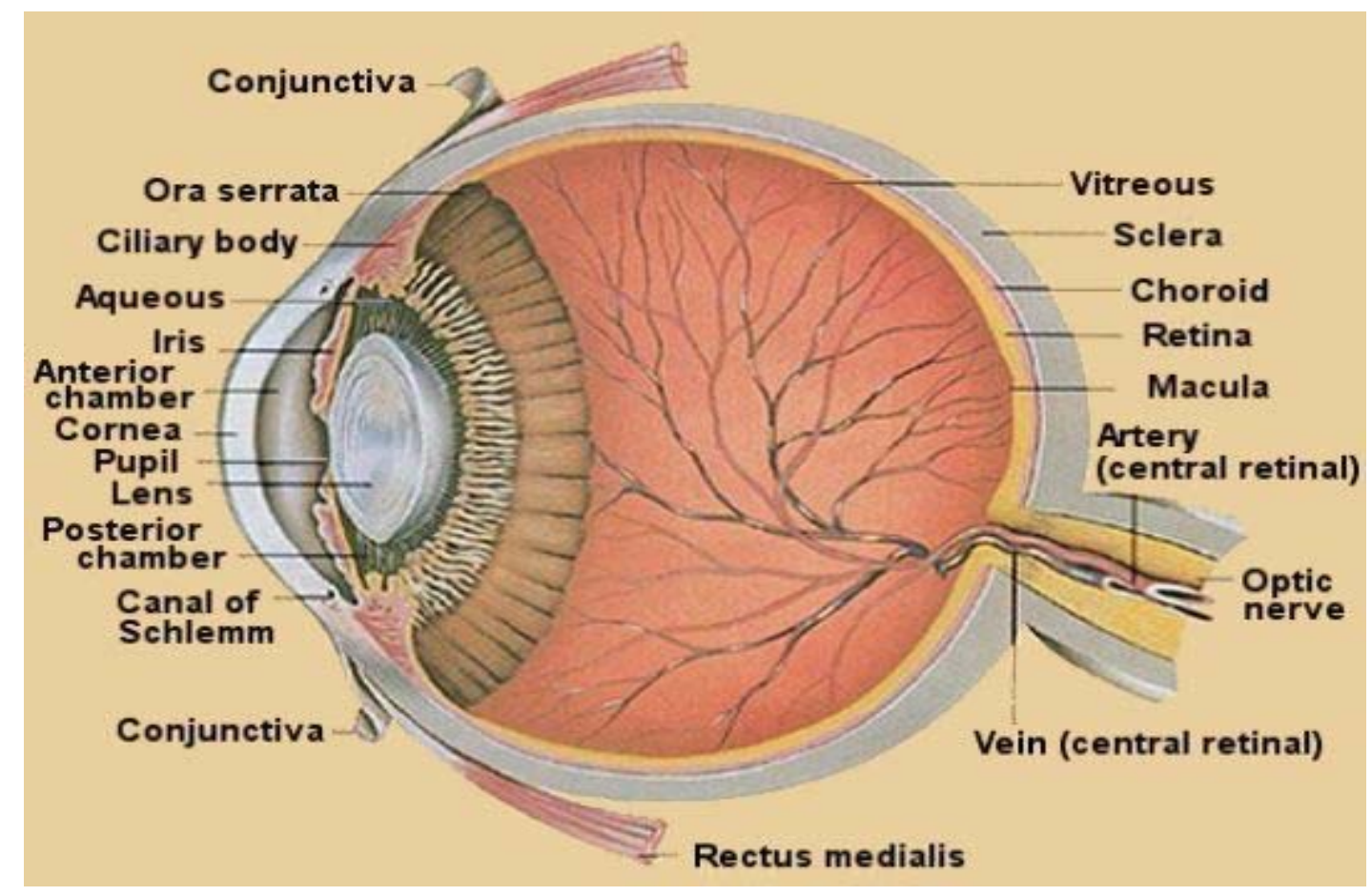

Figure 11 Anatomy of the eye $\mathrm{e}^{33}$

The lens itself is a flattened sphere constructed of a large number of transparent 
fibers arranged in layers. It is connected by ligaments to a ringlike muscle, called the ciliary muscle, which surrounds it. The ciliary muscle and its surrounding tissues form the ciliary body. This muscle, by flattening the lens or making it more nearly spherical, changes its focal length. ${ }^{34}$

The pigmented iris hangs behind the cornea in front of the lens, and has a circular opening in its center. The iris's posterior surface lies next to the lens and the aqueous humor can flow between them. The anterior and posterior chamber is distinguished by the surface. ${ }^{34}$ The size of its opening, the pupil, is controlled by a muscle around its edge. This muscle contracts or relaxes, making the pupil larger or smaller, to control the amount of light admitted to the eye.

Behind the lens the main body of the eye is filled with a transparent substance, the vitreous humor. The pressure of the vitreous humor keeps the eyeball distended.

The retina is a complex layer, composed largely of nerve cells. Directly behind the pupil is a small yellow-pigmented spot, the macula lutea, in the center of which is the fovea centralis, the area of greatest visual acuity of the eye.

\subsubsection{The Composition of Aqueous Humor}

As described above, the aqueous humor is produced in the eye, and diffuses out of the eye into the blood. The aqueous humor is a clear, watery solution in the anterior chamber. 
As shown in Figure 12, the aqueous humor (follow the arrow) is produced by the ciliary body where it flows into the anterior chamber and then out through a spongy tissue at the front of the eye called the trabecular meshwork into a drainage canal. ${ }^{35}$ There are about $20 \%$ of aqueous humor which can not flow to blood due to diffusion into the anterior uvea.

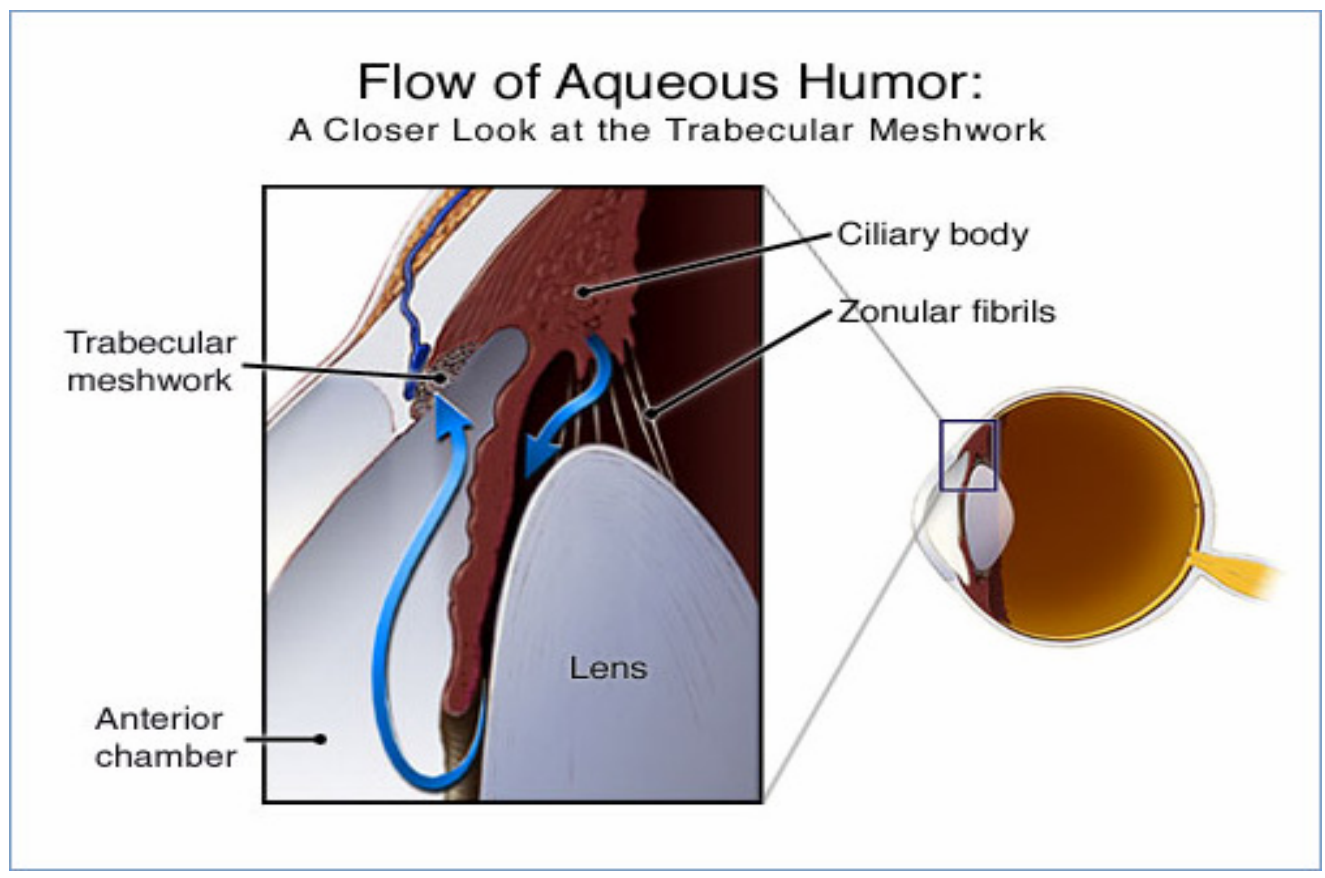

Figure 12 Flow of the aqueous humor ${ }^{35}$

The function of the aqueous humor is to remove waste and replenish the nutrients to the surrounding tissue. The composition of aqueous humor is closed to plasma. The most important difference is the protein concentrations. The aqueous humor contains $5-15 \mathrm{mg} /$ $100 \mathrm{ml}$ while plasma has about 6-7 g/ $100 \mathrm{ml}$. 
Glucose and other substances that transport across the ciliary epithelium are mainly driven by the concentration gradient. The concentration of glucose in aqueous humor is proportional to the glucose level in blood. ${ }^{12,13}$ As stated previously, there are some other optically active substances in aqueous humor, however, these components in the aqueous humor as well as the effects of the temperature and $\mathrm{pH}$ are negligible within physiological ranges for sensing glucose via polarimetry. ${ }^{21}$

\subsubsection{Corneal Birefringence}

The eye is a potential sensor site due to relatively low scattering and path length of adequate $($ size $\approx 1 \mathrm{~cm})$. Another main reason is that the concentration of glucose in aqueous humor is proportional to the glucose level in blood. However, the cornea is a birefringent substance and a confounder for the measurement of glucose especially when coupled with motion artifact.

If a substance has the same the optical properties in all the directions regardless of its orientation, the substance is isotropic. If the substances do not have the same the optical properties in all directions they have more than one index of refraction, they are known as anisotropic. Birefringence is a property of anisotropic substances. A birefringence substance has two orthogonal oriented refractive indices: the ordinary

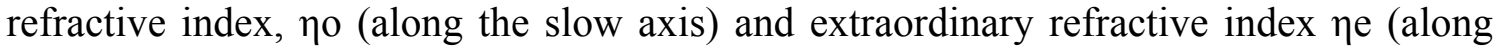


the fast axis). Polarized light travels at a different speed along the two different axes. This difference in the speed of propagation induces a phase difference.

The cornea is a birefringent substance due to stroma that is composed of sheets of lamellae, which are composed of collagen fibers. ${ }^{36}$ Each sheet of lamella is oriented differently with the one following it. Each of these layers contains their own inherent birefringence and the degree of the arrangement of the lamella determines the overall birefringence. ${ }^{36}$ It has been shown that corneal birefringence is function of position. ${ }^{36}$ 


\section{CHAPTER III}

\section{MATERIALS AND METHODS}

This chapter introduces a detail description of the experiments in this research. The first section describes the characterization of the test cell birefringence. The open-loop system and dual wavelength closed-loop system is then presented in predicting glucose concentration in water. The final section explores the possibility of applying the digital dual wavelength, closed-loop system in NZW rabbit eyes.

\subsection{Characterization of the Test Cell Birefringence}

In this research, a birefringent sample cell (Cole-Parmer INC., Vernon Hills, IL) was used. An experimental setup to assess the birefringence of the sample cell is shown in Figure 13. The input beam from a $635 \mathrm{~nm}$ red diode (Laser Max Inc. Rochester, NY) was modulated by an Faraday rotator (Deltronic Crystal Inc., Dover, NJ) at a frequency of $1.09 \mathrm{kHz}$. . The modulated light beam was then separated into two orthogonal propagating beams by a non-polarizing beam splitter (Newport Inc., Irvine CA). The beam propagating perpendicular with respect to the original input beam passed through a Glan-Thompson 100000:1 polarizer (Newport Inc, Irvine CA) and then was detected by a biased photodiode detector (Thorlabs Inc., Newton, NJ) as a reference signal. After an 


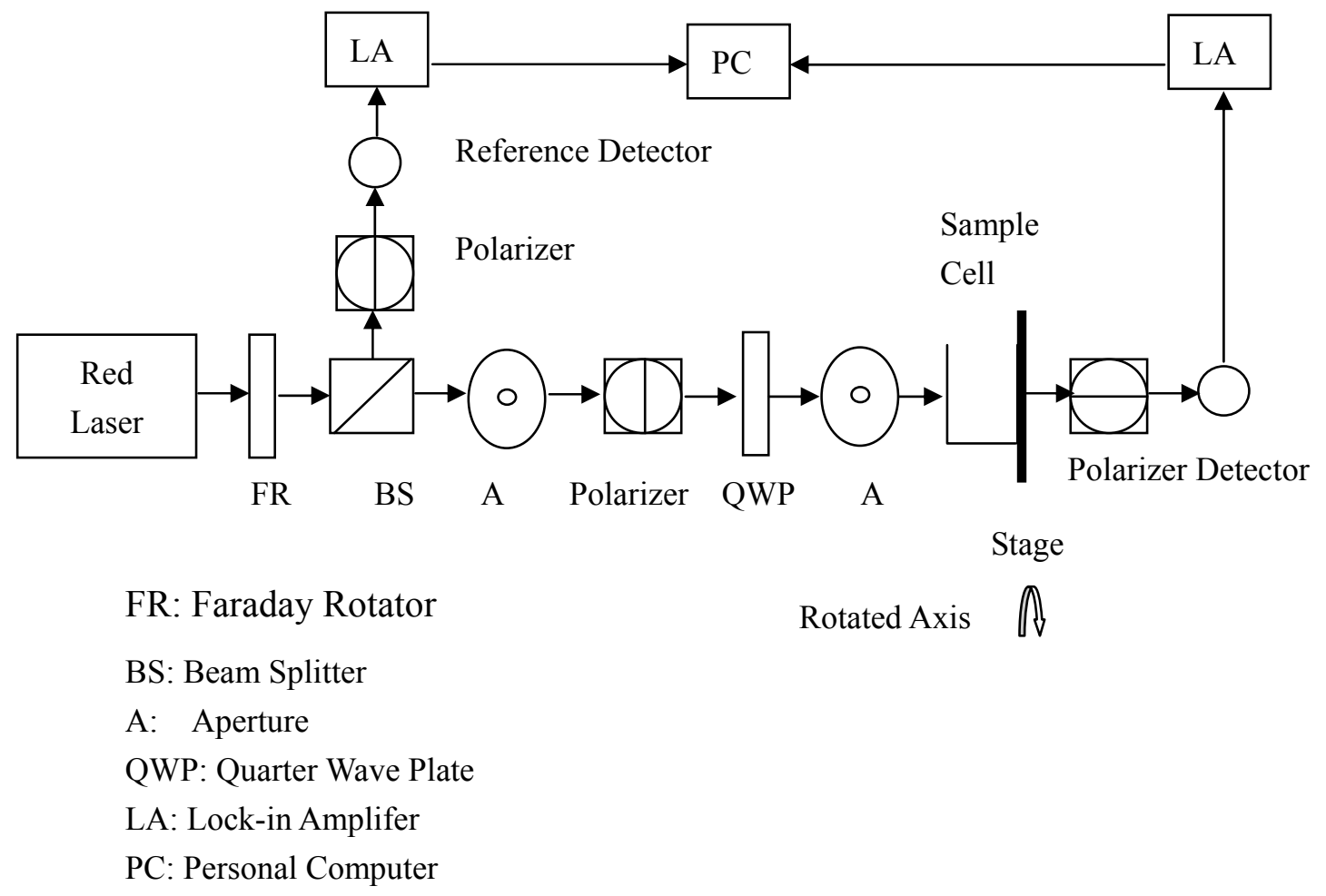

Figure 13 Experimental setup to assess sample cell birefringence

aperture, the beam propagating forward with respect to the original input beam passed through another Glan-Thompson 100 000:1 polarizer (Newport Inc, Irvine CA) which converted it into a linear vertically polarized beam. A quarter wave plate with a fast axis $+45^{\circ}$ with respect to the vertical axis converted the beam into a right circular polarized light. After another aperture, the beam passed through a rectangular sample cell (Cole-Parmer INC., Vernon Hills, IL) constructed of plastic birefringent material with a path length of $1 \mathrm{~cm}$. The sample cell was mounted on a stage, which could be rotated along it axis. The beam was transmitted through a third Glan-Thompson polarizer (Newport Inc, Irvine CA), whose polarization axis was horizontal. The light 
intensity was detected by another photodiode detector. The two detectors converted the measured intensities to proportional voltages that were extracted by lock-in amplifiers SR830 and SR850 (Stanford Research Systems) at $1.09 \mathrm{kHz}$ reference frequency. The output voltage from the lock-in amplifiers was recorded by a Pentium II PC via a GPIB interface operated by a LABVIEW 5.1 (National Instruments, Austin, TX) program. The sample cell was rotated manually from 0 to $180^{\circ}$ in 10 degree increments at five different locations, while keeping the same probing spot of the sample cell in this experiment.

\subsection{Open-loop Experiments}

In order to compensate for motion-induced birefringence using a dual wavelength system, experiments were conducted to observe its effects on the output intensity for each wavelength. Initially, open-loop experiments were performed to determine the relationship between the output intensities of two light sources with respect to changes in the birefringence of the optical signal.

The block diagram of the system is shown in Figure 14. The input light sources used were a red $635 \mathrm{~nm}$ laser diode (LaserMax, Inc., Rochester, NY), emitting 5mW of power, and a green $532 \mathrm{~nm}$ laser diode (Oriel Instruments, Stratford, CT), emitting 20mW of power. $\quad$ Each light beam was passed through a Glan-Thompson 100000:1 


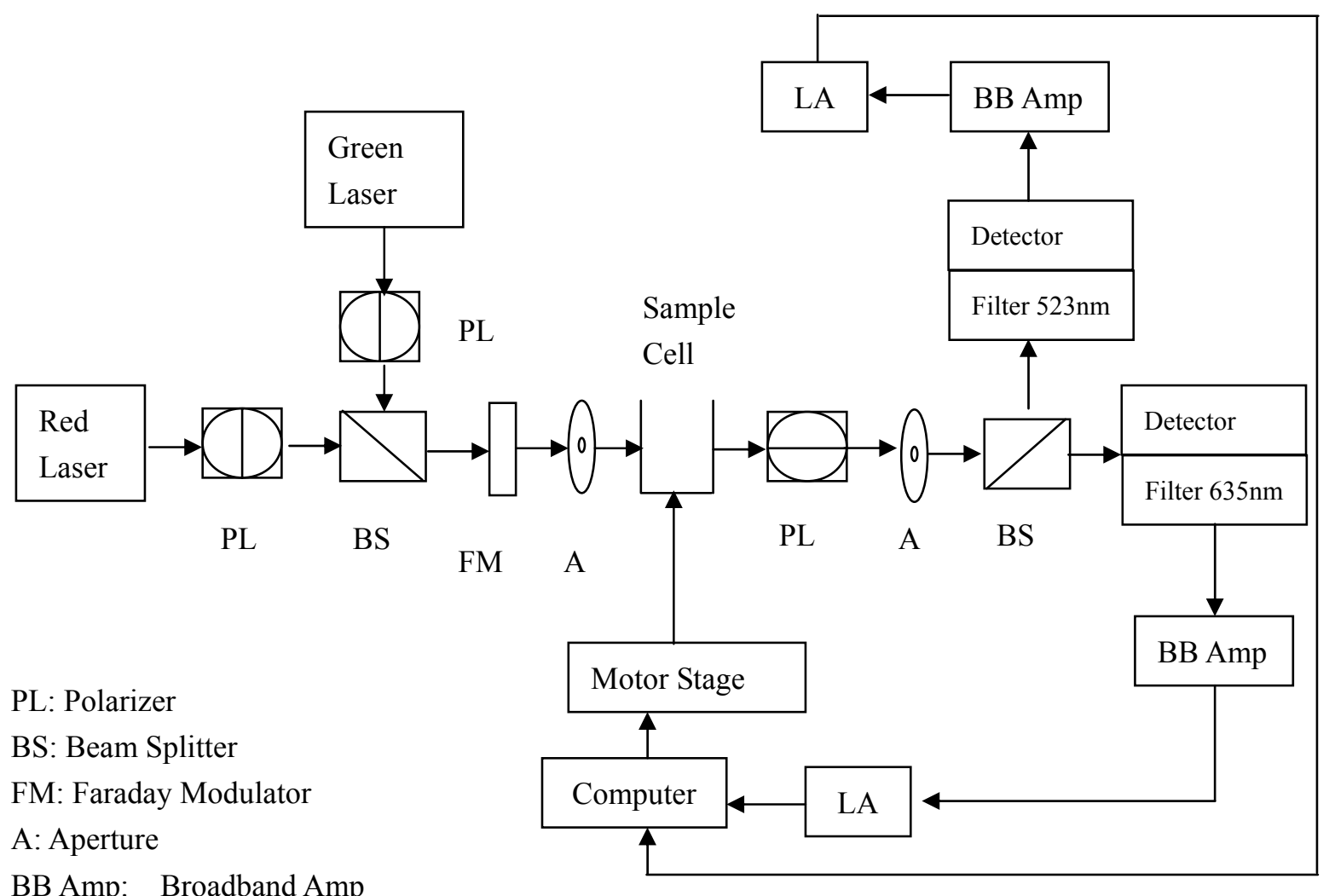

BB Amp: Broadband Amp

LA: Lock-in Amp

Figure 14 Block diagram of the system open-loop system

polarizer (Newport Inc, Irvine CA), which converted the input light into linear, vertically polarized light. In the closed-loop system, each beam is then passed through a faraday rotator that rotated the light a fixed amount proportional to the rotation seen in the first harmonic as described in equations (7) and (8). A non-polarized beam splitter (Newport Inc., Irvine CA) was then used to combine the two beams into a single ray and a Faraday rotator (Deltronic Crystal Inc.,Dover, NJ) modulated the linear polarization vector of each laser by about $2^{\circ}$. The Faraday rotator was driven by a sinusoidal voltage source at 
a frequency of $1.09 \mathrm{kHz}$. An aperture was used to reduce the beam diameter below $1 \mathrm{~mm}$. This modulated signal was then propagated through a rectangular sample cell (Cole-Parmer INC., Vernon Hills, IL) constructed of plastic birefringent material with a path length of $1 \mathrm{~cm}$. The sample cell was filled with glucose-doped water of varying concentrations $(0-600 \mathrm{mg} / \mathrm{dl})$ and was mounted on a motorized stage (18143, Oriel Instruments, Stratford, CT). This stage was controlled by a PC via RS232 to move the sample up and down. A Visual Basic program was used to control the speed and distance of the translation of the motor stage. The birefringence of the sample cell varies with the location on the test cell. By moving the sample cell up and down on the translation stage, a scenario similar to the birefringence changes of the cornea due to motion artifact was created. From the test cell, the light passed through another Glan-Thompson polarizer with a transmission axis oriented perpendicular to that of the initial polarizer. One last aperture was placed after the polarizer to prevent any scattered light from being directed toward the detectors. The combined beam was separated by a beam splitter (Newport Inc., Irvine CA) and transmitted to two detectors (Thorlabs Inc., Newton, NJ). Each detector had a filter window, $635 \mathrm{~nm}$ and $532 \mathrm{~nm}$, respectively placed before them to record only one of the two wavelengths. The output signals were amplified by a broadband amplifier (Melles Griot Electro-optics, Boulder, CO). Two digital lock-in amplifiers, SR830 (DLIA, Stanford Research Systems Sunnyvale, CA) and SR850 
(Stanford Research Systems Sunnyvale, CA), were used to measure the relative amplitude of the signal present at the modulation frequency, allowing for precise measurement of the signal of interest at $1.09 \mathrm{kHz}$ while rejecting other frequency components. The two output voltages from the lock-in amplifiers were sent via GPIB interface to a PC program written in Labview 5.1 (National Instruments, Austin, TX).

A series of experiments was performed to assess the relationship of the two detected wavelengths in the open-loop system as the birefringence of the sample cell was changed. To do this, the test cell was filled with water and the intensities from each detector were measured as the test cell was moved up and down. The cell was limited in its range of motion in order to insure that the birefringence did not exceed the rotation capabilities of the compensating faraday rotators. The same procedure was performed for individual glucose samples between the concentration range of $0-600 \mathrm{mg} / \mathrm{dl}$ in $50 \mathrm{mg} / \mathrm{dl}$ increments. All sample solutions were introduced randomly into the system. For the glucose doped water experiments, all samples were prepared from a $1000 \mathrm{mg} / \mathrm{dl}$ stock glucose solution. This solution was prepared by dissolving $1.0 \mathrm{~g}$ of D-glucose (EM Science) into $100 \mathrm{ml}$ de-ionized water. Individual samples between the concentration ranges of $0-600 \mathrm{mg} / \mathrm{dl}$ in $50 \mathrm{mg} / \mathrm{dl}$ increments were prepared by diluting the stock solution. For each sample, the data collection was performed while randomly moving the sample cell to various locations. 


\subsection{Closed-loop Experiments}

\subsubsection{Experiment Setup}

A series of closed-loop experiments were performed in order to compensate for the effects of motion artifact on measuring the glucose concentration. The dual digital closed-loop controlled polarimeter is identical to the open-loop system with the exception of the addition of the feedback loops and two Faraday rotators (Deltronic Crystal Inc., Dover, NJ) as shown with dashed lines in Figure 15. The two output voltages from the detectors were sent via a GPIB interface to a PC as inputs into the digital control algorithm, which was written in Labview 5.1 (National Instruments. Austin, TX). Using this control algorithm program, the outputs from the D/A board of the two lock-in amplifiers were sent to two line drivers, which provided the necessary current to drive each Faraday compensator. The two linear drivers were employed because the maximum current output of each lock-in amplifier is only $10 \mathrm{~mA}$, which was insufficient to drive the Faraday compensation components. As mentioned, the function of the rotators was to compensate for rotation of the polarization vector due to both the glucose sample and the induced birefringence signal changes from motion artifact by forcing the amplitude of the first harmonic to zero. 


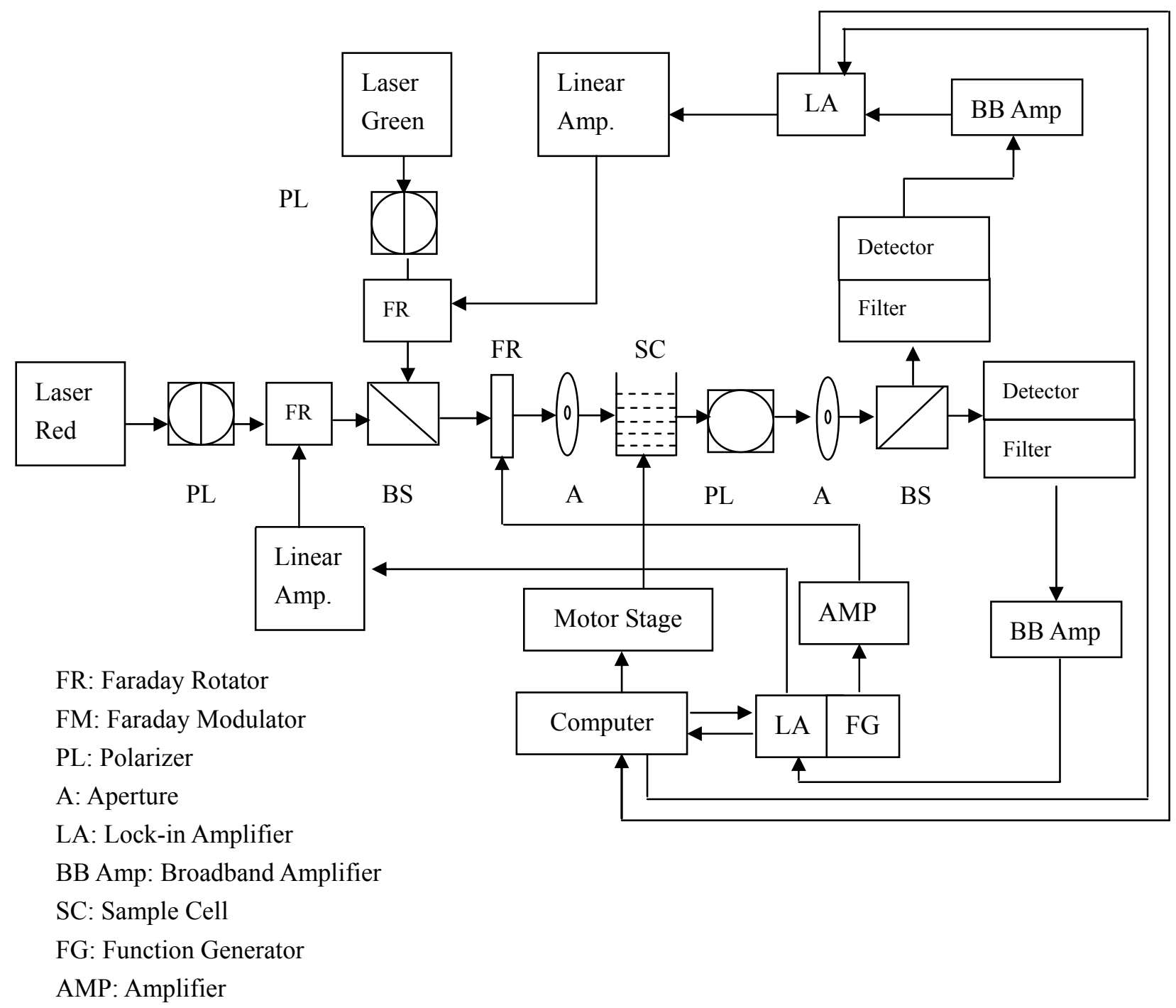

Figure 15 Block diagram of the system with the closed-loop system 


\subsubsection{Control System}

This research used a digital dual wavelength closed-loop feedback. The equation for the compensator of the control system for each wavelength is given by:

$$
y(n)=y(n-1)+k_{1} x(n)+k_{2}(x(n)-x(n-1))
$$

where, $y(n)$ is the output of the system at any given instant ' $n$ ', $x(n)$ is the amplitude of the detected $\omega_{m}$ sinusoid at any given instant ' $\mathrm{n}$ ', $\mathrm{x}(\mathrm{n}-1)$ is the amplitude of the detected $\omega_{m}$ sinusoid at given instant ' $\mathrm{n}-1$ '. The $k_{1}$ and $k_{2}$ coefficients were optimized in the experiments in order to improve the control speed. The output voltage of the control system was applied to compensate the signal due to glucose and induced birefringence for each wavelength.

As stated previously, the net polarization rotation at any point for each wavelength can be expressed as:

$$
\begin{aligned}
& \phi_{1}=\phi_{g_{1}}+\phi_{b_{1}}-\phi_{f_{1}} \\
& \phi_{2}=\phi_{g_{2}}+\phi_{b_{2}}-\phi_{f_{2}}
\end{aligned}
$$

where, $\phi_{g 1}$ and $\phi_{g 2}$ represent the rotation angle induced by the optical activity of glucose from each wavelength, $\phi_{f 1}$ and $\phi_{f 2}$ are the rotations caused by the Faraday rotators from each wavelength at any given time, $\phi_{b_{1}}$ and $\phi_{b_{2}}$ are the change caused by the birefringence from each wavelength at any given time. Although two Faraday rotators were used for the dual wavelength system as feedback components, the 
compensation action was simultaneous when the signal changed at each wavelength.

The lock-in amplifier was a major component of the feedback control system. In this research, SR830 and SR850 lock-in amplifiers were used in order to measure the amplitudes of signal at the reference frequency. The transfer function of lock-in amplifier is given by the following ${ }^{18}$ :

$$
\frac{Z}{Z-e^{-33 T s}}=\frac{Z}{Z-1}
$$

where Ts $=1 / F s$ with $F s=256 \mathrm{kHz}$ which is the sample rate of the lock-in amplifier.

According to the equation of the compensator of the closed-loop system, it can be described in z-domain as:

$Y(z)=Y(z) Z^{-1}+k_{1} X(z)+k_{2}\left(X(z)-X(z) Z^{-1}\right)$

where $k_{1}$ was set to be $200, k_{2}$ was set to be 50 according to the optimized control results.

Thus, the transfer function is:

$$
\frac{Y(z)}{X(z)}=\frac{\left(k_{1}+k_{2}\right) z-k_{2}}{z-1}=\frac{250 z-50}{z-1}
$$

The closed-loop transfer function $(\mathrm{w}(\mathrm{z}))$ of the system is

$$
W(z)=\frac{\frac{z}{z-1} \times \frac{250 z-50}{z-1}}{\frac{z}{z-1} \times \frac{250 z-50}{z-1}+1}=\frac{250 z^{2}-50 z}{251 z^{2}-52 z+1}
$$

According to the control theory, if all roots of the $251 z^{2}-52 z+1$ lie in the unit circle, the system is stable. It is easy to calculate the roots of $251 z^{2}-52 z+1$ are 0.185 
and 0.02 , respectively. Thus, the system is stable since the roots are located within the unit circle.

\subsubsection{Experimental Procedure}

A series of experiments was performed to test and evaluate the system. This section presents these procedures in detail. In order to assess the performance of the motion compensation algorithm, the data was compared with a previously developed single-wavelength close-looped system ${ }^{17,27}$ for two different cases: motionless and with motion.

\section{a. Closed-loop Motionless System}

To do this experiment, a rectangular optical glass sample cell (Starna Cells Inc., Atascadero, CA) was filled with water and mounted in a fixed holder. The same procedure was performed for individual glucose samples between the concentration range of $0-600 \mathrm{mg} / \mathrm{dl}$ in $50 \mathrm{mg} / \mathrm{dl}$ increments. All sample solutions were introduced randomly into the system. For the glucose doped water experiments, all samples were prepared from a $1000 \mathrm{mg} / \mathrm{dl}$ stock glucose solution. This solution was prepared by dissolving $1.0 \mathrm{~g}$ of D-glucose (EM Science) into $100 \mathrm{ml}$ de-ionized water. Individual samples between the concentration ranges of $0-600 \mathrm{mg} / \mathrm{dl}$ in $50 \mathrm{mg} / \mathrm{dl}$ increments were prepared by diluting the stock solution. For each sample, the data collection was 
performed with the sample cell in a fixed position. The digital dual wavelength closed-loop system was used for compensation and data collection.

The system was tested and evaluated for glucose solution in the motionless system in order to assess the performance of the motion compensation algorithm; the data were

compared with a previously developed single wavelength closed-looped system. ${ }^{18}$ The results are presented in the chapter IV.

\section{b. Closed-loop System with Motion}

A series of experiments were performed to test the digital dual wavelength closed-loop system for glucose solution in the sample cell (Cole-Parmer INC., Vernon Hills, IL) coupled with motion artifact.

The setup for this aim was almost the same as the motionless system except that the sample cell was mounted on a motorized stage (model 18143, Oriel Instruments, Stratford, CT). A PC via RS232 controlled this stage by moving the sample up and down. A Visual Basic program was used to control the speed and distance of the translation of the motor stage. The birefringence of the sample cell varied with the location. By moving the sample cell up and down on the translation stage, a scenario similar to the birefringence changes of the cornea due to motion artifact were created.

Similarly, the same procedure was performed for individual glucose samples between the concentration range of $0-600 \mathrm{mg} / \mathrm{dl}$ in $50 \mathrm{mg} / \mathrm{dl}$ increments. All sample 
solutions were introduced randomly into the system. For the glucose doped water experiments, all samples were prepared from a $1000 \mathrm{mg} / \mathrm{dl}$ stock glucose solution. For each sample, the data collection was performed while randomly moving the sample cell to various locations. The experiments were used to determine the relationship of the two detected wavelengths in the closed-loop system as glucose concentrations were varied during the presence of motion artifact. From the open-loop experiments it was shown that the change in glucose concentration did not appreciably affect the slope of the linear fit of the red vs. green light sources with birefringence, however, it did change the intercept of the fit. This is discussed in greater detail in the Results and Discussion chapter.

\section{c. Closed-loop System with Motion Artifact Using NZW Rabbit Eyes}

The digital dual wavelength, closed-loop system was tested by passing the light through the cornea of a moving eye in vitro since this is where glucose will ultimately need to be detected. The setup for this experiment was the same as before, except that rabbit eyes were used as the sample along with the static optical test cell (Cole-Parmer INC., Vernon Hills, IL) to change the glucose concentration. This experiment explored the possibility of applying the digital dual wavelength, closed-loop system in NZW rabbit eyes. The challenge was that the eye is a more complex birefringent medium than the sample cell 
and the path length of the eye also varies when it was moved up and down.

Five New Zealand White (NZW) rabbits' eyes were collected in Laboratory Animal Care of Texas A \&M University. The eyes were harvested immediately after the animal was euthanized. Each eye was kept in a sample holder with saline after rinsing the eye's surface to get rid of blood. All eyes were kept in a cooler with ice. When performing this experiment, three of six eyes were chosen because the other three became cloudy, which would cause large error due to scattering.

The experiments were performed with the moving eyes with individual glucose samples among the concentration ranges of $0-600 \mathrm{mg} / \mathrm{dl}$ in $50 \mathrm{mg} / \mathrm{dl}$ increments. The data from the water sample for each wavelength was used as a background signal. 


\section{CHAPTER IV}

\section{RESULTS AND DISCUSSION}

This chapter presents the results obtained during this research. The chapter is divided into sections which corresponds to the order presented in the Material and Methods chapter. The discussion part of each section is combined with the results of that section.

\subsection{Characterization of the Test Cell Birefringence}

A set of experiments was conducted on the test cell itself to determine its fast axis and to relate the birefringence of the test cell to previous work conducted on the rabbit cornea. ${ }^{21}$ The sample cell was placed on a rotating mount in the same location along the optical train with water solution in the cell. The sample cell was rotated from 0 to 180 degrees in 10 degree increments at five different locations on the sample cell and the intensity was recorded in Figure 16.

From the curves in Figure 16, one can see that as the test cell was rotated from 0 to 180 degrees at a given vertical location, the fast axis of the test cell varied from 10 to 30 degrees from horizontal as determined by the peak value on the plot (i.e. the value at which the fast axis is aligned with the polarizer). Thus, given the direction of the applied motion of the test cell was vertical and not along the fast or slow axis, there was 
a significant change in birefringence produced. In fact, the changes in birefringence were actually larger than those reported to occur in the rabbit cornea. ${ }^{21}$ Therefore, since the system can compensate for the larger birefringence changes of the moving test cell it is believed that it should be able to compensate for the lesser birefringence changes of the cornea.

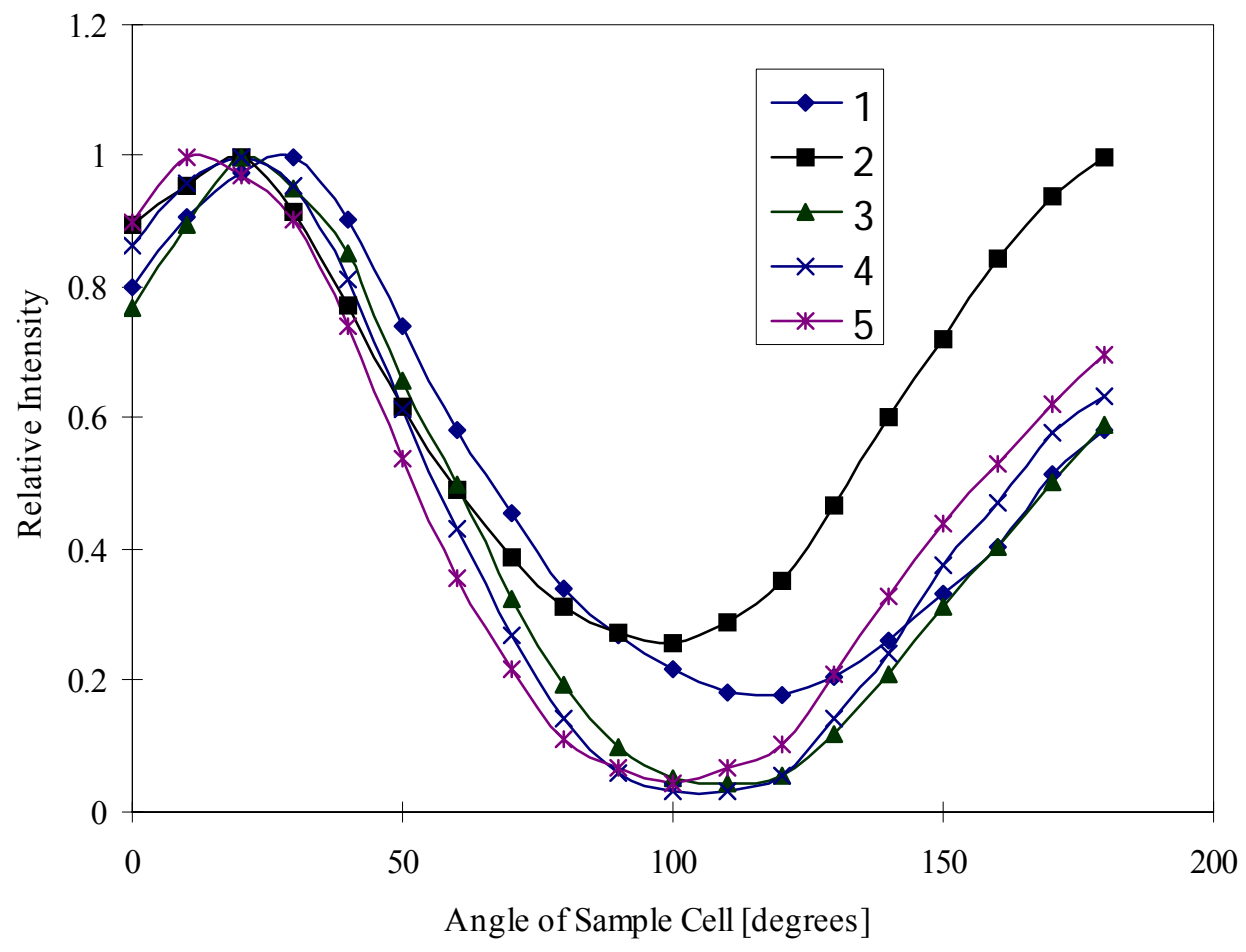

Figure 16 Intensity change of the detected signal as a function of the angle of rotation of the test cell recorded at five different locations on the test cell. Note that the maximum and hence fast axis appears between 10 and 30 degrees depending on the location of the beam on the test cell. 


\subsection{Open-loop Experiments}

The open loop system was used with varying concentrations to show the effects of both the birefringence and the glucose concentration changes on the detected voltage. A concentration range of $0-600 \mathrm{mg} / \mathrm{dl}$ in $50 \mathrm{mg} / \mathrm{dl}$ increments was used in this experiment. The system was calibrated such that the output and input polarizers were cross polarized when there was no glucose in the test cell while the beam was directed at some arbitrary location on the test cell. The presence of glucose in the test cell caused a rotation in the plane of polarized light and this rotation shows up in the first harmonic component of the output signal as shown in equations (7) and (8). Any deviation from this location or any addition of glucose would produce a different intensity and hence a different voltage in both detectors. For a given concentration of glucose a line was fit describing the linear relationship that exists between the red and green feedback voltages as the birefringence of the sample cell was changed through moving the translation stage up and down. The result is shown in Figure 17. The direction of the applied motion of the test cell is not particularly important as long as changes in birefringence occur in translation. From the figure, it can be observed that the slope of this fitted line remained relatively constant while the intercept varied with the glucose concentration present in the test cell. 


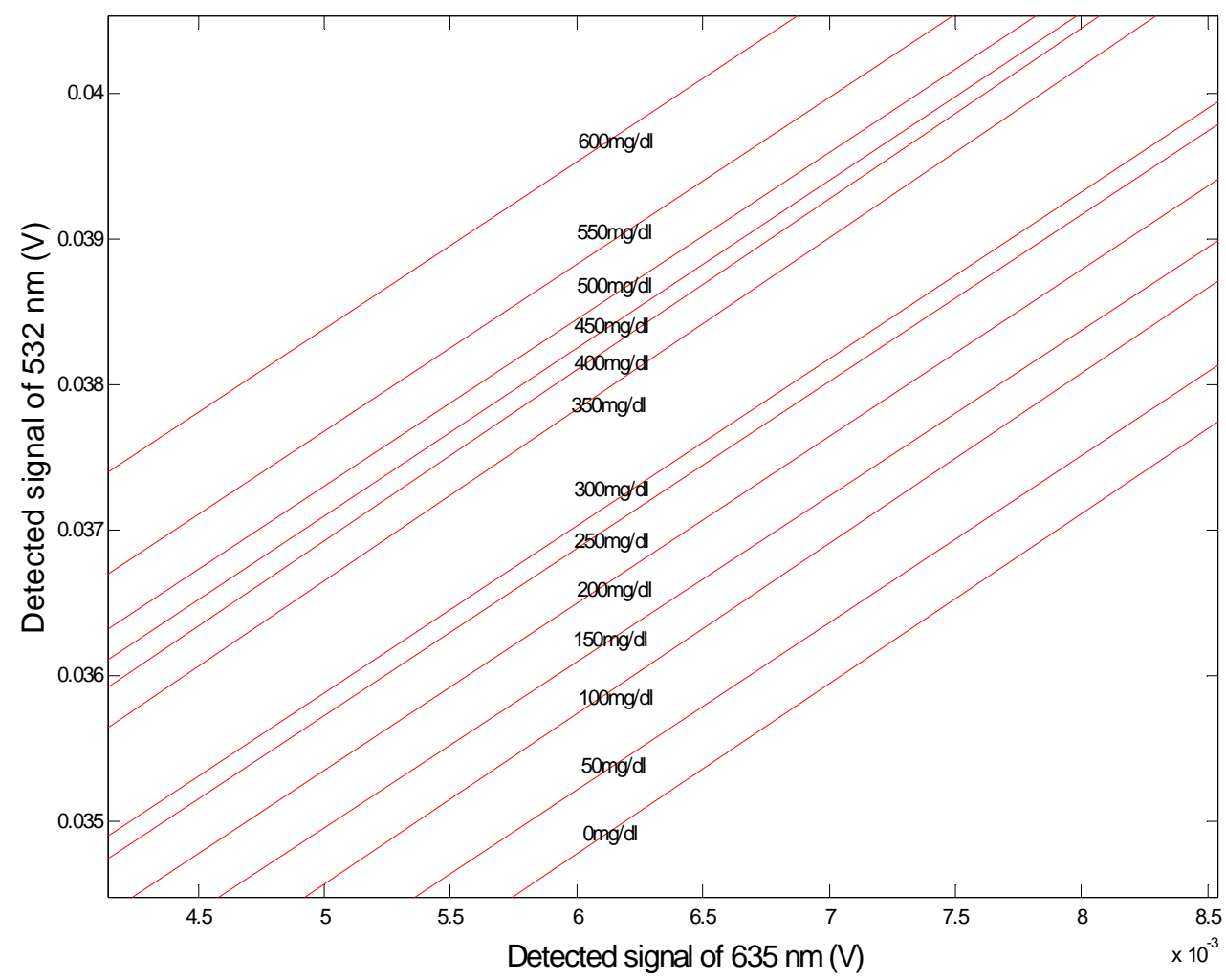

Figure 17 Regression relationships between the two detected signals from 0 to 600 $\mathrm{mg} / \mathrm{dl}$ in the presence of motion.

In fact, the mean of the slope across the thirteen concentrations was 1.158 and the standard deviation of the slope was 0.013 , as shown in Table 4 , justifying the assumption that changes in the slope are negligible. This assumption is necessary for the development of the calibration and prediction method used for the closed-loop system. Determining the effects of both birefringence and glucose concentration changes for the open loop system was performed in order to develop this algorithm, as well as provid a range of voltages that would need to be fed back into the Faraday compensators in order 
to force the fundamental frequency component of the output signal back to zero. However, the research has shown that the open loop system is not as stable as the closedloop system due to the open-loop nature of the system. The voltage changes in the closed-loop system are, however, linear and equidistant with concentration.

Table 4 Slope values of the fitted lines for the open-loop glucose measurements coupled with motion across the range of $0-600 \mathrm{mg} / \mathrm{dl}$.

\begin{tabular}{|c|c|c|c|}
\hline Concentration & Slope & Concentration & Slope \\
\hline $0 \mathrm{mg} / \mathrm{dl}$ & 1.17 & $350 \mathrm{mg} / \mathrm{dl}$ & 1.18 \\
\hline $50 \mathrm{mg} / \mathrm{dl}$ & 1.15 & $400 \mathrm{mg} / \mathrm{dl}$ & 1.18 \\
\hline $100 \mathrm{mg} / \mathrm{dl}$ & 1.17 & $450 \mathrm{mg} / \mathrm{dl}$ & 1.16 \\
\hline $150 \mathrm{mg} / \mathrm{dl}$ & 1.14 & $500 \mathrm{mg} / \mathrm{dl}$ & 1.15 \\
\hline $200 \mathrm{mg} / \mathrm{dl}$ & 1.15 & $550 \mathrm{mg} / \mathrm{dl}$ & 1.15 \\
\hline $600 \mathrm{mg} / \mathrm{dl}$ & 1.15 & $600 \mathrm{mg} / \mathrm{dl}$ & 1.15 \\
\hline $300 \mathrm{mg} / \mathrm{dl}$ & 1.15 & $\mathrm{STDEV}$ & 0.013 \\
\hline
\end{tabular}

\subsection{Closed-loop Experiments}

In order to assess the performance of the motion compensation algorithm, the data was compared with a previously developed single-wavelength close-looped system ${ }^{17,27}$ for two different cases: motionless and with motion. 


\subsubsection{Closed-loop in the Motionless System}

A concentration range of $0-600 \mathrm{mg} / \mathrm{dl}$ in $50 \mathrm{mg} / \mathrm{dl}$ increments was used in this experiment. The motionless system was calibrated and then the glucose concentrations were extracted through linear regression. The experiments were repeated twice and the results from both experiments are shown in Figure 18.

In each experiment, two data sets were recorded for the two wavelengths, $635 \mathrm{~nm}$ and $523 \mathrm{~nm}$, for varying glucose samples $(0-600 \mathrm{mg} / \mathrm{dl})$, respectively. The signal from the test cell filled with water $(0 \mathrm{mg} / \mathrm{dl})$ was used as a background signal and was subtracted from all other signal values. Least-squares linear regression (LSLR) was then used to calibrate the model. The predicted versus actual glucose concentrations were plotted for the single wavelength system for both the red and green light source as shown in Figures 18(a) and 18(b) respectively. The dual wavelength closed-loop system for a motionless sample was also plotted for comparison to the two single wavelength methods in Figure 18(c). One can see that a high degree of linearity exists for all three cases since each correlation coefficient exceeds 0.999 and the standard error of prediction (SEP) is less than $10 \mathrm{mg} / \mathrm{dl}$. This corresponds to a system accuracy of less than 0.4 millidegrees,

which is comparable to results shown previously by Cameron et al. ${ }^{18,26}$ In order to compare the results, the correlation coefficient and standard deviation for each case is listed in Table 5. 


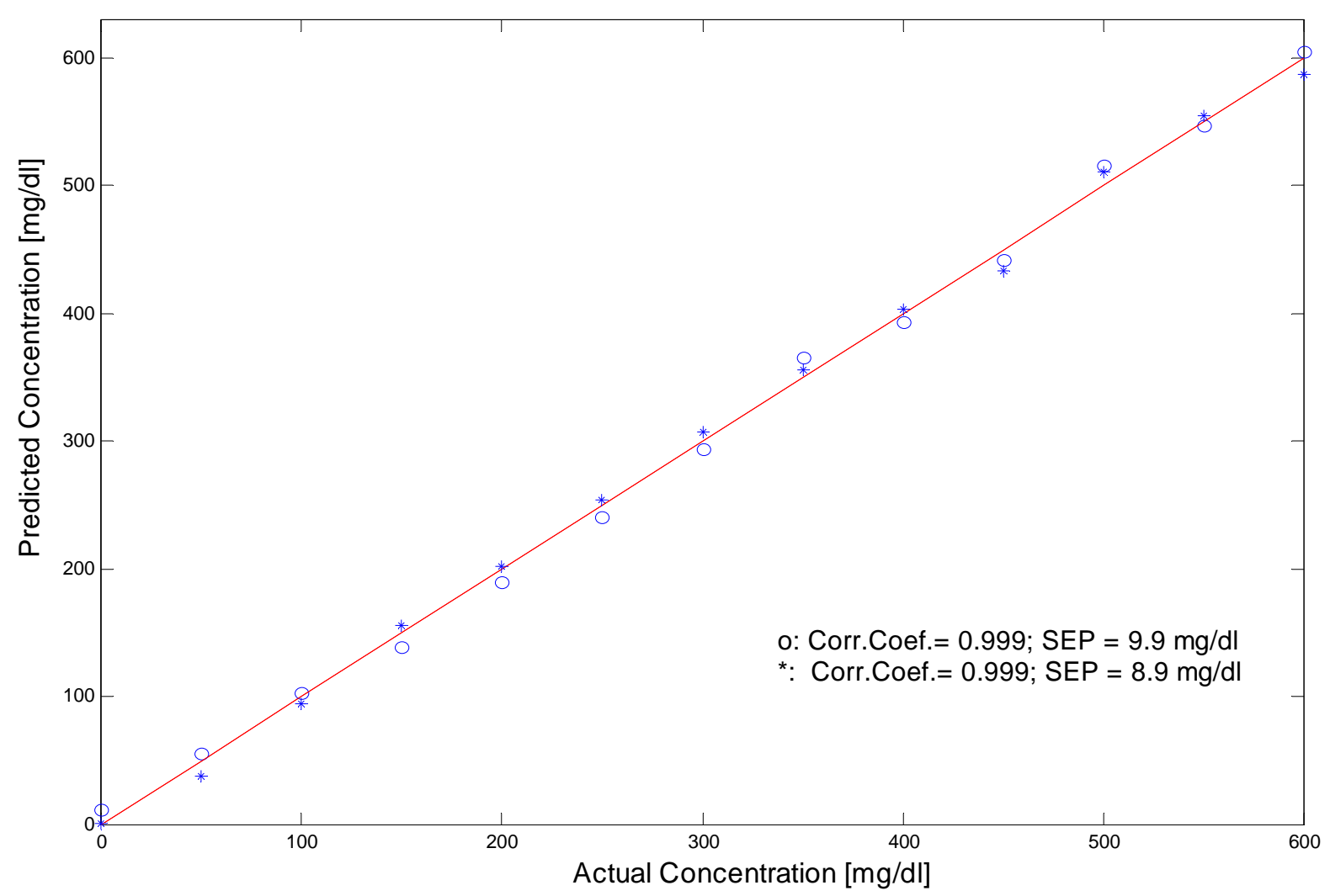

(a)

Figure 18 Actual versus predicted glucose concentration for glucose-doped water for sample experiments without motion. (a) includes two separate experiments run at 635 nm using a single closed-loop system (o: experiment \#1, *: experiment \#2) (b) two separate experiments run at $523 \mathrm{~nm}$ using a single closed-loop system (o: experiment \#1, *: experiment \#2) (c) two experiments run using the dual wavelength (635 nm and 523 $\mathrm{nm}$ ) closed loop system (o: experiment \#1, *: experiment \#2). 


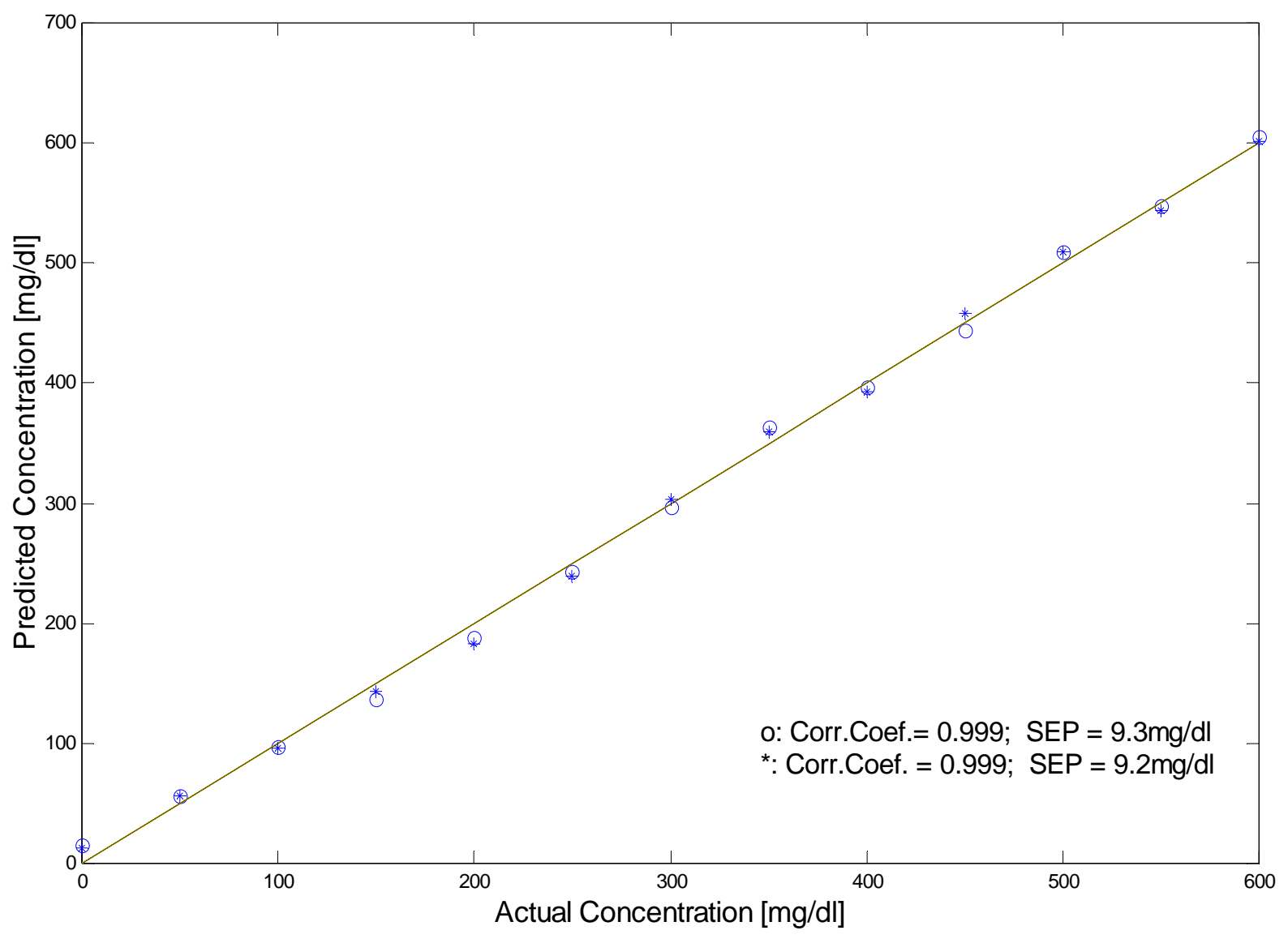

(b)

Figure 18 Continued 


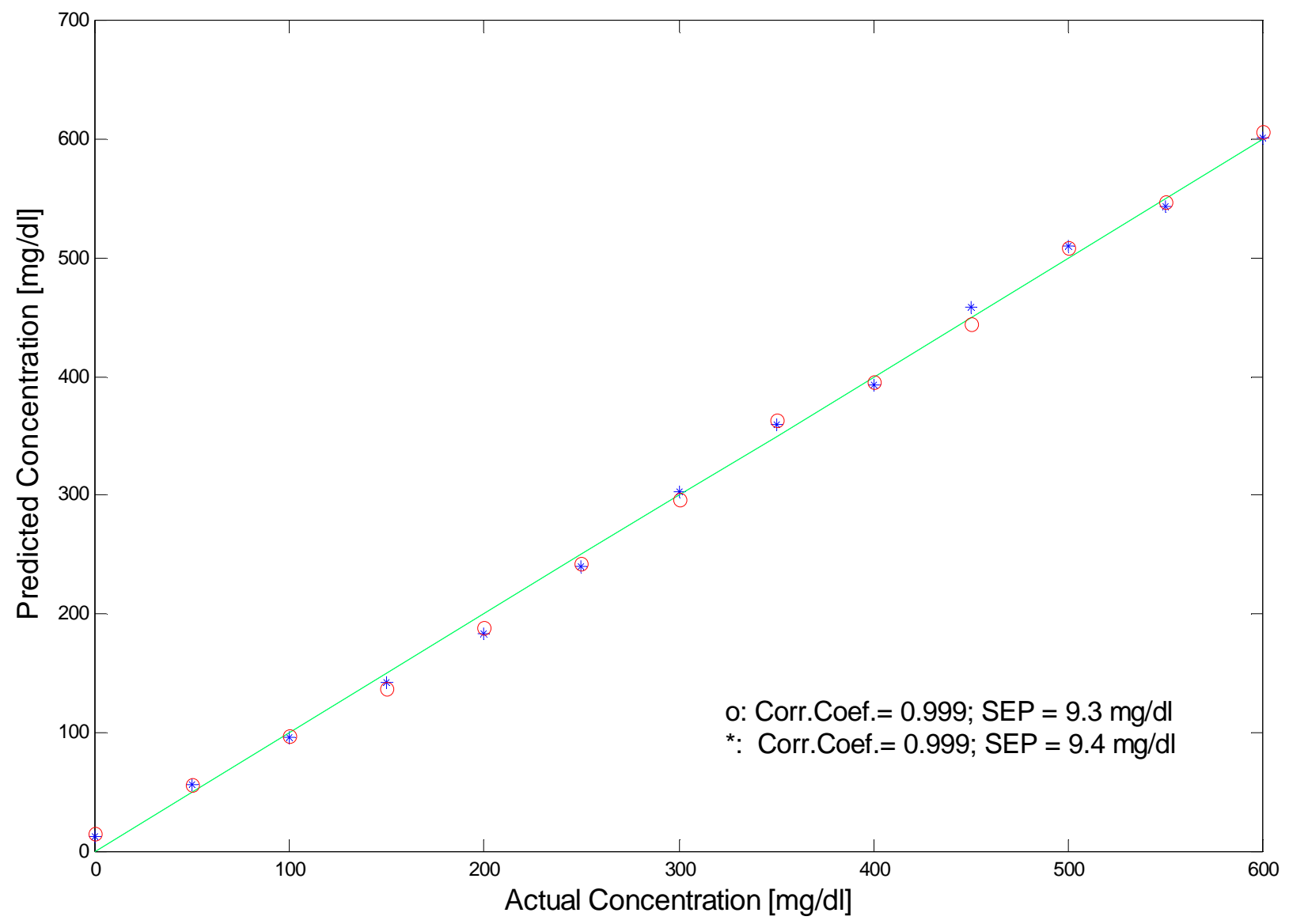

(c)

Figure 18 Continued 
Table 5 Summary of correction coefficients and standard deviation for the closed-loop in the motionless system

\begin{tabular}{|c|c|c|c|c|}
\hline \multicolumn{2}{|c|}{ Experiment \# } & $\begin{array}{l}\text { Single } \\
\text { Wavelength } \\
(635 \mathrm{~nm})\end{array}$ & $\begin{array}{l}\text { Single } \\
\text { Wavelength } \\
(523 \mathrm{~nm})\end{array}$ & $\begin{array}{l}\text { Dual Wavelength } \\
(635 \mathrm{~nm}, 523 \mathrm{~nm})\end{array}$ \\
\hline \multirow[b]{2}{*}{1} & $\begin{array}{l}\text { Correlation } \\
\text { Coefficient }\end{array}$ & 0.999 & 0.999 & 0.999 \\
\hline & $\begin{array}{l}\text { Standard } \\
\text { Deviation } \\
(\mathrm{mg} / \mathrm{dl}) \\
\end{array}$ & 9.9 & 9.3 & 9.3 \\
\hline \multirow[b]{2}{*}{2} & $\begin{array}{l}\text { Correlation } \\
\text { Coefficient }\end{array}$ & 0.999 & 0.999 & 0.999 \\
\hline & $\begin{array}{l}\text { Standard } \\
\text { Deviation } \\
(\mathrm{mg} / \mathrm{dl})\end{array}$ & 8.9 & 9.2 & 9.4 \\
\hline
\end{tabular}

\subsubsection{Closed-loop System in the Motion System}

The same procedure was conducted again while introducing motion into the system. The system with motion was calibrated and then the glucose concentrations were extracted through linear regression. This was done for glucose concentrations from $0-600 \mathrm{mg} / \mathrm{dl}$ in increments of $50 \mathrm{mg} / \mathrm{dl}$. For the closed-loop experiments an output from each of the detectors at the two wavelengths was taken.

In order to compare the results of the single wavelength closed-loop and dual wavelength closed-loop system, actual versus predicted glucose concentration for glucose-doped water coupled with a varying birefringence signal using the single 
wavelength closed-loop system for each wavelength $(635 \mathrm{~nm}$ wavelength, $523 \mathrm{~nm}$ wavelength) is plotted in Figure 19. As shown in Figure 19, the predicted glucose concentrations cannot be predicted using a single closed-loop system, since the signal could not distinguish the changes due to glucose from the changes due to varying birefringence in the sample. Thus, the single wavelength model breaks down completely in the presence of birefringence changes due to motion.

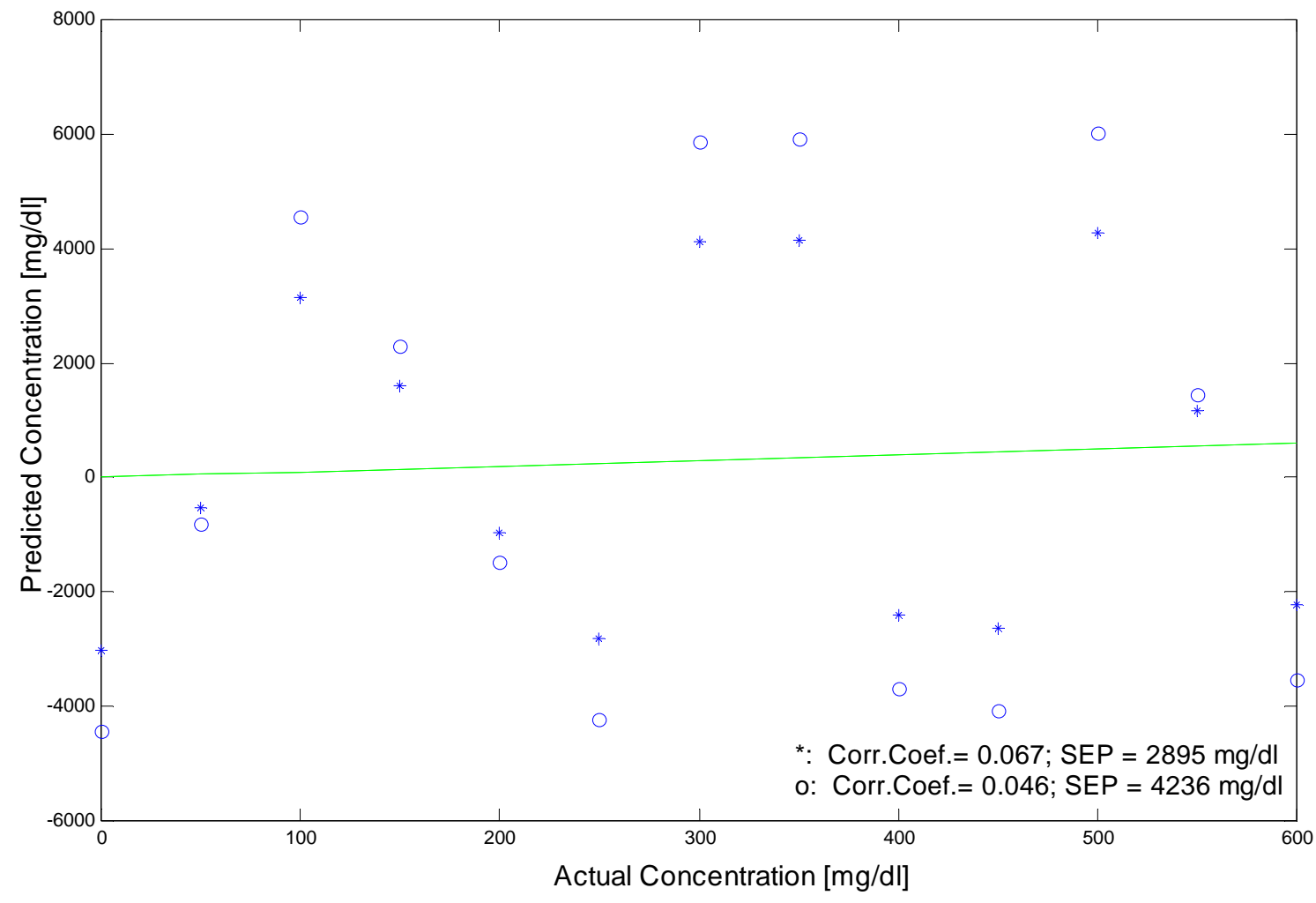

Figure 19 Actual versus predicted glucose concentration for glucose-doped water coupled with varying birefringence signal using the single wavelength closed-loop system for each wavelength (*: $635 \mathrm{~nm}$ wavelength, o: $523 \mathrm{~nm}$ wavelength). Note that using either single wavelength system does not allow for any reasonable predictive capability with motion artifact. 
Using the slope measured for water in the closed-loop system with the two voltage values, the y-intercept can be calculated. From this data a linear fit was applied to describe the glucose concentration measured as a function of the y-intercept of the red and green light relationship. Three measurements were then taken while varying both the glucose concentration and the motion of the sample cell to verify the validity of the model. Individual predicted concentrations and the mean predicted concentration results are shown in Figure 20 and Figure 21, respectively.

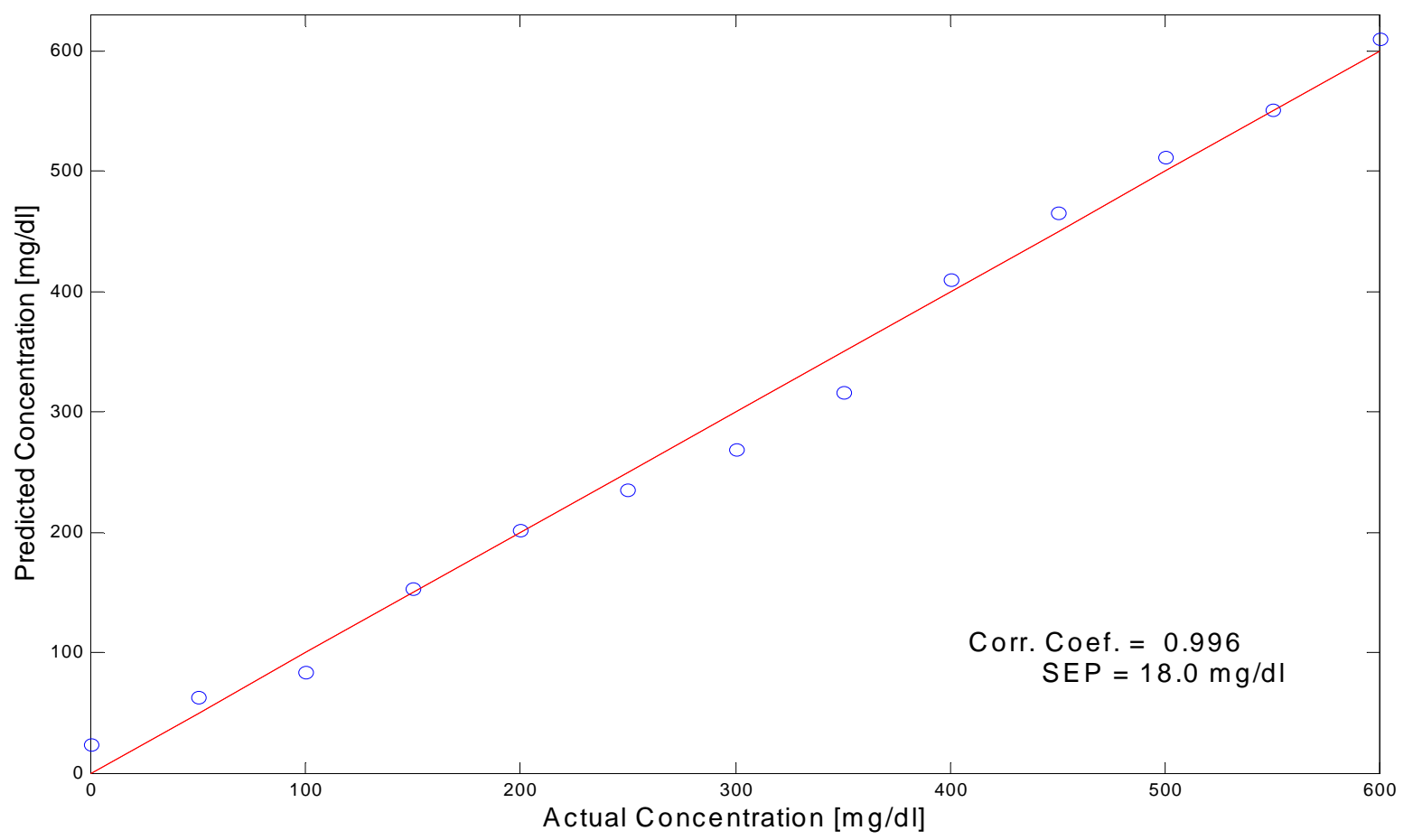

(a)

Figure 20 Actual versus predicted glucose concentration for glucose-doped water coupled with varying birefringence signal using the dual wavelength closed-loop system. (a) experiment \#1 (b) experiment \#2 (c) experiment \#3 


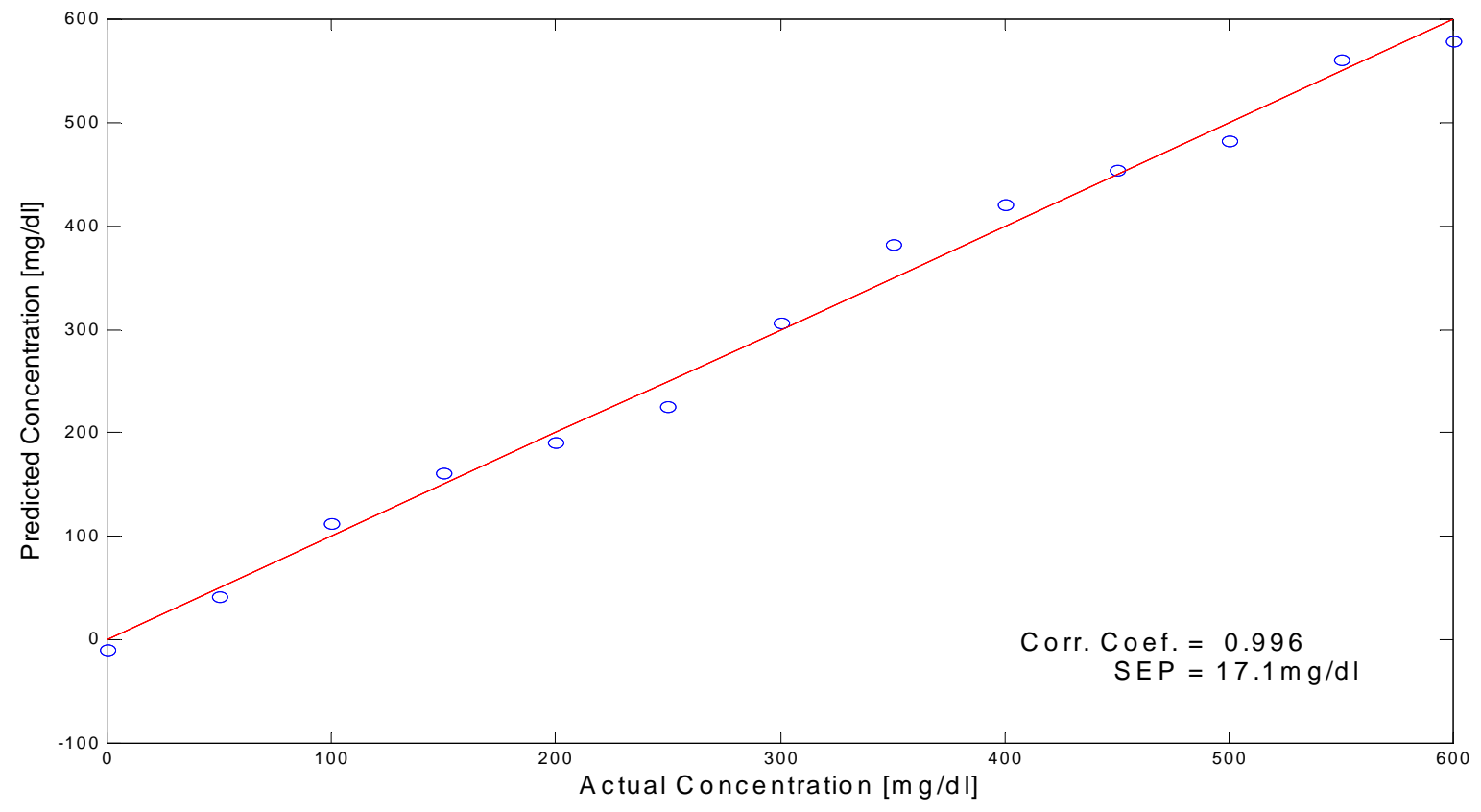

(b)

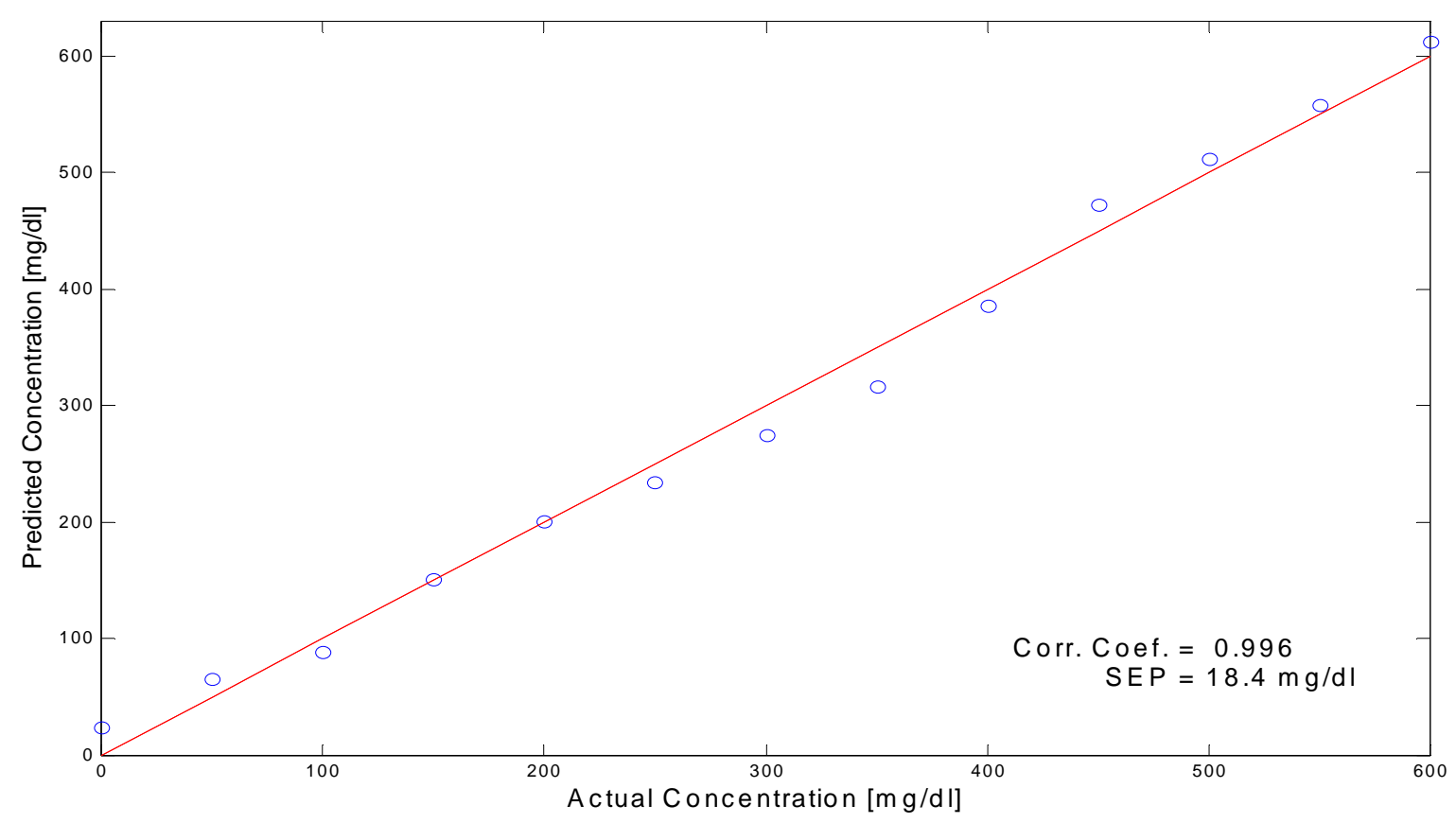

(c)

Figure 20 Continued 
The Deviation of the Predicted Concentration

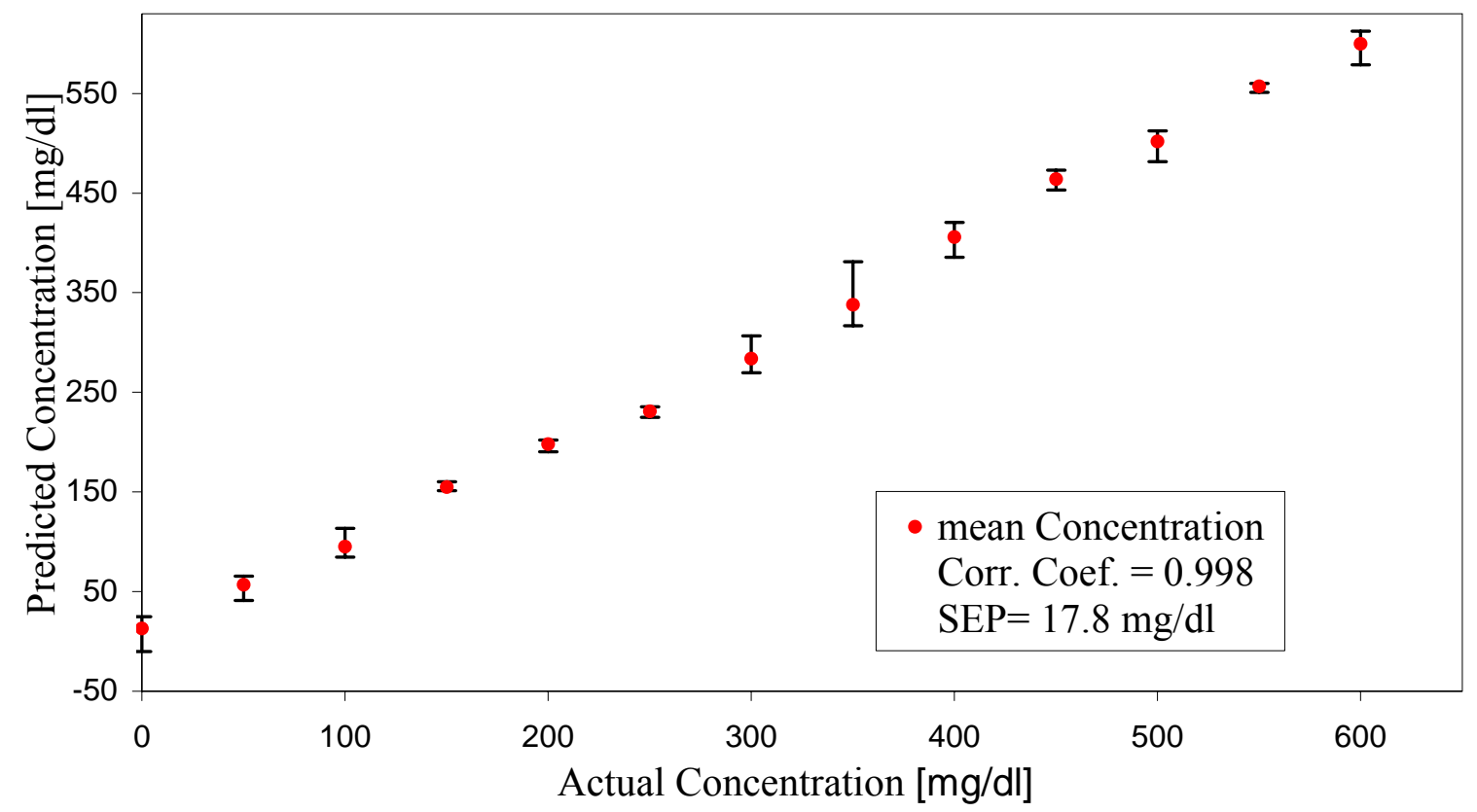

Figure 21 Mean predicted concentrations with error bars for three repetitions using the dual wavelength (635 $\mathrm{nm}$ and $523 \mathrm{~nm}$ ) closed-loop system in the presence of motion artifact. Note that by using two wavelengths that the system is now capable of predicting glucose in the presence of motion.

The mean predicted calibration results showed a high degree of linearity with a correlation coefficient of 0.998 and a standard error of prediction of $17.8 \mathrm{mg} / \mathrm{dl}$ as depicted in Figure 20. No outliers were present in any of the data sets. The SEP was greater than the motionless system and this could be attributed, in part, to the algorithm and method of calibration. The motionless system was calibrated while fixing the birefringent test cell at a specific location. Therefore, the calibration corresponded 
specifically to measurements made at that exact location. The linear fit from that calibration describes only the effects of glucose changes on the voltage fed back to the compensator. However, when motion is induced in the system, we essentially move from the realm of one regression approximation describing the system to two: an approximation fitting the red vs. green light in the presence of motion, and an approximation fitting the intercept calculated vs. the glucose concentration. As in any linear regression fit, there is an associated error with that fit. Since the birefringence changes of the test cell were compensated for, it is believed that the smaller changes that occur in the eye could also be compensated.

\subsubsection{Closed-loop with Motion Artifact in NZW Rabbit Eyes}

The same procedure was conducted while introducing motion into the NZW rabbits' eyes. The digital dual wavelength, closed-loop system was used by passing the light through the cornea of a moving eye in vitro since this is where glucose will ultimately be detected. The motion system was calibrated and then the glucose concentrations were extracted through linear regression as in the previous procedure. For the closed-loop experiments an output from each of the detectors at the two wavelengths was taken.

From this data a linear fit was applied to describe the glucose concentration measured as a function of the y-intercept of the red and green light relationship. Three 
eyes were used to perform the experiment while varying both the glucose concentration and the motion of each eye to verify the validity of the model. Individual predicted concentrations and the mean predicted concentrations result are shown in Figure 22 and Figure 23, respectively.

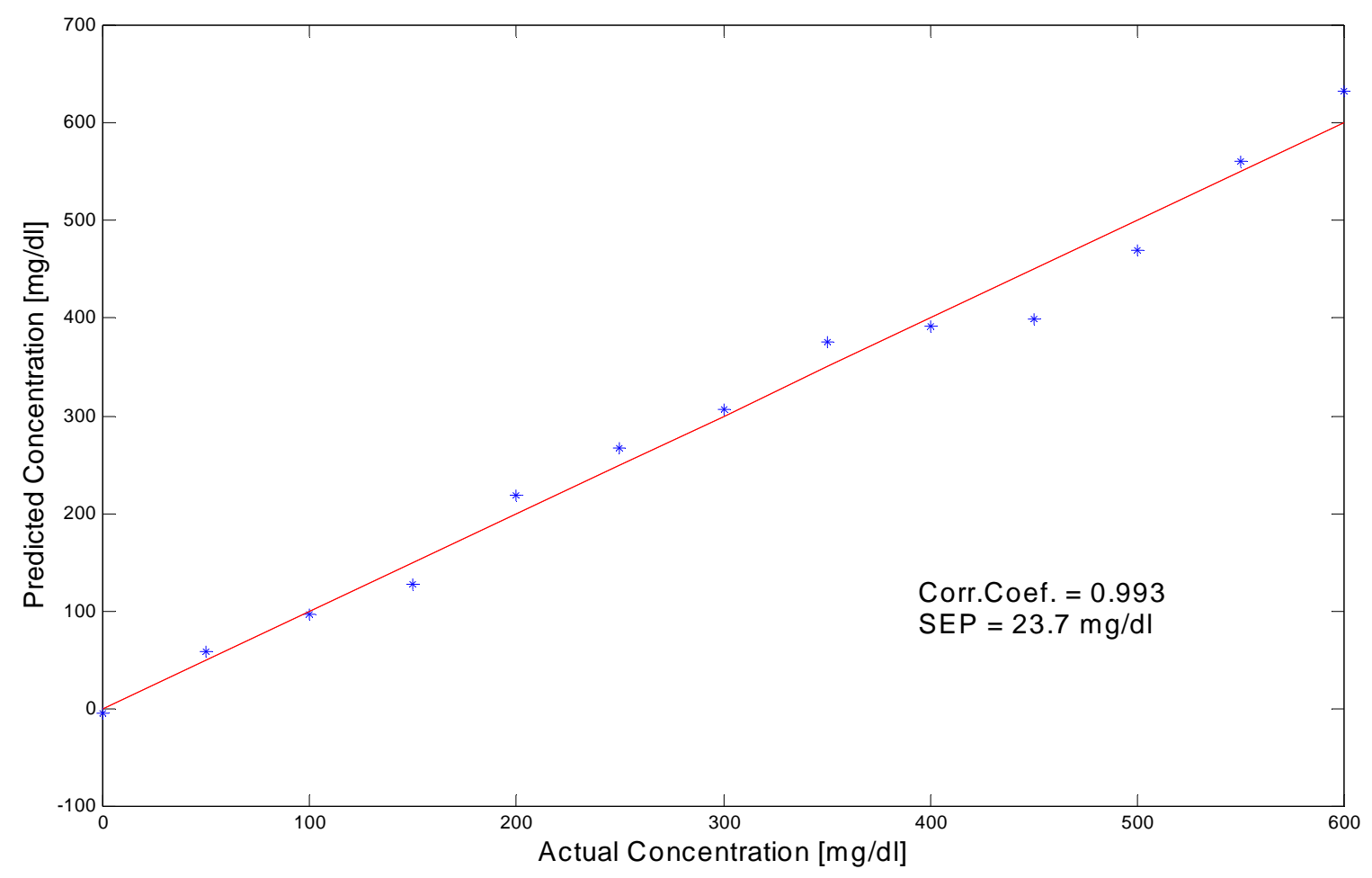

(a)

Figure 22 Actual versus predicted glucose concentration for glucose-doped water coupled with motion artifact in rabbit eyes using the dual wavelength closed-loop system. (a) experiment \#1 (b) experiment \#2 (c) experiment \#3 


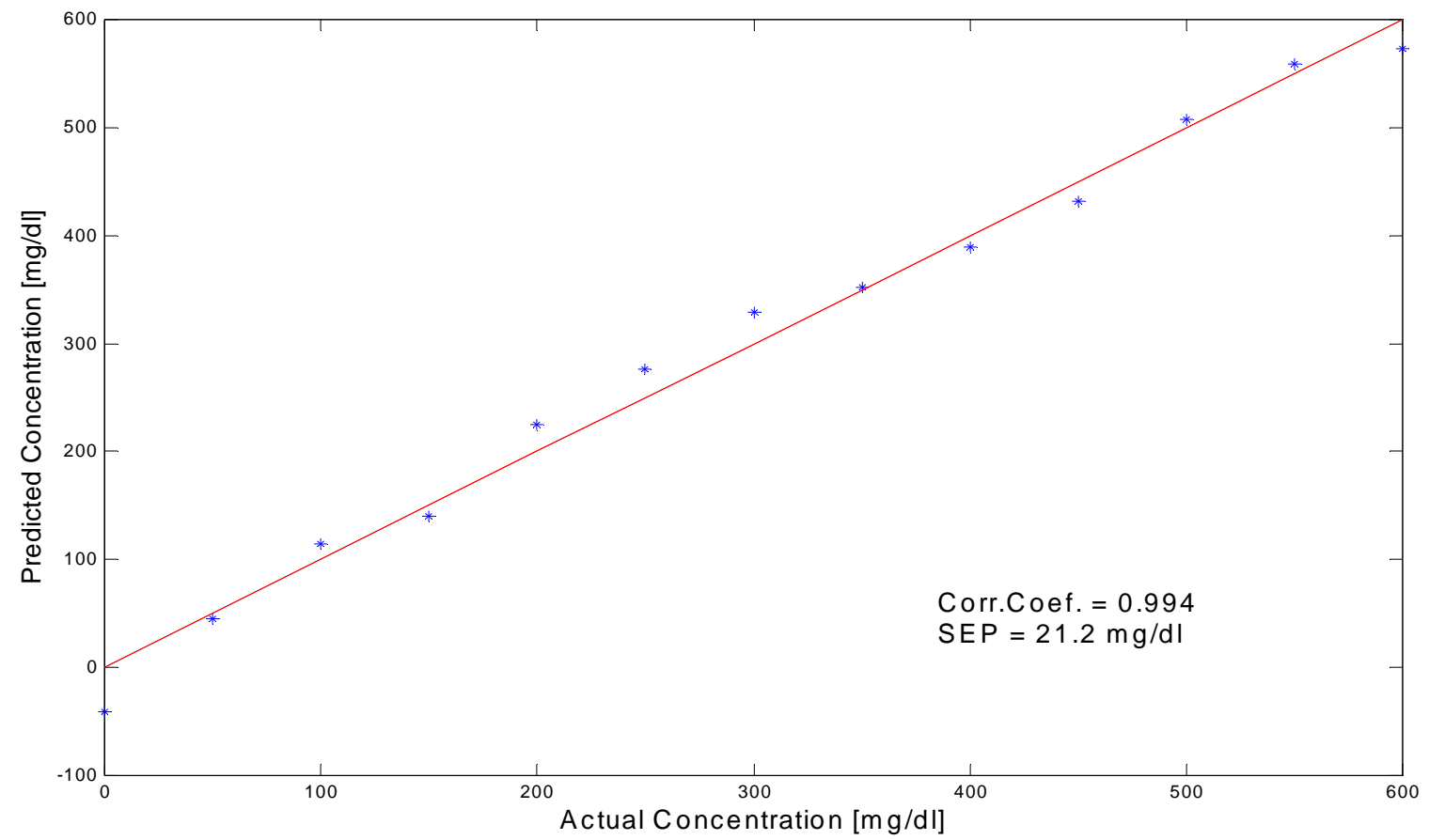

(b)

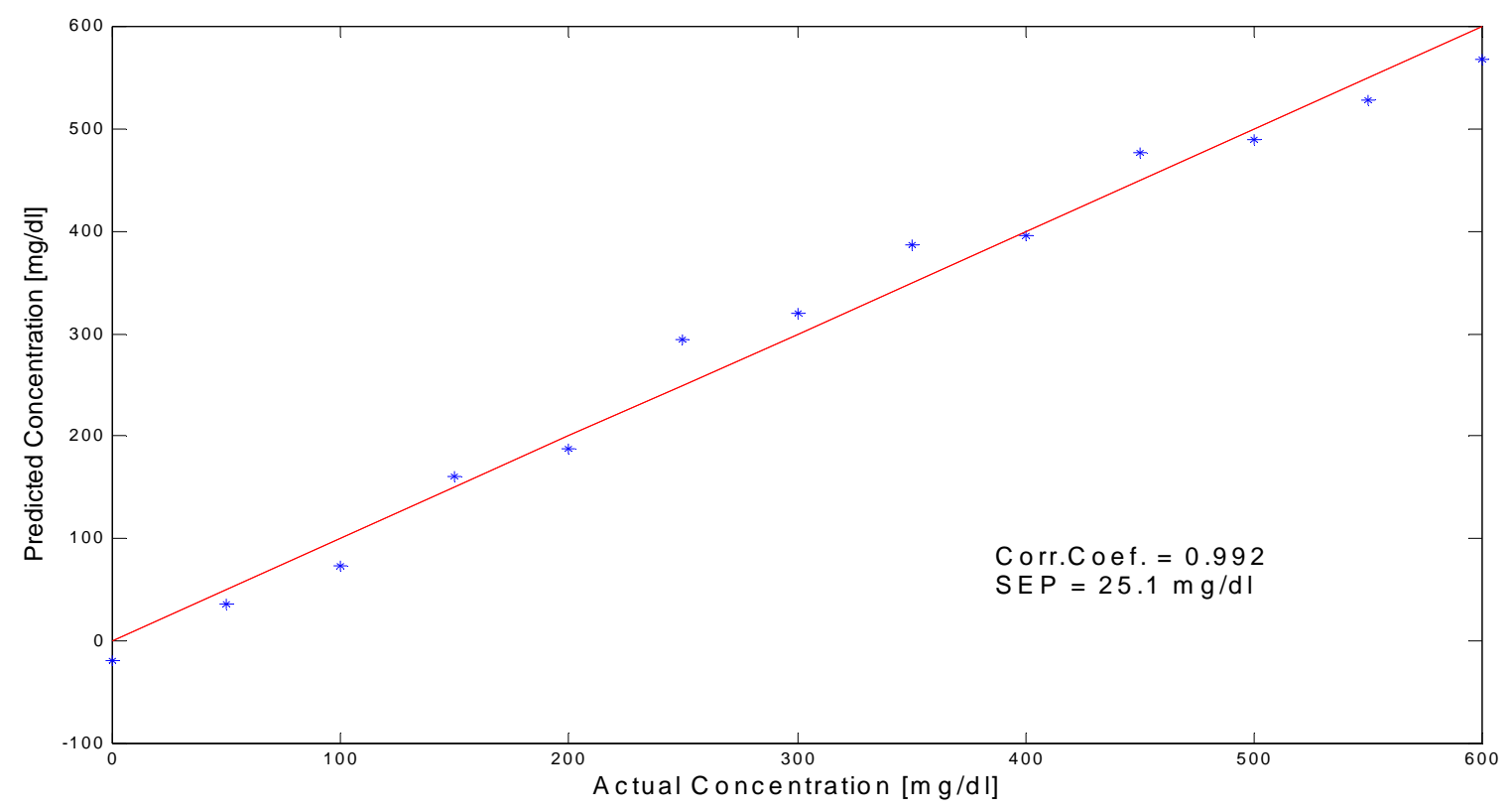

(c)

Figure 22 Continued 
The Deviation of Predicted Concentration

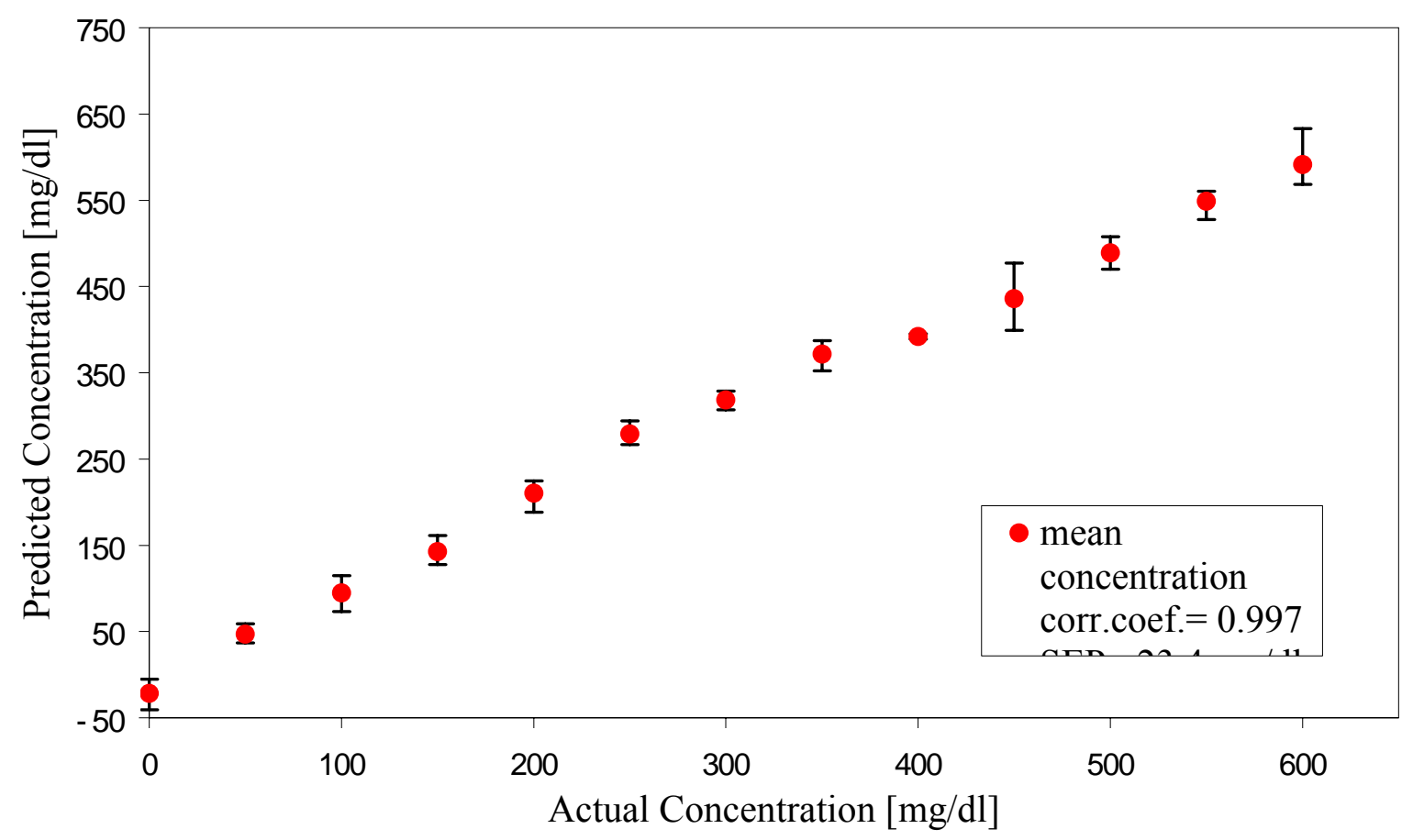

Figure 23 Mean predicted concentrations with error bars for three eyes using the dual wavelength (635 $\mathrm{nm}$ and $523 \mathrm{~nm}$ ) closed-loop system in the presence of motion artifact.

The mean predicted calibration result showed a high degree of linearity with a correlation coefficient of 0.997 and a standard error of prediction of $23.4 \mathrm{mg} / \mathrm{dl}$ as depicted in Figure 23. No outliers were present in any of the data sets. The SEP is greater than the sample cell system and this could be attributed, in part, to the fact that the eye is a more complex birefringent medium than the sample cell and the path length of the eye also varies when it was moved up and down. It needs to be noted that the three eyes are not completely identical and there are some minor differences in physiology, 
such as the different size of the cornea in width and height. From Figure 22, it can be seen that the SEP of each experiment is slightly different. This could be attributed, in part, to the above reason. 


\section{CHAPTER V \\ CONCLUSIONS AND FUTURE WORK}

With diabetes on the rise, a reliable non-invasive glucose sensor has yet to be developed to meet the need for glucose regulation. While polarimetric approaches have achieved very promising results in vitro, no one has yet to develop a device using such an approach that could be used in vivo, in part, because of the noise (i.e. birefringence) induced through motion artifact of the cornea.

This thesis presents the next step toward the development of a noninvasive glucose sensor, which may eventually be capable of detecting glucose levels through the aqueous humor of the eye by compensating for birefringence changes due to motion artifact. It was successfully shown that the glucose concentration could be measured in vitro when motion artifact is present in a birefringent sample cell as well as in rabbit eyes through the use of a dual-wavelength closed-loop system, something that was not possible with previous single-wavelength methods developed. Although the results of these experiments are not as accurate as the closed-loop motionless system, the dual wavelength closed-loop provided a promising method to minimize the effect of motion induced cornea birefringence artifact.

The future research will focus on two aspects. One is to improve the accuracy of the 
algorithm of the dual wavelength closed-loop system. Another aspect focuses on the motion induced corneal birefringence artifact in vivo. The current system can only generate a simple motion induced corneal birefringence artifact due to limitations of current instruments, however, the motion artifact induced in vivo is due to respiratory motion and, to a limited extent, the cardiac cycle. ${ }^{21}$ Therefore, this motion artifact needs to be further studied and the dual wavelength closed-loop system eventually needs to be developed to compensate for the motion artifact in vivo. 


\section{REFERENCES}

1. National Institute of Diabetes and Kidney Diseases, "Total prevalence of Diabetes in the United States," NIH Report 04-3892, (2004), http://diabetes.niddk.nih.gov/dm/pubs/statistics/index.htm, accessed 05/20/2003.

2. National Institute of Diabetes and Kidney Diseases, "Prevalence of Diabetes," NIH Report 02-3892, (2002), http://www.niddk.nih.gov/health/diabetes/pubs/dmstats/dmstats.htm, accessed 06/27/2003.

3. R. S. Cotran, V. Kunmar, and S. L. Robbins, Robbins Pathologic Basis of Disease, 4th.ed., Saunders, Philadelphia, PA (1989).

4. K. C. Hanssen, "Diabetic control and microvascular complications: The near-normoglycaemic experience,” Diabetologia. 29, 677-784 (1986).

5. National Institute of Diabetes and Digestive and Kidney Diseases "The diabetes control and complications," trial (June 1993).

6. Glucowatch G2, "Important news for people with Diabetes," http://www.glucowatch.com/us/consumer/frame_set.asp?splash=headlinepi2, accessed 05/22/04.

7. D. C. Klonoff, "Noninvasive blood glucose monitoring," Diabetes Care 20 (3),433-437 (1997).

8. R. J. McNichols and G. L. Coté, "Optical glucose sensing in biological fluids: an Overview," J.Biomed. Opt, 5(1) 5-16 (2000).

9. J. Liu, M. Bagherzadeh, C. K. Hitzenberger, M. Pircher, R. Zawadzki, and A. F. Fercher, "Glucose dispersion measurement using white-light LCI," SPIE Proc. 4956, 348-351 (2003).

10. C. A. Browne and F. W. Zerban, Physical and Chemical Methods of Sugar Analysis, 3rd ed., Wiley, New York (1941).

11. J. McMurry, Organic Chemistry," $3^{\text {rd }}$ ed., Brooks/Cole Publishing Company, 
Pacific Grove, California (1992).

12. B. Rabinovitch, W. F. March, and R. L. Adams, "Noninvasive glucose monitoring of the aqueous humor of the eye. Part I. Measurement of very small optical rotations," Diabetes Care 5, 254-258 (1982).

13. W. F. March, B. Rabinovitch, and R. L. Adams, "Noninvasive glucose monitoring of the aqueous humor of the eye. Part II. Animal studies and the scleral lens," Diabetes Care 5, 259-265 (1982).

14. S. Pohjola, "The glucose content of aqueous humor in man," ActaOphthalmol. 88, $11-80$ (1966).

15. G. L. Coté, M. D. Fox, and R. B. Northrop, "Noninvasive optical polarimetric glucose sensing using a true phase technique," IEEE Trans. Biomed. Eng. 39(7), $752-756$ (1992).

16. M. J. Goetz, "Microdegree polarimetry for glucose detection," MS thesis, University of Connecticut, Storrs, CT (1992).

17. T. W. King, G. L. Coté, R. McNichols and M. J. Gotez, "Multispectral polarimetric glucose detection using a single Pockels cell,” Opt. Eng. 33(8), 2746-2753 (1994).

18. B. D. Cameron and G. L. Coté, "Noninvasive glucose sensing utilizing a digital closed-loop polarimetric approach," IEEE Trans. Biomed. Eng. 44, 1221-1227 (1997).

19. B. D. Cameron, H. W. Gorde, B. Satheesan, and G. L. Coté, "The use of polarized laser light through the eye for noninvasive glucose monitoring," Diabetes Technology \& Therapeutics 1, 135-143 (1999).

20. B. D. Cameron, J. S. Baba, and G. L. Coté, "Measurements of the glucose transport time-delay between blood and aqueous humor of the eye for the eventual development of a noninvasive glucose sensor," Diabetes Technol Ther. 3(2), 201-207 (2001).

21. J. S. Baba, B. D. Cameron, S. Theru, and G. L. Coté, "Effect of temperature, pH, and corneal birefringence on polarimetric glucose monitoring in the eye," J.Biomed. Opt. 7, 321-328 (2002). 
22. C. Chou, C. Y. Han, W. C. Kuo, Y.C. Huang, C. M. Feng, and J. C. Shyu, "Noninvasive glucose monitoring in vivo with an optical heterodyne polarimeter," Appl. Opt. 37, 3553-3557 (1998).

23. C. Chou, Y. C. Huang, C. M. Feng, M. Chang, “Amplitude sensitive optical heterodyne and phase lock-in technique on small optical rotation angle detection of chiral liquid," J. Appl. Phys. 36, 356-359 (1997).

24. S. Bockle, L. Rovati, and R. R. Ansari, "Polarimetric glucose sensing using the Brewster Reflection off the eye lens II: Theoretical analysis," Abstract 4624-24.

25. S. Bockle, L. Rovati, and R. R. Ansari, "Polarimetric glucose sensing using the Brewster Reflection off the eye lens I: Preliminary experimental results," Abstract 4623-24.

26. B. D. Cameron, "The application of polarized light to biomedical diagnostics and monitoring," Ph.D Dissertation, Texas A\&M University, College Station, TX (2000).

27. H. Anumula, A. Nezhuvingal, Y. Li, and B. D. Cameron, "Development of a noninvasive corneal birefringence compensated glucose sensing polarimeter," Proc. SPIE 4958, 303-312 (2003).

28. J. S. Baba and G. L. Coté, "Dual-detection polarimetry for compensation of motion artifact in a glucose sensing system," Proc. SPIE 4624, 76-80 (2002).

29. Hyperphysics, "Linear polarization", http://hyperphysics.phy-astr.gsu.edu/hbase/phyopt/polclas.html\#c4, accessed 08/20/2004.

30. E. L. Eliel and S.H. Wilen, Stereochemistry of Organic Compounds, John Wiley \& Sons Company, New York (1994).

31. E. Hecht, Optics, 2nd ed., Addison-Wesley Publishing Company, Menlo park, CA (1990).

32. J. S. Baba, "The use of polarized light for biomedical applications," Ph.D Dissertation, Texas A\&M University, College Station, TX ( 2003). 
33. Discovery, "Anatomy of the eye," http://www.discoveryfund.org/anatomyoftheeye.html, accessed 08/22/2004.

34. J. H. Green and P. H. Silver, An Introduction to Human Anatomy, Oxford Medical Publications, New York (1981).

35. American Health Assistance Foundation, "Flow of aqueous humor," http://www.ahaf.org/glaucoma/about/AqueousHumor.htm, accessed 08/23/2004.

36. J.W. Jaronski, H. T. Kasprzak and E. B. Jakowska-Kuchta, "Numerical and experiment study of the corneal anisotropy," Proc. SPIE 2628, 263-268 (1996). 
APPENDIX A

DUAL WAVELENGTH OPEN-LOOP SYSTEM LABVIEW PROGRAM

Main Program

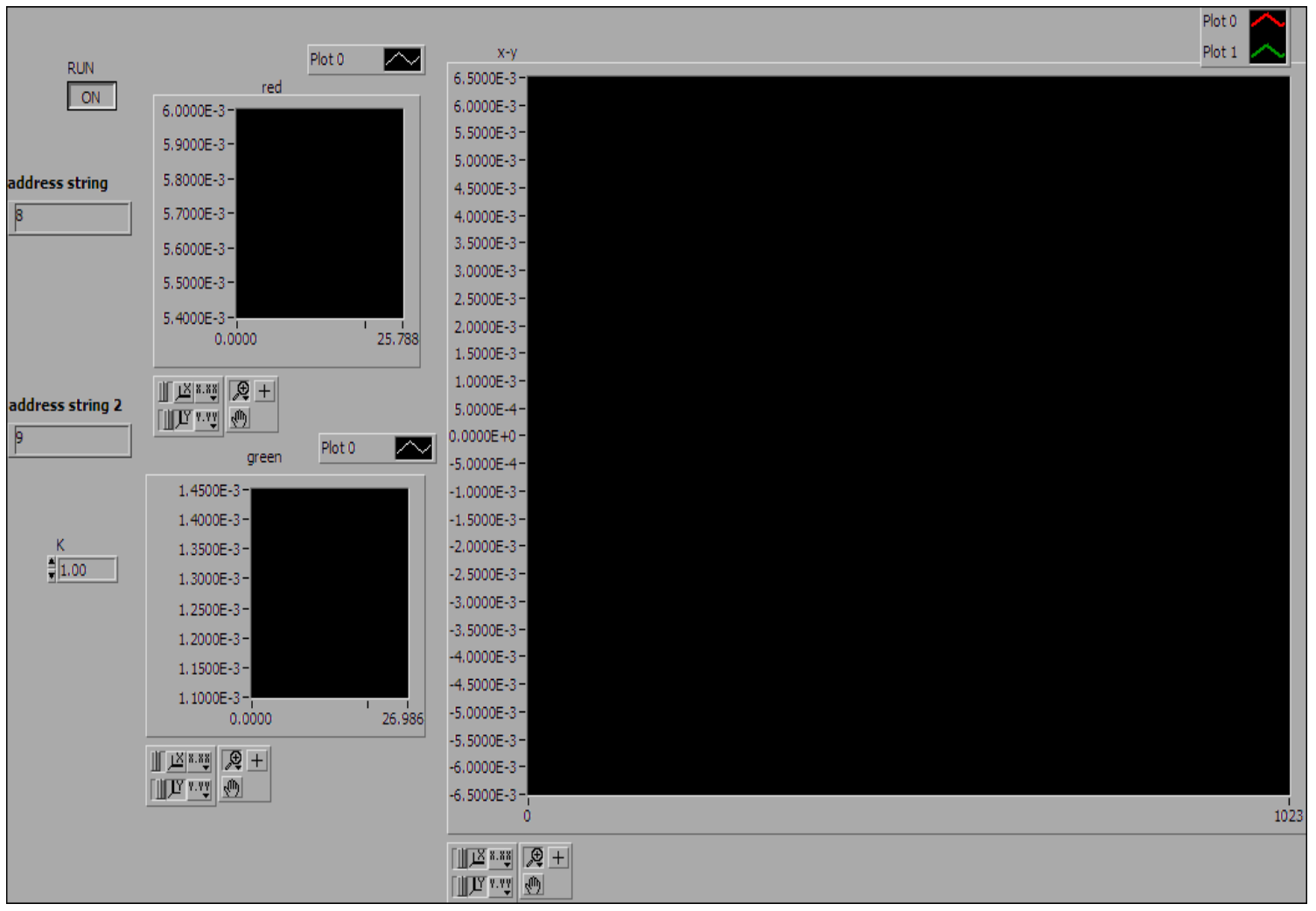




\section{Block Diagram}

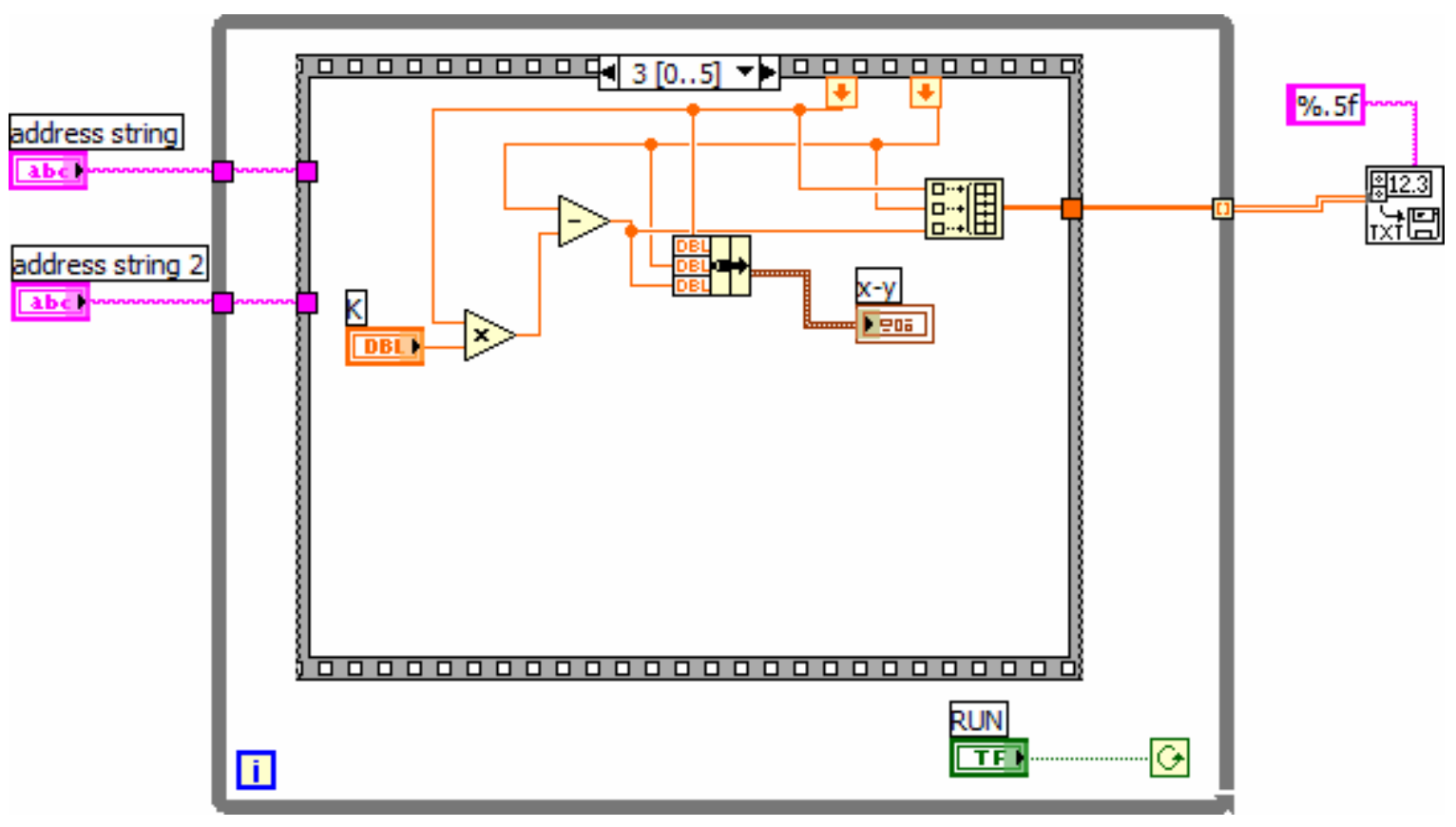




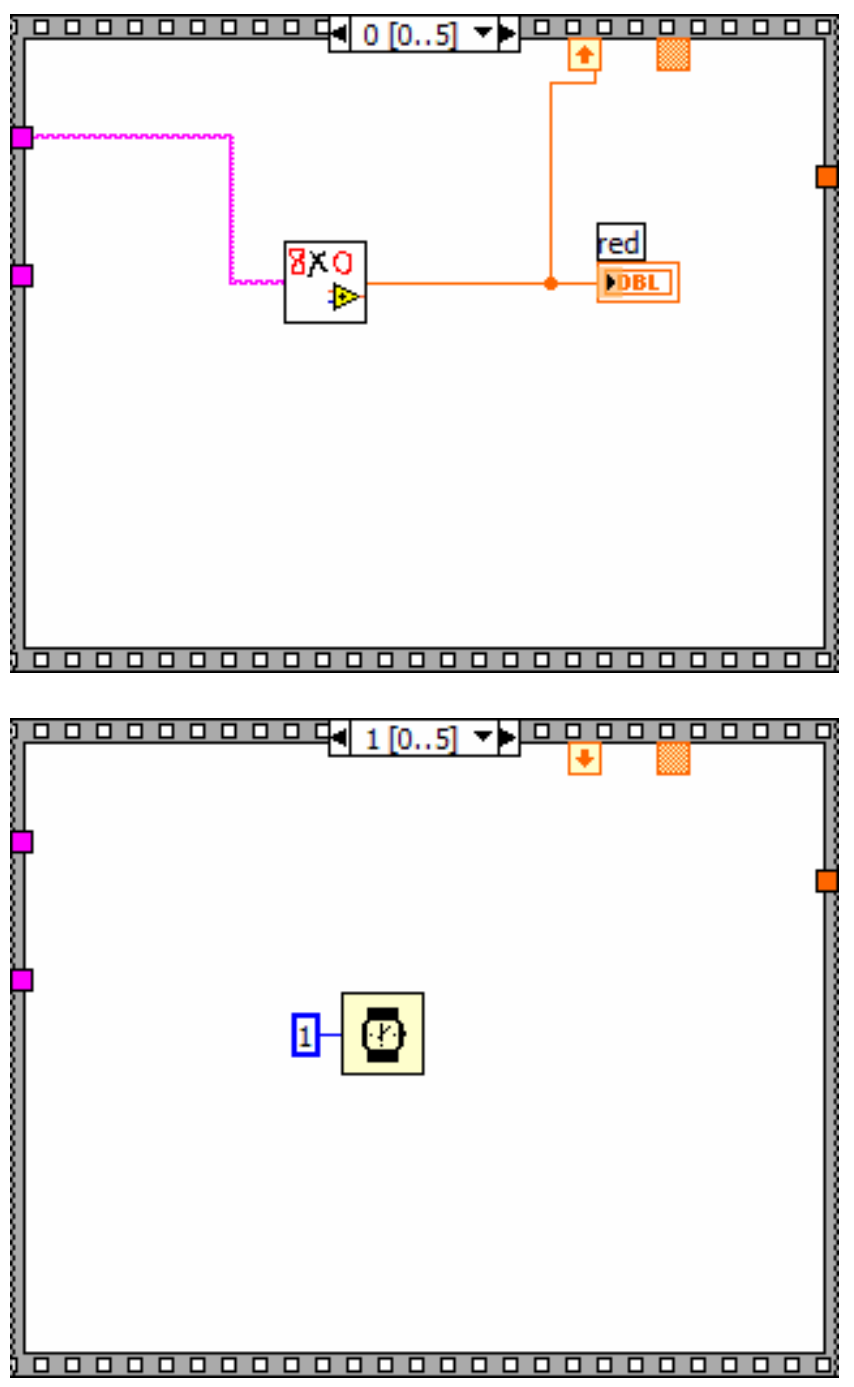



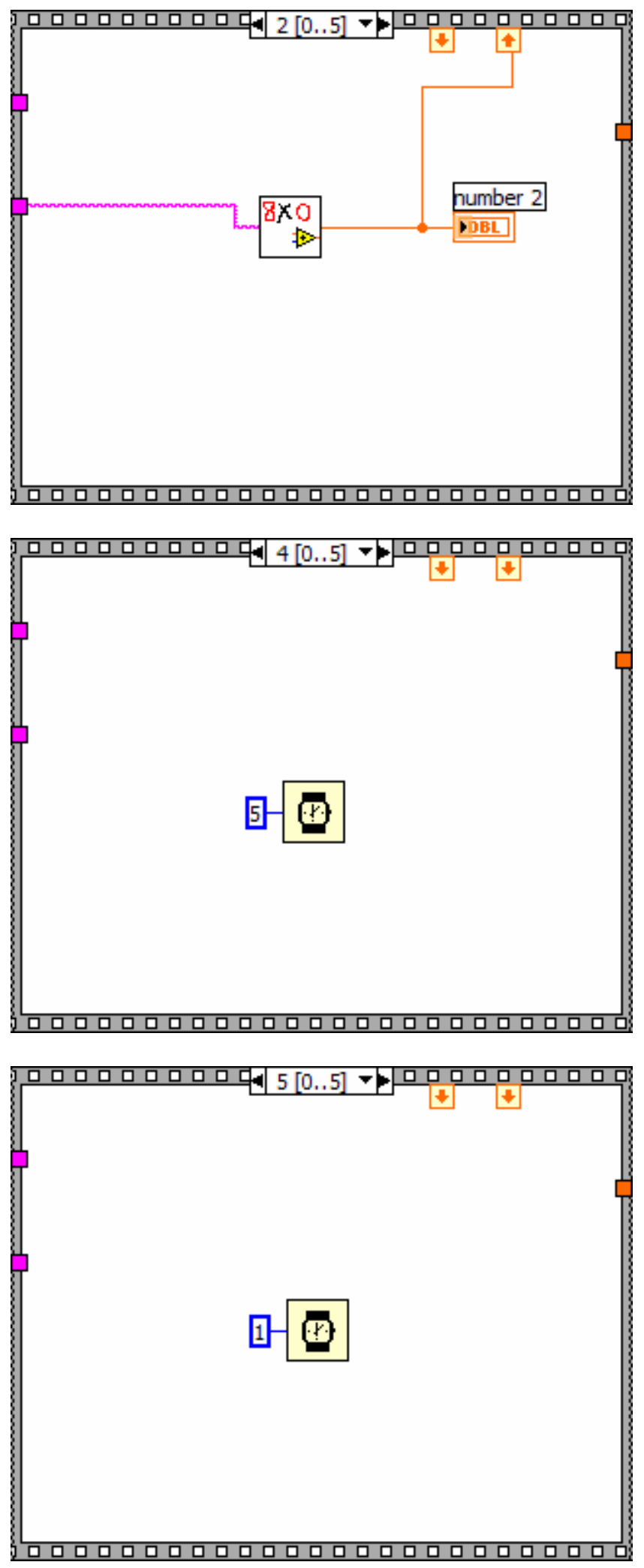
APPENDIX B

DUAL WAVELENGTH CLOSED-LOOP SYSTEM LABVIEW PROGRAM

Main Program

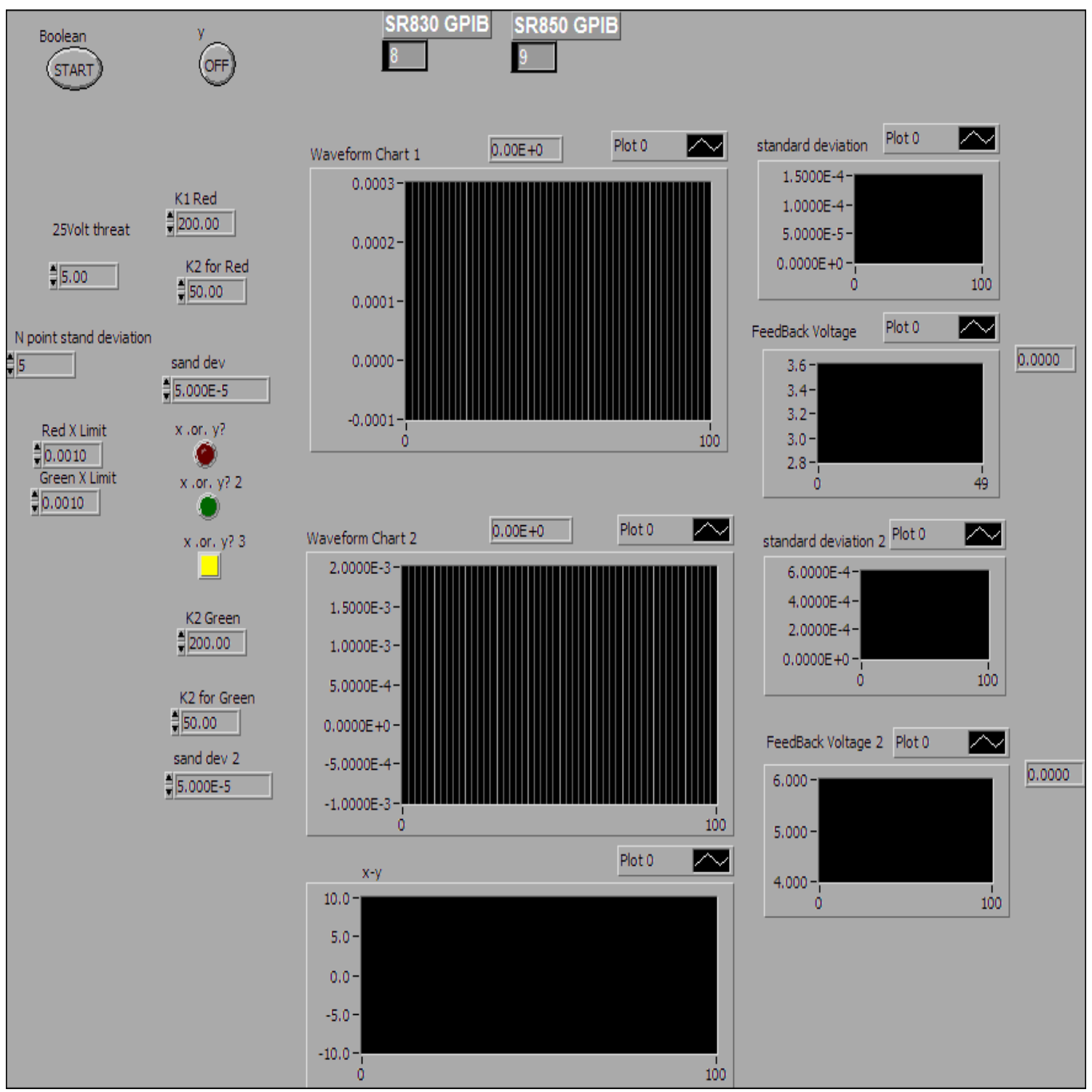




\section{Block Diagram}

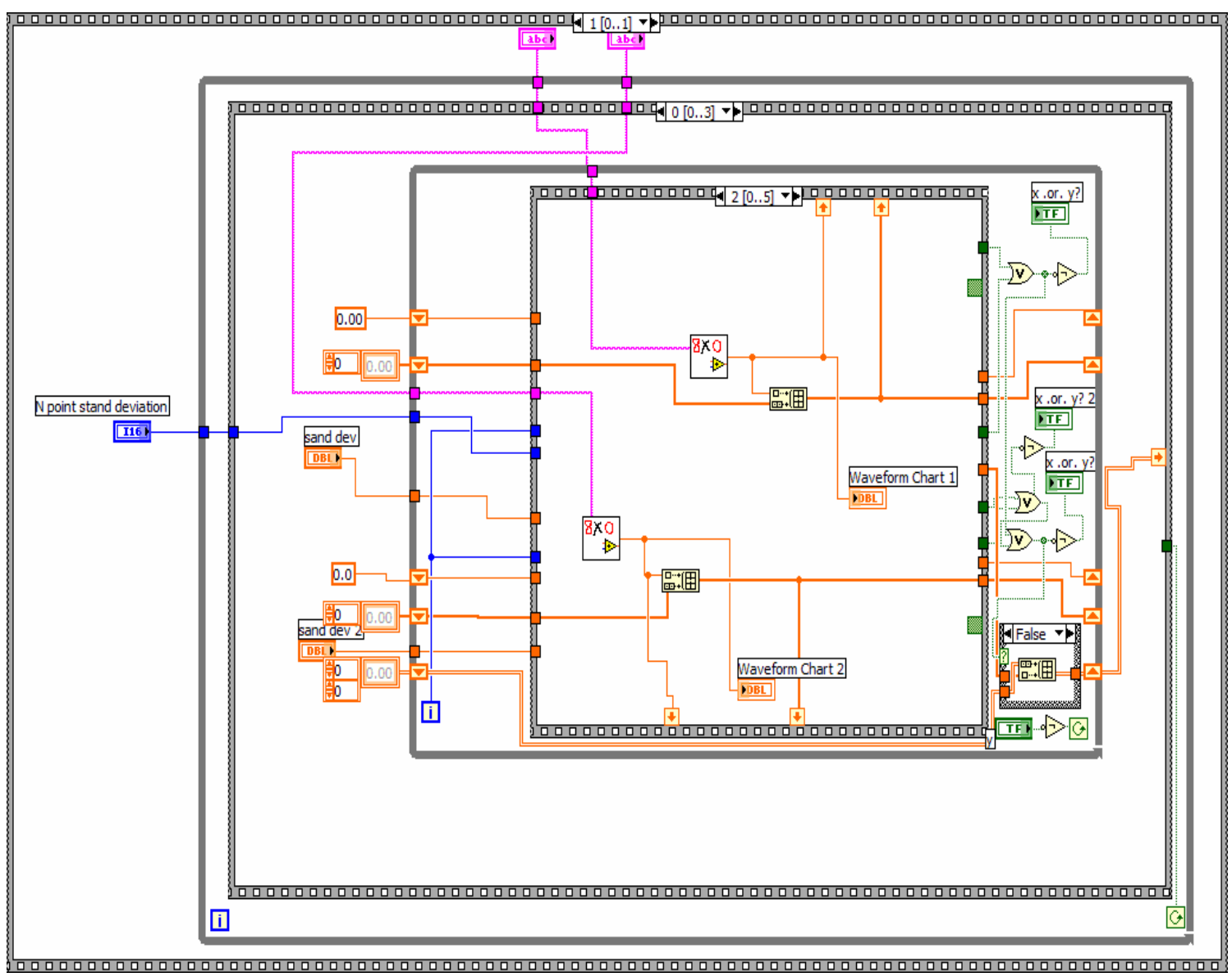




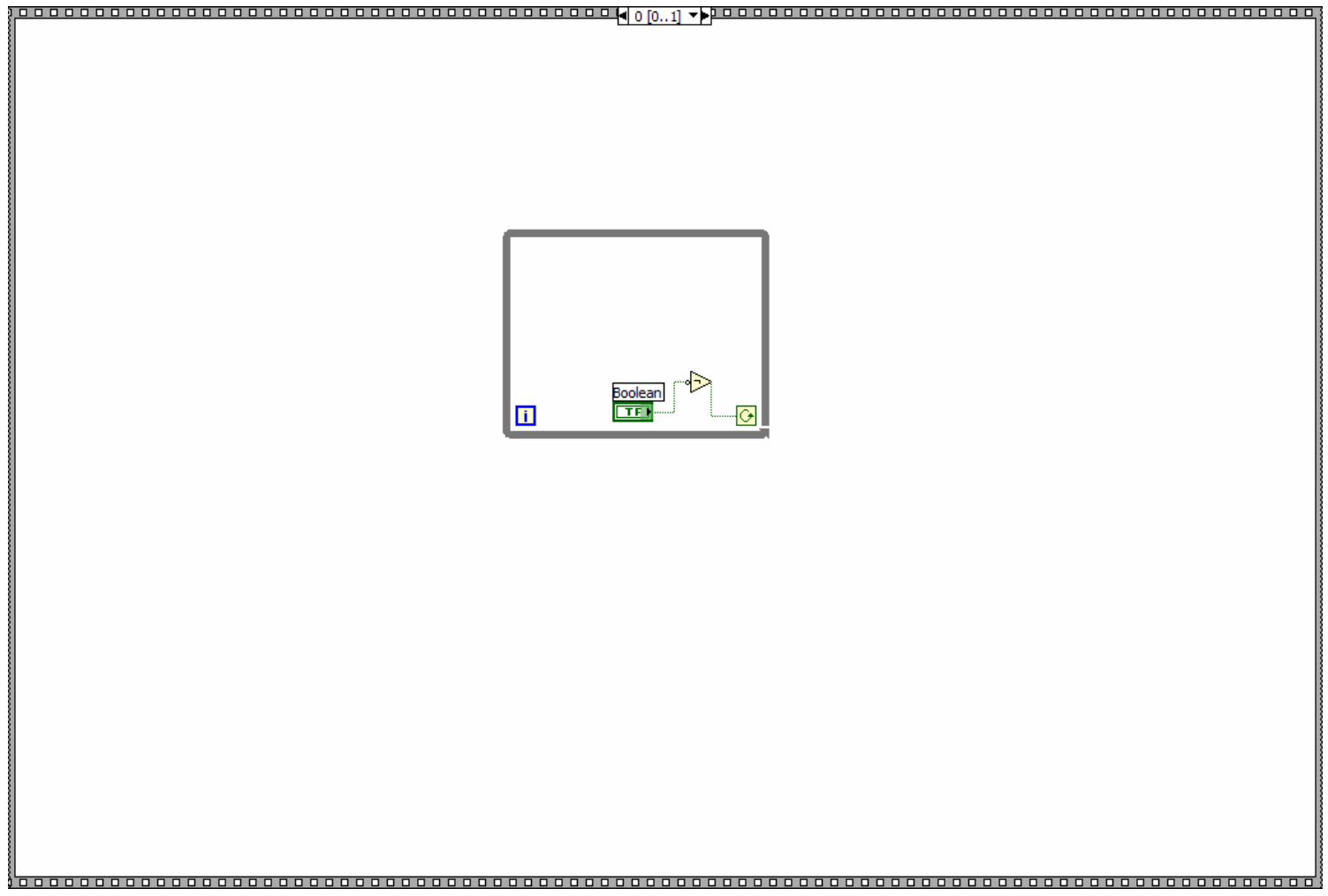



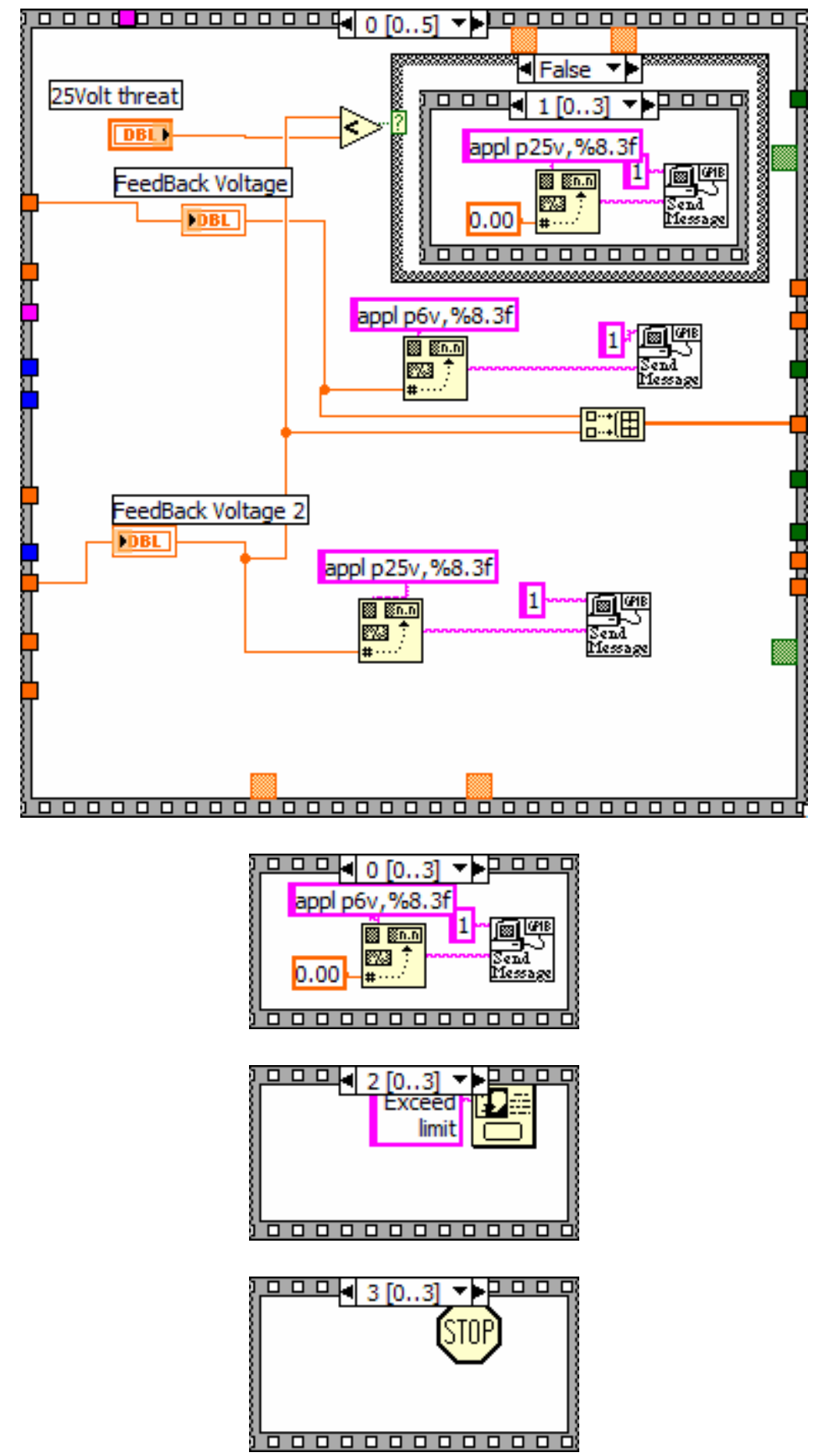

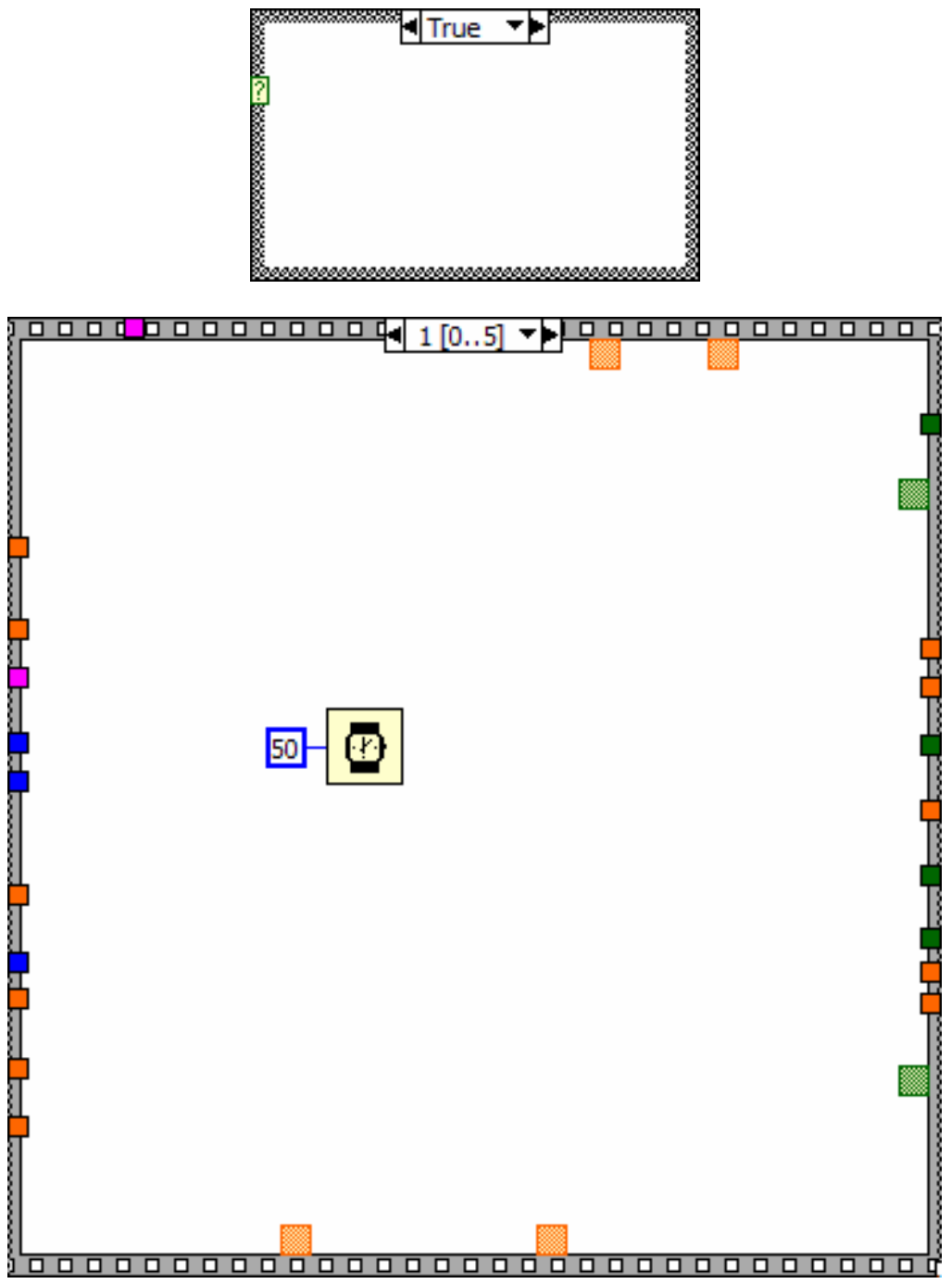

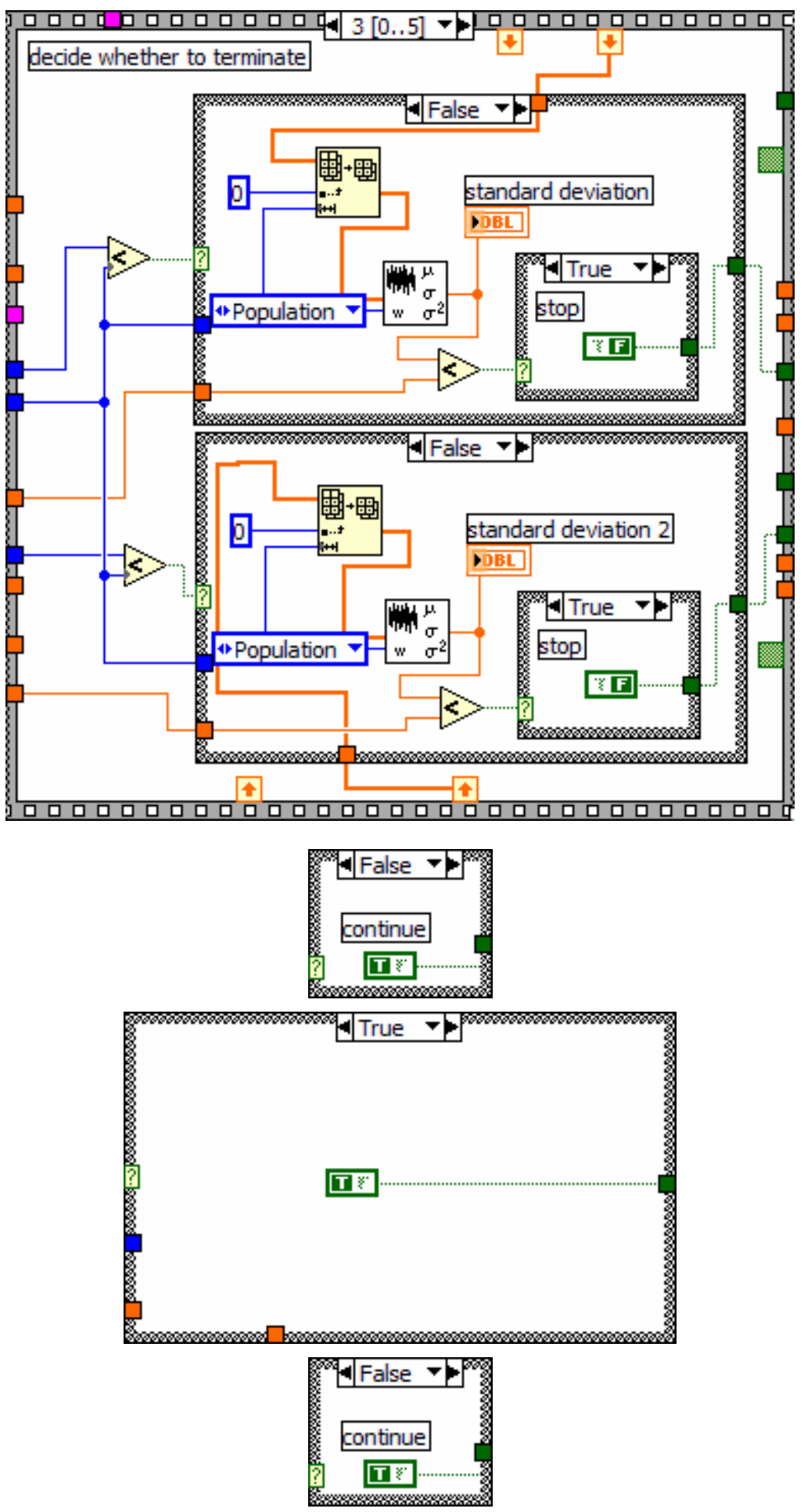


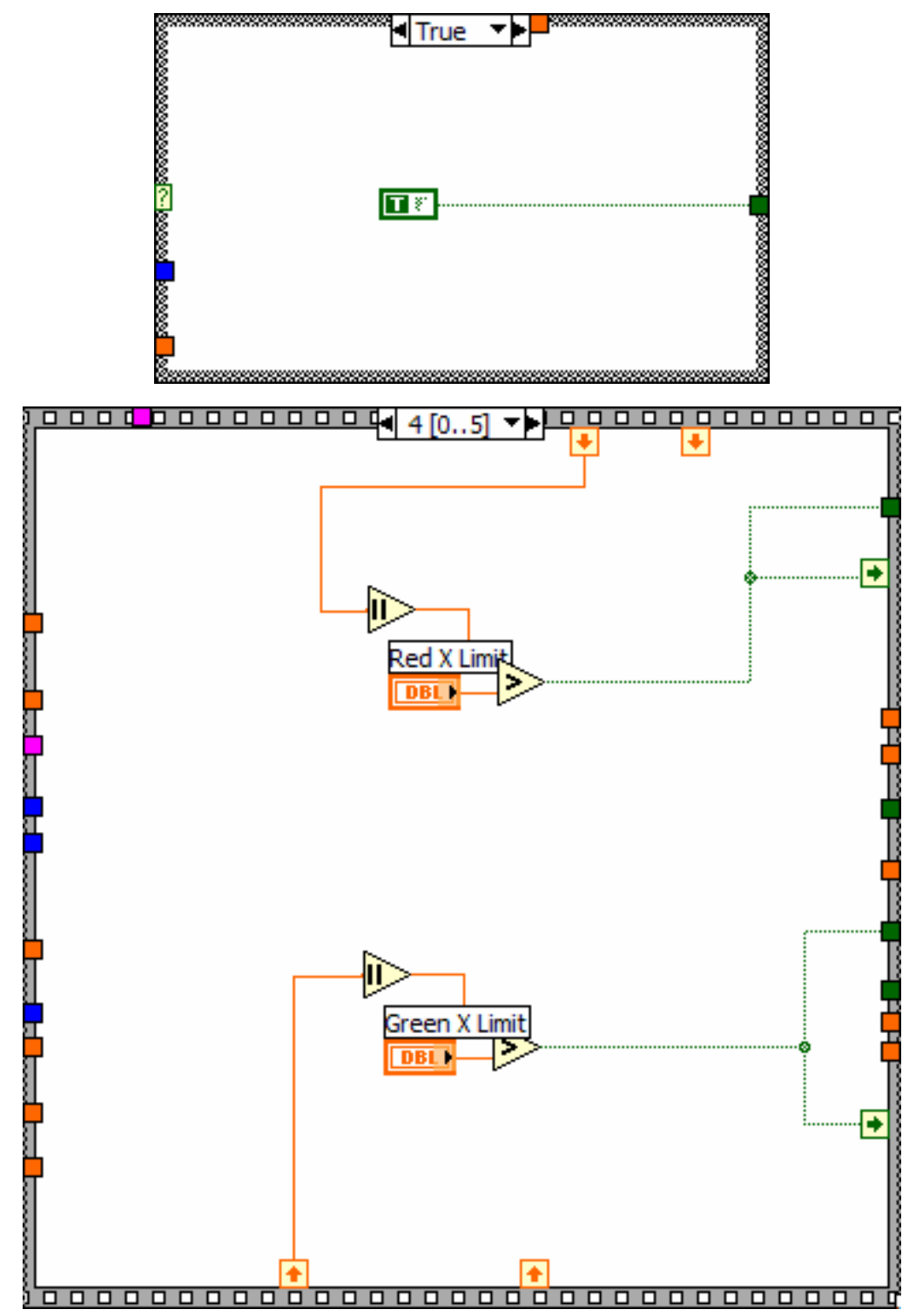



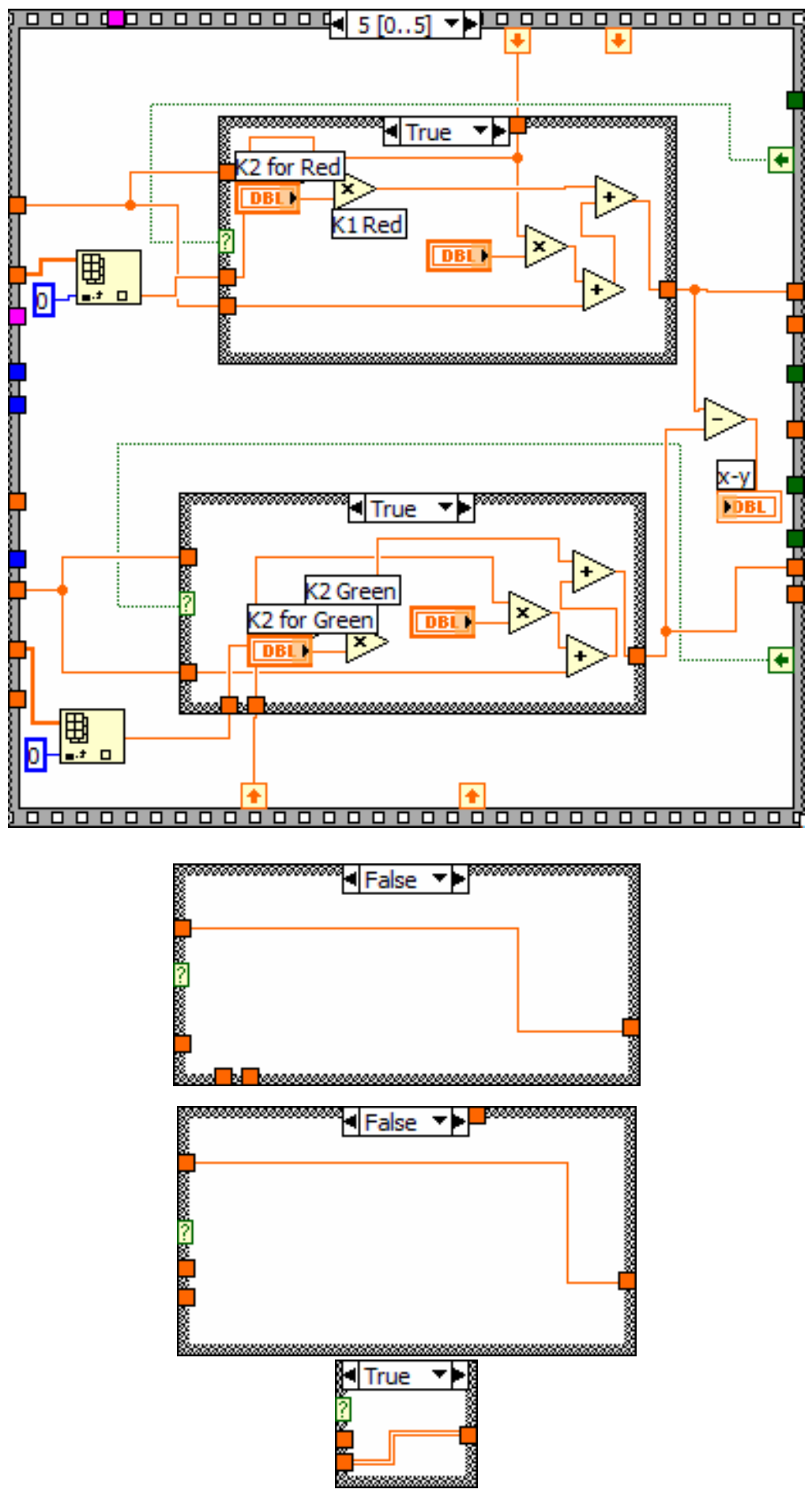


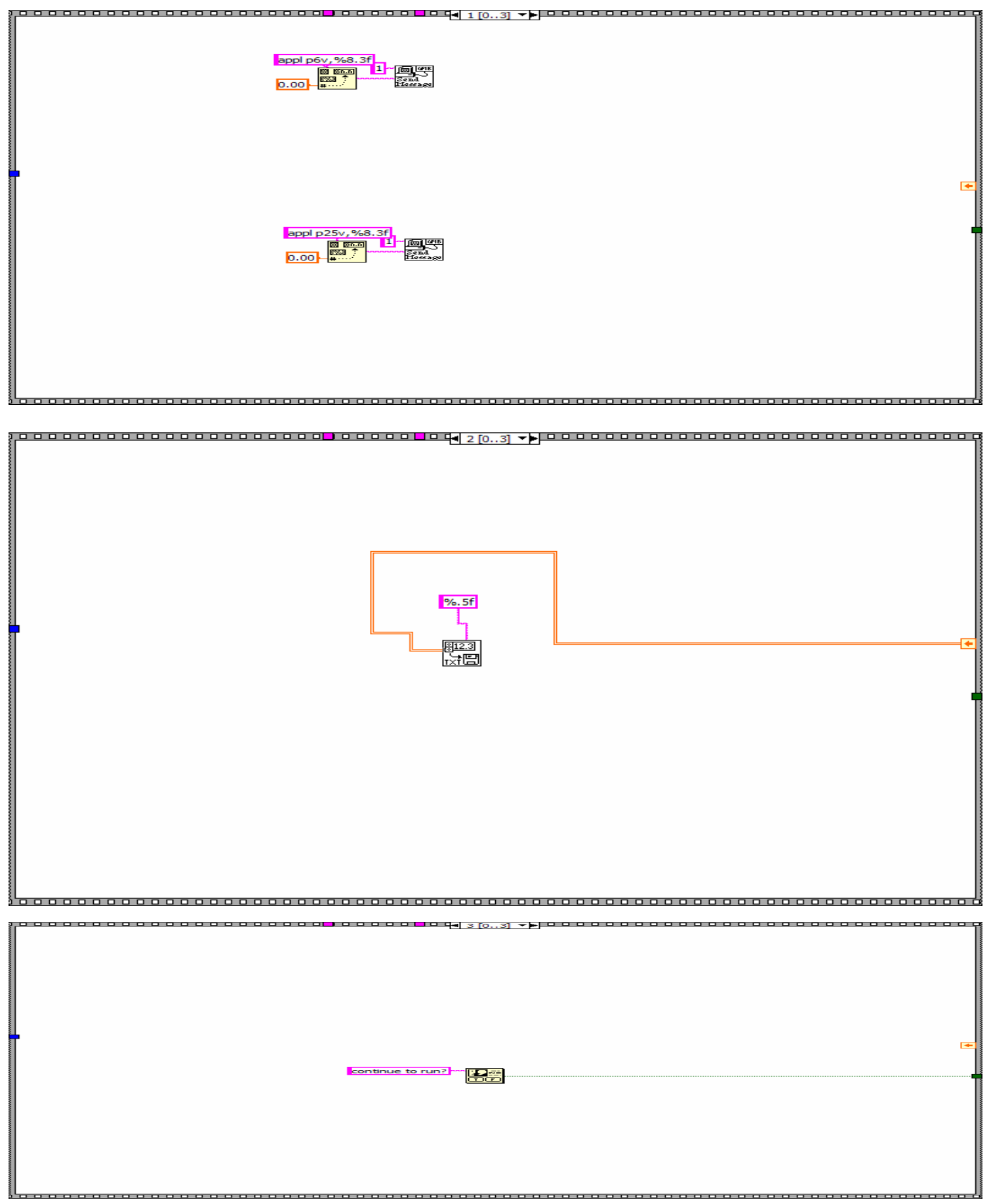




\section{APPENDIX C}

ORIEL TWO AXIS STEPPER MOTOR DRIVER WITH RS-232 INTERFACE

Visual Basic Terminal

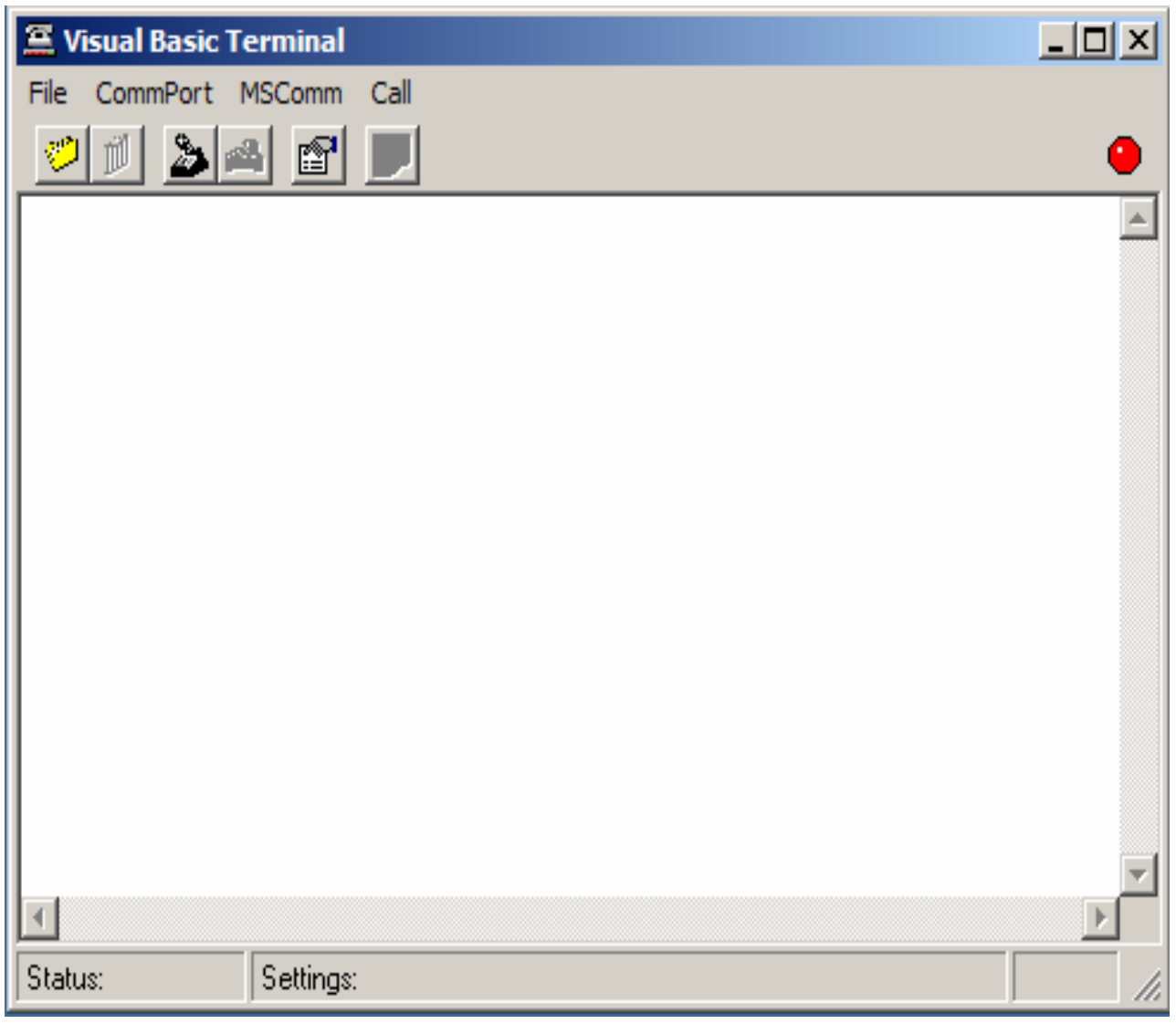


The Setting of the Commport Properties

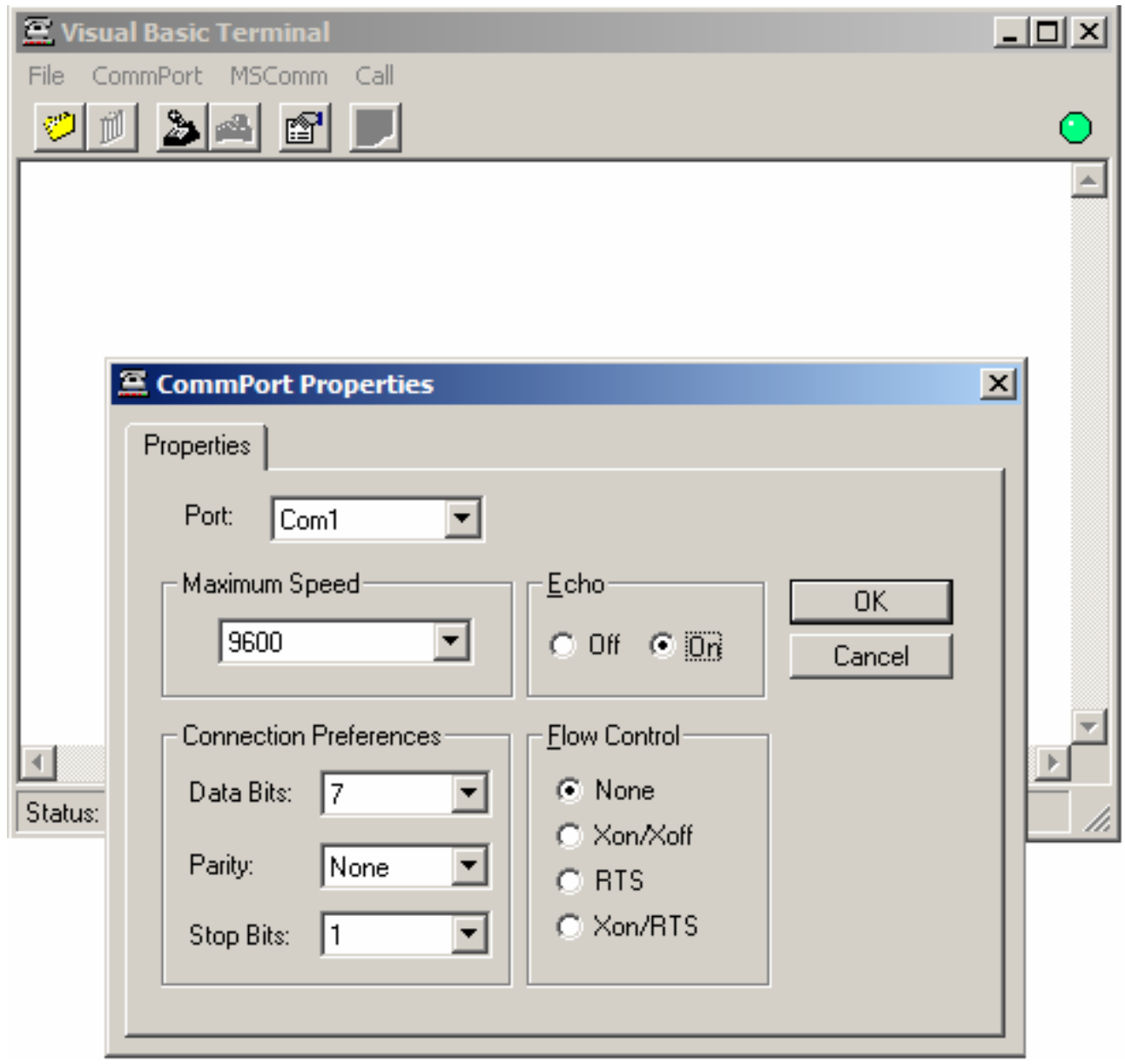


The Used Commands

D: To disable the motor driver

E: Enables the motor driver

F: Changes to full step motor operation

$\mathrm{H}$ Changes to half operation

$\mathrm{R}$ To set up the desired step rate for each motor. There are 8 preset setup rates and they can be changed at any time. $\mathrm{n}=0-7$

$\mathrm{T}$ This command includes a data field consisting of up to a 8 decimal digital of data terminated by a comma. After the $8^{\text {th }}$ digit, the numeric field is automatically terminated.

+ To preset the direction to clockwise

- $\quad$ To preset the direction to counter-clockwise. 


\section{APPENDIX D}

\section{MATLAB PROGRAM FOR CALIBRATION}

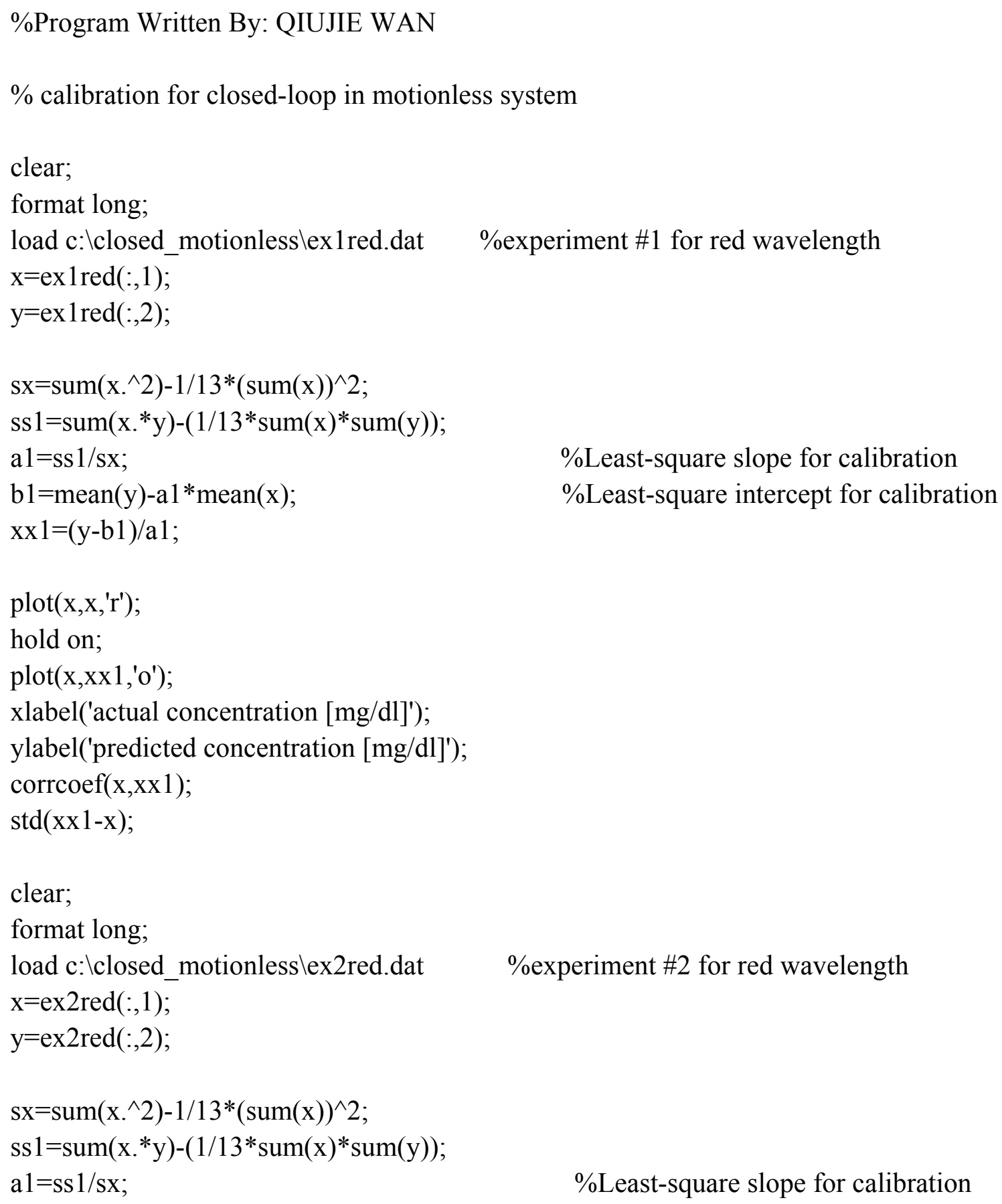




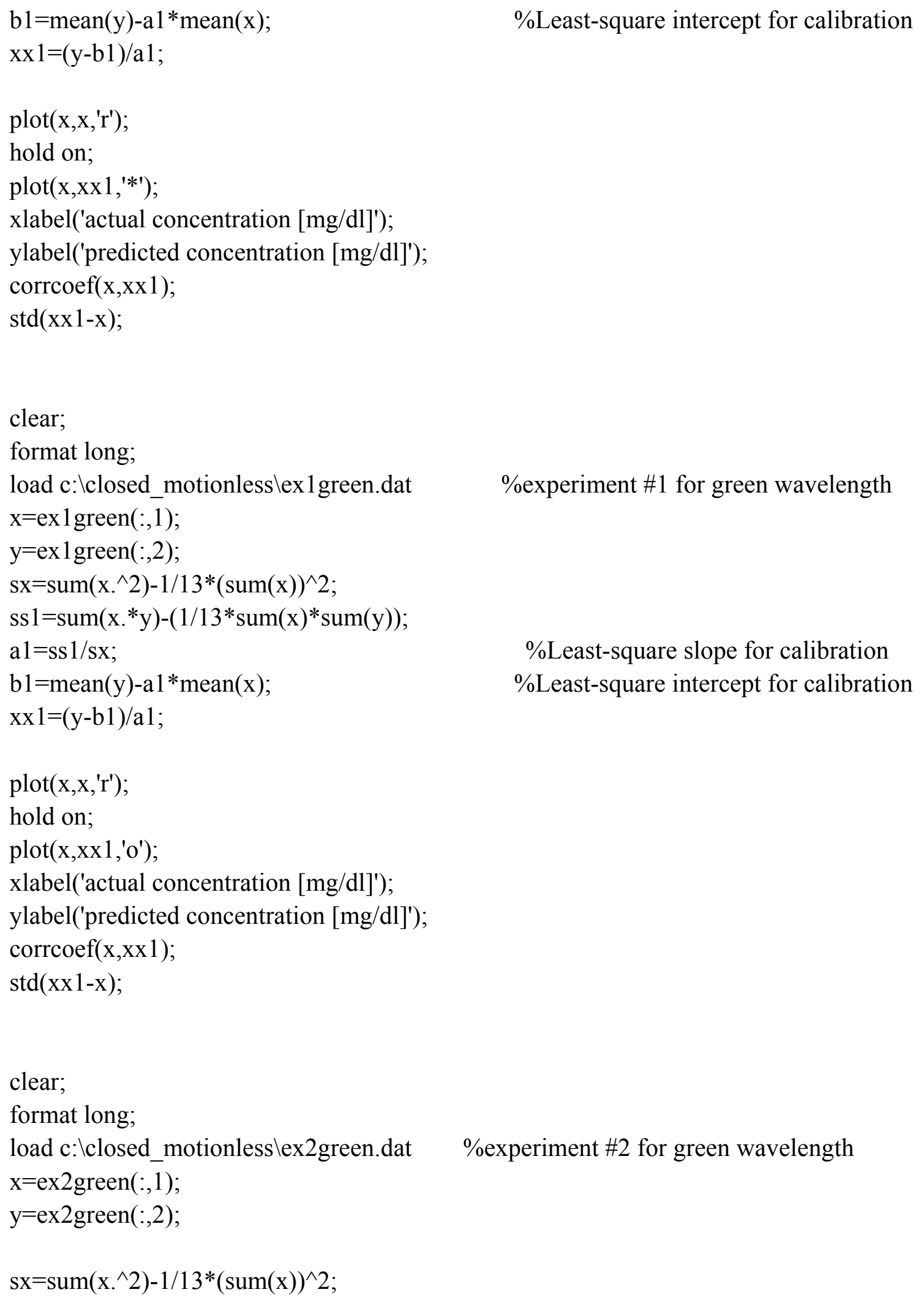

$\%$ Least-square slope for calibration $\%$ Least-square intercept for calibration 
$\operatorname{ss} 1=\operatorname{sum}\left(x \cdot{ }^{*} \mathrm{y}\right)-\left(1 / 13^{*} \operatorname{sum}(\mathrm{x}) * \operatorname{sum}(\mathrm{y})\right)$

$\mathrm{a} 1=\mathrm{ss} 1 / \mathrm{sx}$;

\%Least-square slope for calibration

$\mathrm{b} 1=\operatorname{mean}(\mathrm{y})-\mathrm{a} 1 * \operatorname{mean}(\mathrm{x})$;

$\%$ Least-square intercept for calibration

$\mathrm{xx} 1=(\mathrm{y}-\mathrm{b} 1) / \mathrm{a} 1$;

$\operatorname{plot}\left(\mathrm{x}, \mathrm{x}, \mathrm{r}^{\prime}\right)$;

hold on;

$\operatorname{plot}\left(\mathrm{x}, \mathrm{xx} 1,{ }^{\prime} *^{\prime}\right)$;

xlabel('actual concentration [mg/dl]');

ylabel('predicted concentration [mg/dl]');

corrcoef $(\mathrm{x}, \mathrm{xx} 1)$;

$\operatorname{std}(x x 1-x)$;

************************************************************************************

$* * * * * * * * * * * * * * * * * * * * * * * * * * * * * * * * * * * * * * *$

$\%$ Calibration for dual wavelength closed-loop in motion system for glucose doped water and \%NZW rabbits eyes.

$\%$ This is example (experiment \#1) of calibration in motion system.

$\%$ The procedure was used for the three data sets.

clear;

format long;

load c: lclosed_motion $\backslash$ ex $1 \mathrm{~g} 0$. dat $\%$ experiment \#1 for water using dual wavelength

$\mathrm{x}=\operatorname{ex} \lg 0(:, 1)$;

$\mathrm{y}=\operatorname{ex} \lg 0(:, 2)$;

$\mathrm{n}=\operatorname{size}(\mathrm{x})$;

$\operatorname{sx}=\operatorname{sum}(x \cdot \wedge 2)-n^{*}(\operatorname{sum}(x))^{\wedge} 2$

$\mathrm{ss}=\operatorname{sum}\left(\mathrm{x} \cdot{ }^{*} \mathrm{y}\right)-(\mathrm{n} * \operatorname{sum}(\mathrm{x}) * \operatorname{sum}(\mathrm{y}))$;

$\mathrm{a}=\mathrm{ss} / \mathrm{sx}$

$\%$ least-square slope of water

$\mathrm{b}=\operatorname{mean}(\mathrm{y})-\mathrm{a}^{*} \operatorname{mean}(\mathrm{x})$;

$\%$ least-square intercept of water

$\mathrm{z} 0=\mathrm{y}-\mathrm{a} * \mathrm{x}-\mathrm{b}$;

$\%$ the intercept of the linear fit

load c:lclosed_motion $\backslash$ ex1g50.dat \%experiment \#1 for $50 \mathrm{mg} / \mathrm{dl}$ using dual wavelength $\mathrm{x}=\operatorname{ex} \lg 50(:, 1)$;

$\mathrm{y}=\operatorname{ex} \lg 50(:, 2)$;

$\mathrm{n}=\operatorname{size}(\mathrm{x})$;

$\operatorname{sx}=\operatorname{sum}\left(x .^{\wedge} 2\right)-n^{*}(\operatorname{sum}(x))^{\wedge} 2 ;$ 


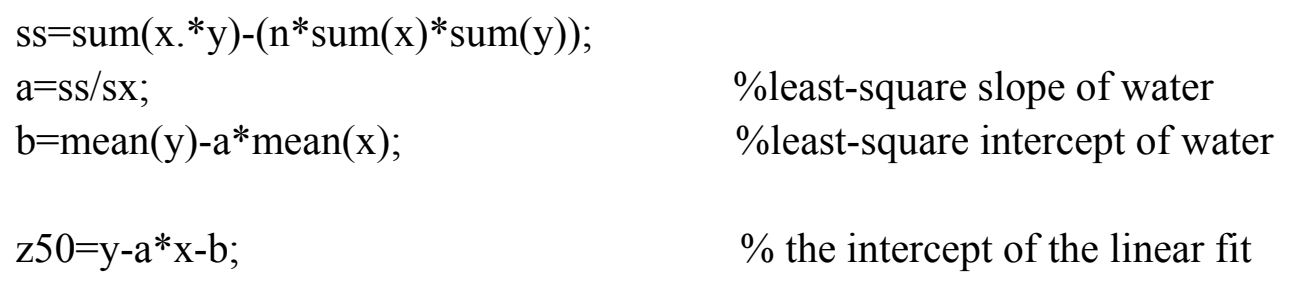

load c:lclosed_motionlex $1 \mathrm{~g} 100$. dat \%experiment $\# 1$ for $100 \mathrm{mg} / \mathrm{dl}$ using dual wavelength $\mathrm{x}=\operatorname{ex} \lg 100(:, 1)$;

$\mathrm{y}=\operatorname{ex} \lg 100(:, 2)$;

$\mathrm{n}=\operatorname{size}(\mathrm{x})$;

$\mathrm{sx}=\operatorname{sum}\left(\mathrm{x} \cdot{ }^{\wedge} 2\right)-\mathrm{n}^{*}(\operatorname{sum}(\mathrm{x}))^{\wedge} 2$

$\mathrm{ss}=\operatorname{sum}\left(\mathrm{x} \cdot{ }^{*} \mathrm{y}\right)-\left(\mathrm{n}^{*} \operatorname{sum}(\mathrm{x}) * \operatorname{sum}(\mathrm{y})\right)$;

$\mathrm{a}=\mathrm{ss} / \mathrm{sx}$

$\mathrm{b}=$ mean $(\mathrm{y})-\mathrm{a}^{*} \operatorname{mean}(\mathrm{x})$;

$\mathrm{z} 100=\mathrm{y}-\mathrm{a} * \mathrm{x}-\mathrm{b}$;

$\%$ least-square slope of water

$\%$ least-square intercept of water

$\%$ the intercept of the linear fit

load c: \closed_motion $\backslash$ ex 1 g150.dat

$\%$ experiment \#1 for $150 \mathrm{mg} / \mathrm{dl}$ using dual

wavelength

$\mathrm{x}=\operatorname{ex} \lg 150(:, 1)$;

$\mathrm{y}=\operatorname{ex} \lg 150(:, 2)$;

$\mathrm{n}=\operatorname{size}(\mathrm{x})$;

$\operatorname{sx}=\operatorname{sum}\left(x .^{\wedge} 2\right)-n^{*}(\operatorname{sum}(x))^{\wedge} 2$

$\mathrm{ss}=\operatorname{sum}\left(\mathrm{x} .{ }^{*} \mathrm{y}\right)-(\mathrm{n} * \operatorname{sum}(\mathrm{x}) * \operatorname{sum}(\mathrm{y}))$;

$\mathrm{a}=\mathrm{ss} / \mathrm{sx}$;

$\mathrm{b}=\operatorname{mean}(\mathrm{y})-\mathrm{a}^{*} \operatorname{mean}(\mathrm{x})$;

$\mathrm{z} 150=\mathrm{y}-\mathrm{a} * \mathrm{x}-\mathrm{b}$;
$\%$ least-square slope of water $\%$ least-square intercept of water
$\%$ the intercept of the linear fit

load c:lclosed_motion $\backslash$ ex $1 \mathrm{~g} 200$.dat \%experiment $\# 1$ for $200 \mathrm{mg} / \mathrm{dl}$ using dual wavelength

$\mathrm{x}=\operatorname{ex} \lg 200(:, 1)$;

$\mathrm{y}=\operatorname{ex} \lg 200(:, 2)$;

$\mathrm{n}=\operatorname{size}(\mathrm{x})$;

$\mathrm{sx}=\operatorname{sum}\left(\mathrm{x} \cdot{ }^{\wedge} 2\right)-\mathrm{n}^{*}(\operatorname{sum}(\mathrm{x}))^{\wedge} 2$

$\mathrm{ss}=\operatorname{sum}(\mathrm{x} \cdot * \mathrm{y})-(\mathrm{n} * \operatorname{sum}(\mathrm{x}) * \operatorname{sum}(\mathrm{y}))$;

$\mathrm{a}=\mathrm{ss} / \mathrm{sx}$

$\%$ least-square slope of water

$\mathrm{b}=\operatorname{mean}(\mathrm{y})-\mathrm{a}^{*} \operatorname{mean}(\mathrm{x})$;

$\%$ least-square intercept of water

$\mathrm{z} 200=\mathrm{y}-\mathrm{a} * \mathrm{x}-\mathrm{b}$;

$\%$ the intercept of the linear fit 
load c: \closed_motion $\backslash$ ex1g250.dat \%experiment \#1 for $250 \mathrm{mg} / \mathrm{dl}$ using dual wavelength $\mathrm{x}=\operatorname{ex} \lg 250(:, 1)$;

$\mathrm{y}=\operatorname{ex} \lg 250(:, 2)$;

$\mathrm{n}=\operatorname{size}(\mathrm{x})$;

$\operatorname{sx}=\operatorname{sum}\left(x .^{\wedge} 2\right)-n^{*}(\operatorname{sum}(x))^{\wedge} 2$

$\mathrm{ss}=\operatorname{sum}\left(\mathrm{x} \cdot{ }^{*} \mathrm{y}\right)-(\mathrm{n} * \operatorname{sum}(\mathrm{x}) * \operatorname{sum}(\mathrm{y}))$;

$\mathrm{a}=\mathrm{ss} / \mathrm{sx}$;

$\%$ least-square slope of water

$\mathrm{b}=$ mean $(\mathrm{y})-\mathrm{a}^{*} \operatorname{mean}(\mathrm{x})$;

$\%$ least-square intercept of water

$\mathrm{z} 250=\mathrm{y}-\mathrm{a} * \mathrm{x}-\mathrm{b}$;

$\%$ the intercept of the linear fit

load c:lclosed_motion $\backslash$ ex $1 \mathrm{~g} 300$.dat \%experiment $\# 1$ for $300 \mathrm{mg} / \mathrm{dl}$ using dual wavelength $\mathrm{x}=\operatorname{ex} \lg 300(:, 1)$;

$\mathrm{y}=\operatorname{ex} \lg 300(:, 2)$;

$\mathrm{n}=\operatorname{size}(\mathrm{x})$;

$\operatorname{sx}=\operatorname{sum}(x \cdot \wedge 2)-n^{*}(\operatorname{sum}(x))^{\wedge} 2$

$\mathrm{ss}=\operatorname{sum}\left(\mathrm{x} \cdot{ }^{*} \mathrm{y}\right)-(\mathrm{n} * \operatorname{sum}(\mathrm{x}) * \operatorname{sum}(\mathrm{y}))$;

$\mathrm{a}=\mathrm{ss} / \mathrm{sx}$;

$\mathrm{b}=\operatorname{mean}(\mathrm{y})-\mathrm{a} * \operatorname{mean}(\mathrm{x})$;

$\mathrm{z} 300=\mathrm{y}-\mathrm{a} * \mathrm{x}-\mathrm{b}$;

$\%$ least-square slope of water

$\%$ least-square intercept of water

$\%$ the intercept of the linear fit

load c: Iclosed_motion $\backslash$ ex 1 g350.dat

$\%$ experiment $\# 1$ for $350 \mathrm{mg} / \mathrm{dl}$ using dual

wavelength

$\mathrm{x}=\operatorname{ex} \lg 350(:, 1)$;

$\mathrm{y}=\operatorname{ex} \lg 350(:, 2)$;

$\mathrm{n}=\operatorname{size}(\mathrm{x})$;

$\operatorname{sx}=\operatorname{sum}\left(x .^{\wedge} 2\right)-n^{*}(\operatorname{sum}(x))^{\wedge} 2$

$\mathrm{ss}=\operatorname{sum}\left(\mathrm{x} .{ }^{*} \mathrm{y}\right)-\left(\mathrm{n}^{*} \operatorname{sum}(\mathrm{x}) * \operatorname{sum}(\mathrm{y})\right)$;

$\mathrm{a}=\mathrm{ss} / \mathrm{sx}$;

$\mathrm{b}=\operatorname{mean}(\mathrm{y})-\mathrm{a} * \operatorname{mean}(\mathrm{x})$;

$\mathrm{z} 350=\mathrm{y}-\mathrm{a} * \mathrm{x}-\mathrm{b}$;

$\%$ least-square slope of water

$\%$ least-square intercept of water

$\%$ the intercept of the linear fit

load c:lclosed_motionlex1g400.dat \%experiment \#1 for 400mg/dl using dual wavelength

$\mathrm{x}=\operatorname{ex} \lg 400(:, 1)$;

$\mathrm{y}=\operatorname{ex} \lg 400(:, 2)$; 
$\mathrm{n}=\operatorname{size}(\mathrm{x})$;

$\mathrm{sx}=\operatorname{sum}\left(\mathrm{x} \cdot{ }^{\wedge} 2\right)-\mathrm{n}^{*}(\operatorname{sum}(\mathrm{x}))^{\wedge} 2$;

$\mathrm{ss}=\operatorname{sum}\left(\mathrm{x} .{ }^{*} \mathrm{y}\right)-\left(\mathrm{n}^{*} \operatorname{sum}(\mathrm{x}) * \operatorname{sum}(\mathrm{y})\right)$;

$\mathrm{a}=\mathrm{ss} / \mathrm{sx}$;

$\mathrm{b}=\operatorname{mean}(\mathrm{y})-\mathrm{a}^{*} \operatorname{mean}(\mathrm{x})$;

$\mathrm{z} 400=\mathrm{y}-\mathrm{a} * \mathrm{x}-\mathrm{b}$;

$\%$ least-square slope of water

$\%$ least-square intercept of water

$\%$ the intercept of the linear fit

load c:lclosed_motion $\backslash$ ex 1 g450.dat \%experiment $\# 1$ for $450 \mathrm{mg} / \mathrm{dl}$ using dual wavelength $\mathrm{x}=\operatorname{ex} \lg 450(:, 1)$;

$\mathrm{y}=\operatorname{ex} \lg 450(:, 2)$;

$\mathrm{n}=\operatorname{size}(\mathrm{x})$;

$\operatorname{sx}=\operatorname{sum}(x \cdot \wedge 2)-n^{*}(\operatorname{sum}(x))^{\wedge} 2$

$\mathrm{ss}=\operatorname{sum}\left(\mathrm{x} \cdot{ }^{*} \mathrm{y}\right)-(\mathrm{n} * \operatorname{sum}(\mathrm{x}) * \operatorname{sum}(\mathrm{y}))$;

$\mathrm{a}=\mathrm{sS} / \mathrm{sx}$;

$\mathrm{b}=\operatorname{mean}(\mathrm{y})-\mathrm{a} * \operatorname{mean}(\mathrm{x})$;

$\mathrm{z} 450=\mathrm{y}-\mathrm{a} * \mathrm{x}-\mathrm{b}$

$\%$ least-square slope of water

$\%$ least-square intercept of water

$\%$ the intercept of the linear fit

load c:lclosed_motion $\backslash$ ex 1 g500.dat \%experiment $\# 1$ for $500 \mathrm{mg} / \mathrm{dl}$ using dual wavelength

$\mathrm{x}=\operatorname{ex} \lg 500(:, 1)$;

$\mathrm{y}=\operatorname{ex} \lg 500(:, 2)$;

$\mathrm{n}=\operatorname{size}(\mathrm{x})$;

$\mathrm{sx}=\operatorname{sum}\left(\mathrm{x} \cdot{ }^{\wedge} 2\right)-\mathrm{n}^{*}(\operatorname{sum}(\mathrm{x}))^{\wedge} 2$;

$\mathrm{ss}=\operatorname{sum}\left(\mathrm{x} .{ }^{*} \mathrm{y}\right)-\left(\mathrm{n}^{*} \operatorname{sum}(\mathrm{x}){ }^{*} \operatorname{sum}(\mathrm{y})\right)$;

$\mathrm{a}=\mathrm{ss} / \mathrm{sx}$;

$\%$ least-square slope of water

$\mathrm{b}=\operatorname{mean}(\mathrm{y})-\mathrm{a} * \operatorname{mean}(\mathrm{x})$;

$\%$ least-square intercept of water

$\mathrm{z} 500=\mathrm{y}-\mathrm{a} * \mathrm{x}-\mathrm{b}$;

$\%$ the intercept of the linear fit

load c:lclosed_motion $\backslash$ ex 1 g550.dat \%experiment $\# 1$ for $550 \mathrm{mg} / \mathrm{dl}$ using dual wavelength $\mathrm{x}=\operatorname{ex} \lg 550(:, 1)$;

$\mathrm{y}=\operatorname{ex} \lg 550(:, 2)$;

$\mathrm{n}=\operatorname{size}(\mathrm{x})$;

$\operatorname{sx}=\operatorname{sum}\left(x \cdot{ }^{\wedge} 2\right)-n^{*}(\operatorname{sum}(x))^{\wedge} 2$

$\mathrm{ss}=\operatorname{sum}\left(\mathrm{x} \cdot{ }^{*} \mathrm{y}\right)-(\mathrm{n} * \operatorname{sum}(\mathrm{x}) * \operatorname{sum}(\mathrm{y}))$;

$\mathrm{a}=\mathrm{ss} / \mathrm{sx}$;

$\mathrm{b}=$ mean $(\mathrm{y})-\mathrm{a}^{*} \operatorname{mean}(\mathrm{x})$;

$\%$ least-square slope of water

$\%$ least-square intercept of water 
load c:lclosed_motionlex $1 \mathrm{~g} 600$.dat \%experiment $\# 1$ for $600 \mathrm{mg} / \mathrm{dl}$ using dual wavelength $\mathrm{x}=\operatorname{ex} \lg 600(:, 1)$;

$\mathrm{y}=\operatorname{ex} \lg 600(:, 2)$;

$\mathrm{n}=\operatorname{size}(\mathrm{x})$;

$\mathrm{sx}=\operatorname{sum}\left(\mathrm{x} \cdot{ }^{\wedge} 2\right)-\mathrm{n} *(\operatorname{sum}(\mathrm{x}))^{\wedge} 2$

$\mathrm{ss}=\operatorname{sum}\left(\mathrm{x} .{ }^{*} \mathrm{y}\right)-(\mathrm{n} * \operatorname{sum}(\mathrm{x}) * \operatorname{sum}(\mathrm{y}))$;

$\mathrm{a}=\mathrm{ss} / \mathrm{sx}$

\%least-square slope of water

$\mathrm{b}=$ mean $(\mathrm{y})-\mathrm{a} * \operatorname{mean}(\mathrm{x})$;

$\%$ least-square intercept of water

$\mathrm{z} 600=\mathrm{y}-\mathrm{a} * \mathrm{x}-\mathrm{b}$;

$\%$ the intercept of the linear fit

$\%$ Calibration for the intercepts

load c: c:lclosed_motionlex1z.dat

$\mathrm{x}=\operatorname{ex} 1 \mathrm{z}(:, 1)$;

$\mathrm{y}=\operatorname{ex} 1 \mathrm{z}(:, 2)$;

$\operatorname{sx}=\operatorname{sum}\left(\mathrm{x} .{ }^{\wedge} 2\right)-1 / 13^{*}(\operatorname{sum}(\mathrm{x}))^{\wedge} 2$;

$\operatorname{ss} 1=\operatorname{sum}(\mathrm{x} . * \mathrm{y})-(1 / 13 * \operatorname{sum}(\mathrm{x}) * \operatorname{sum}(\mathrm{y}))$;

$\mathrm{a} 1=\mathrm{ss} 1 / \mathrm{sx}$;

$\mathrm{b} 1=$ mean $(\mathrm{y})-\mathrm{a} 1 * \operatorname{mean}(\mathrm{x})$;

$\mathrm{xx} 1=(\mathrm{y}-\mathrm{b} 1) / \mathrm{a} 1$;

$\operatorname{plot}\left(\mathrm{x}, \mathrm{x}, \mathrm{r}^{\prime}\right)$;

hold on;

$\operatorname{plot}\left(\mathrm{x}, \mathrm{xx} 1, \mathrm{o}^{\prime}\right)$;

xlabel('actual concentration [mg/dl]');

ylabel('predicted concentration [mg/dl]');

corrcoef(x,xx1);

$\operatorname{std}(\mathrm{xx} 1-\mathrm{x})$; 


\section{VITA}

Qiujie Wan was born in Chouzhou, Anhui, China. She graduated from Chouzhou high School (Chouzhou, Anhui) in the summer of 1992 and entered the Anhui University of Technology in the fall of 1992. During that time, she participated in some research work for undergraduate students and developed a microcomputer-based temperature program. In 1995, she was selected as Outstanding Undergraduate Student of Anhui University of Technology for 1995. In summer of 1996, she graduated from Anhui University of Technology with a Bachelor of Engineering degree in electrical engineering. Then she worked as a computer technician in Anhui University of Technology from 1996 to 1998. In fall of 1998, she continued on at Anhui University of Technology for a Master of Engineering degree in electrical engineering. Between the years of 1998-2001 she worked as a Graduate Research Assistant in her projects. She got Outstanding the Graduate Student Scholarship of Anhui University of Technology in 1999 and was selected as Outstanding Graduate Student of Anhui University of Technology in 2001. In the spring of 2001, she graduated from Anhui University of Technology with a Master of Engineering degree. She started graduate work in Biomedical Engineering Texas A\&M University in the fall of 2002, joined the Optical Biosensing Laboratory (OBSL) in the spring of 2003, and worked on the noninvasive glucose detection project. Her permanent address is Anhui University of Technology, Apt 18-304, Ma'anshan, Anhui, China, 2400223. 